\title{
On the pathway from stress to psychosis
}

Citation for published version (APA):

Lataster, H. W. G. (2009). On the pathway from stress to psychosis. [Doctoral Thesis, Maastricht University]. Datawyse / Universitaire Pers Maastricht. https://doi.org/10.26481/dis.20091014hl

Document status and date:

Published: 01/01/2009

DOI:

10.26481/dis.20091014hl

Document Version:

Publisher's PDF, also known as Version of record

\section{Please check the document version of this publication:}

- A submitted manuscript is the version of the article upon submission and before peer-review. There can be important differences between the submitted version and the official published version of record.

People interested in the research are advised to contact the author for the final version of the publication, or visit the DOI to the publisher's website.

- The final author version and the galley proof are versions of the publication after peer review.

- The final published version features the final layout of the paper including the volume, issue and page numbers.

Link to publication

\footnotetext{
General rights rights.

- You may freely distribute the URL identifying the publication in the public portal. please follow below link for the End User Agreement:

www.umlib.nl/taverne-license

Take down policy

If you believe that this document breaches copyright please contact us at:

repository@maastrichtuniversity.nl

providing details and we will investigate your claim.
}

Copyright and moral rights for the publications made accessible in the public portal are retained by the authors and/or other copyright owners and it is a condition of accessing publications that users recognise and abide by the legal requirements associated with these

- Users may download and print one copy of any publication from the public portal for the purpose of private study or research.

- You may not further distribute the material or use it for any profit-making activity or commercial gain

If the publication is distributed under the terms of Article $25 \mathrm{fa}$ of the Dutch Copyright Act, indicated by the "Taverne" license above, 
On the pathway from stress to psychosis 
ISBN 9789052788593

(C) H.W.G. Lataster, Maastricht 2009

Printing: Datawyse / Universitaire Pers Maastricht 


\title{
On the pathway from stress to psychosis
}

\author{
PROEFSCHRIFT
}

ter verkrijging van de graad van doctor aan de Universiteit Maastricht, op gezag van de Rector Magnificus, Prof. mr. G.P.M.F. Mols,

volgens het besluit van het College van Decanen,

in het openbaar te verdedigen op woensdag 14 oktober 2009 om 14:00 uur

door

Hubertina Wilhelmina Gerarda Lataster

Geboren op 3 oktober 1981 te Kerkrade

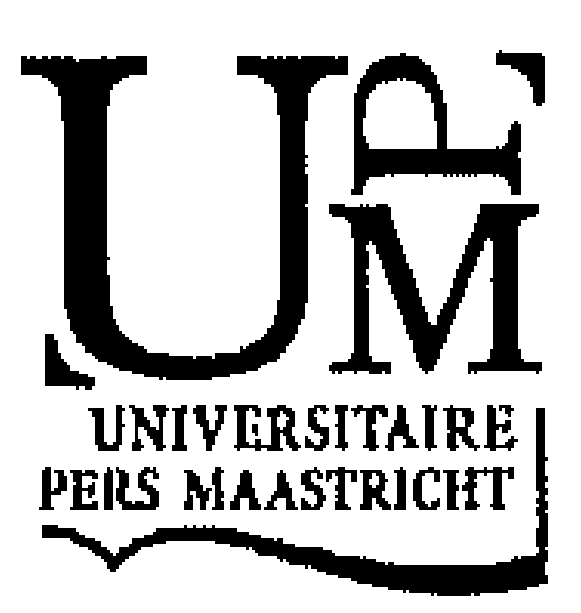




\section{Promotor}

Prof. dr. J. van Os

\section{Co-promotor}

Dr. I. Myin-Germeys

\section{Beoordelingscommissie}

Prof. dr. M. De Vries (voorzitter)

Prof. dr. D. Linszen (Universiteit van Amsterdam)

Dr. M. Marcelis

Dr. L. Valmaggia (Institute of Psychiatry, Kings College, London, UK)

Prof. dr. M. Zeegers

South Limburg Mental Health and Teaching Network PhD Series

The research presented in this thesis was conducted at the Brain \& Behaviour Institute and the Department of Psychiatry and Neuropsychology of Maastricht University, Maastricht University Medical Centre and Mondriaan Zorggroep. 
Voor mijn ouders 


\section{Paranimfen}

Nienke Jabben

Cécile Henquet 


\section{CONTENTS}

Chapter 1 Introduction 9

Chapter 2 Evidence that self-reported psychotic experiences represent 23 the transitory developmental expression of genetic liability to psychosis in the general population.

Chapter 3 Does reactivity to stress cosegregate with subclinical psychosis? Findings from a general population twin study.

Chapter 4 Stress-reactivity and cognitive impairments: separate mechanisms underlying different symptoms in psychosis.

Chapter 5 Increased reactivity to stress clusters within families of 77 patients with non-affective psychosis.

Chapter 6 Childhood victimization and developmental expression of nonclinical delusional ideation and hallucinatory experiences.

Chapter 7 Discussion 


\section{CHAPTER 1}

Introduction 


\section{ON THE PATHWAY FROM STRESS TO PSVCHOSIS}

\section{Phenomenology of schizophrenia}

Schizophrenia is one of the most severe mental illnesses, with a worldwide prevalence of about one percent (Jablensky and others 1992; Sartorius and others 1986). The core symptoms of schizophrenia, as described in the fourth edition of the Diagnostic and Statistical Manual of Mental Disorders (DSM IV) (APA 1994), include positive and negative symptomatology. The criteria for schizophrenia, as mentioned in DSM IV, are i) presence of at least two of the following: delusions, hallucinations, disorganized speech, catatonic behaviour, or negative symptoms with a minimum duration of one month, and (ii) the symptoms cause occupational and social dysfunction for at least 6 months and are not present due to the acute effects of substance use or a medical condition (APA 1994). Additional common symptoms in schizophrenia that are not included in the current DSM IV criteria are impairments in general (i.e. attention, working memory, and executive function) and social (i.e. Theory of Mind, source monitoring, and jumping to conclusions) cognition. Both are relatively stable during the course of the disease and occur independent of positive symptoms (Frith and Corcoran 1996; Keefe and others 2005). A diagnostic construct in psychiatry should (i) have an association with a measurable phenotype that exists in nature, (ii) combine aetiological, symptomatic, prognostic, and treatment specificity in such a way that it can be distinguished form other disorders, and (iii) be useful and acceptable (van Os 2008). It has been suggested by some authors that these three elements do not apply to the diagnostic construct of schizophrenia (Brockington 1992; Kendell and Jablensky 2003). Clearly, schizophrenia is a clinically heterogeneous disorder and the development of the fifth edition of the DSM has fuelled the discussion whether schizophrenia is a valid and useful entity (Allardyce and others 2007a). More traditional views suggest that the extensive clinical heterogeneity in schizophrenia can be reduced to two main forms. The positive syndrome, or non-developmental, type I schizophrenia is characterized by a sudden onset, an episodic course, a good outcome, a good response to anti-psychotic drug treatment and high levels of positive symptoms (Andreasen 1985; Carpenter and others 1988; Crow 1980; Murray and Lewis 1988; Murray and others 1992; Robins and Guze 1970; van Os and Selten 1998). It is often suggested that alterations at the level of neurotransmitter signalling play an important role and that this subtype is more sensitive to aversive environmental influences (Murray and Lewis 1988). The negative syndrome, or developmental, type II schizophrenia is characterized by a gradual onset, a chronic course, a poor outcome, resistance to drug treatment, high leveis of negative symptoms and cognitive impairments (Andreasen 1985; Carpenter and others 1988; Crow 1980; Murray and Lewis 1988; Murray and others 1992; Robins and Guze 1970; van Os and Selten 1998). Structural brain abnormalities and cognitive dysfunction are thought to be most prevalent in this subsyndrome (Green 


\section{CHAPTER 1}

1998; Gur and others 2007; Hulshoff Pol and Kahn 2008; Joyce and Roiser 2007; Murray and Lewis 1988; Staal and others 1999).

In more recent psychiatric literature, on the other hand, several authors have favoured a dimensional approach in which patients have more or less psychopathology rated on several symptom dimensions (Allardyce and others 2007b; Cuesta and others 2006; McGorry and others 1998; van Os and others 1996; Van Os and others 1999a; van Os and others 1999b). Thus, even though for clinical purposes the psychosis phenotype is generally thought of as a dichotomous entity, there is increasing support for a dimensional approach.

\section{A continuum of psychotic symptoms}

Evidence for this dimensional approach of psychosis comes form general population studies showing that psychotic disorder exists as a continuum of severity rather than as an all-or-none phenomenon (Rose and Barker 1978). The suggestion of a psychosis continuum in the general population does not necessarily imply, however, that there is a continuum of the disorder. In both the US National Comorbidity Survey (Kendler and others 1996) and the Dutch NEMESIS study (Bijl and others 1998) the rate of any psychotic or psychosis-like symptoms was $28 \%$ and $17.5 \%$ respectively. However, only $0.7 \%$ and $0.4 \%$ of the subjects fulfilled criteria for a DSM-III-R diagnosis of non-affective psychosis (Kendler and others 1996; van Os and others 2000; van Os and others 2001). Thus, there is robust evidence indicating that selfreported, subclinical psychotic experiences are very common in the general population and that these subclinical symptoms only very rarely transit into clinical symptoms.

Additionally, it has been shown that psychosis incidence increases dramatically in adolescence and early adulthood (WHO 1992). Moreover, even though these subclinical psychotic phenomena are transitory in most individuals (Cougnard and others 2007; Hanssen and others 2005), there is contrasting evidence suggesting that there is familial (Kendler and others 1995) and aetiological (Johns and van Os 2001) continuity between subclinical' psychotic experiences and psychotic disorders. Familial continuity means that the subclinical psychotic experiences in relatives of schizophrenia patients are similar to the clinical symptoms of the patients and characterize relatives of schizophrenia patients compared with relatives of matched controls (Kendler and others 1995). With regard to aetiological continuity it was found that subclinical psychotic experiences and clinical psychotic symptoms are associated in the same way with numerous risk factors (Johns and van Os 2001).

The above findings suggest that a broad distribution of the psychosis phenotype exists in nature, and that this broad phenotype, even though transitory in most cases, shows aetiological and familial continuity with the clinical phenotype of psychotic disorder. Putting these findings together, it seems attractive to hypothesize 


\section{ON THE PATHWAY FROM STRESS TO PSYCHOSIS}

that there is also a genetic continuity between subclinical and clinical psychosis, meaning that genetic risk factors play an important role in the transition to disorder. Additionally, it can be suggested that the prognosis of this expression of psychosis in the general population, in terms of persistence and clinical need, is predicted by additional environmental exposures interacting with genetic risk (Cougnard and others 2007). In CHAPTER 2, a cross-twin, cross-trait design was used to put the hypothesis that self-reported subclinical psychotic experiences represent a broadly distributed phenotype that is the developmental expression of genetic liability to psychosis to the test. This method was used in two recent studies from our group investigating risk factors for depression (Wichers and others 2007; Wichers and others 2008). The design typically examines the association between one trait measured in the proband (twin 1) and another trait measured in the co-twin (twin 2) (Figure 1, page 18).

\section{An affective pathway to psychosis}

The search for causal mechanisms of schizophrenia has lead to an increased interest in the study of endophenotypes (Gottesman and Gould 2003; Tsuang 2001; Weinberger 1999). These endophenotypes are indicators of genetic risk that are not directly visible to the naked eye. They are thus more closely related to genetic aetiology and its interaction with environmental risk factors which makes them good candidates for revealing mechanisms that lead to the development of psychotic symptoms (Claridge 1994). In line with a dimensional approach to psychosis it seems particularly useful to investigate underlying risk factors that are related to specific symptom dimensions of the disorder. Within this line of reasoning it is at tractive to hypothesize that several endophenotypes play a role in the development of psychosis, possibly independent of each other (Myin-Germeys and van Os 2007). Emotional reactivity to stress in daily life and cognitive impairments are thought to be possible endophenotypes. Stress-reactivity is thought to be at the core of the clinical manifestation of the reactive, good outcome, type I schizophrenia, whereas the cognitive impairments are thought to play an important role in the clinical manifestation of the developmental subtype (Myin-Germeys and van Os 2007).

\section{Stress-reactivity: possible unconfounded endophenotype for psychosis}

There is accumulating evidence on the role of stress in the emergence of psychosis. The most widely accepted framework for the study of the aetiology of psychosis is the vulnerability-stress model (Katschnig 1991; Nuechterlein and Dawson 1984; Zubin and Spring 1977). This model states that whenever a stressor exceeds the individuals' vulnerability level, psychopathology will emerge. It is assumed that the individuals' vulnerability level is a stable within-person characteristic. Stressful life events (Bebbington and others 1993; Bebbington and others 1996; Carr and others 


\section{CHAPER I}

2000), aversive family environments (Bebbington and Kuipers 1994; Butzlaff and Hooley 1998), urbanicity (Krabbendam and van Os 2005; Spauwen and others 2004; van Os and others 2003), victimization and childhood trauma (Bebbington and others 2004; Janssen and others 2003; Janssen and others 2004; Read 1997; Read 1998; Read and others 2003) have all been repeatedly associated with the formation of psychotic symptoms. Most of these studies focus on either the vulnerability marker or the stressor, but not on the interaction between the two as is implied by the vulnerability-stress model. To investigate stress as a possible endophenotype, it is essential to look at the association between stressors and the individuals' way of coping with them. The Experience Sampling Method (ESM) was developed in Maastricht to look into these moment-to-moment emotional reactions to stress in the flow of an individuals' daily life (hereafter: "stress-reactivity") (Delespaul 1995; deVries 1992; Myin-Germeys and others 2003; Myin-Germeys and van Os 2007). ESM is a within-day, momentary self-assessment technique (Myin-Germeys and others 2009). Subjects typically receive a digital wristwatch and self-assessment forms collated in a booklet for each day. The method is used to assess current context, thoughts, mood, and symptoms in the flow of daily life. Ten times a day on six consecutive days, the watch emits a signal (beep) at unpredictable moments between 7:30 a.m. and 10:30 p.m. Subjects are asked to immediately report after each beep their thoughts, current context, appraisals of the current situation, and mood. Stress-reactivity is usually defined as the symptomatic response (increases in negative affectivity) to individual self-reported stressful daily life events or activities. Measuring individual reactivity to stress in such a way makes it possible to investigate whether it is an underlying endophenotype.

In a first ESM study it was investigated whether stress-reactivity constitutes part of the liability to psychosis (Myin-Germeys and others 2001). Forty two patients with psychosis in a state of clinical remission, 47 relatives, and 49 healthy control subjects were assessed with ESM to investigate their emotional reactivity to stress in daily life. It was found that patients and relatives showed larger increases in negative affect as response to stressful events or activities in their daily life than healthy control subjects. More specific, patients showed higher increases than the relative group meaning that higher levels of familial risk were associated with higher levels of stress-reactivity in a dose-response fashion (Myin-Germeys and others 2001). These results suggest that stress-reactivity is a possible endophenotype for psychosis. However, the study did not resolve the issue of measurement contamination, since the risk factor (stress-reactivity) may be contaminated by the presence of residual symptoms in patients or by subclinical psychotic experiences in relatives. Using a cross-twin, cross-trait design (Figure 1, page 18) offers an elegant way of getting around this problem. Applying this method offers the opportunity to control for possible confounding influences of trait 2 in the proband (twin 1). The aim of the study presented in CHAPTER 3 was to examine whether stress-reactivity is an un- 


\section{ON THE PATHWAY PROM STRESS TO PSYCHOSIS}

confounded and uncontaminated risk factor for psychosis in a general population twin sample. CHAPTER 5 presents the results of a study investigating the same hypothesis in a clinical sample.

Stress-reactivity: association with cognition, symptom dimensions, and familial clustering

Cognitive impairments have been repeatedly studied as possible underlying vulnerability substrate of schizophrenia (Cosway and others 2000; Harvey and others 1996; Jabben and others 2007; Kraepelin 1919; Weickert and others 2000). It is often suggested that cognitive impairments contribute to course and outcome of schizophrenia in a causal way, since they are found to be associated with negative symptoms (Liddle 1987; van Os and others 1996) and predict functional outcome in an independent way (Green 1996; Harvey and others 1998). If stress-reactivity would indeed be an endophenotype for psychosis, then the question would arise how altered reactivity to stress in daily life relates to this cognitive endophenotype. One possible model would suggest that stress-reactivity lies on the causal pathway between cognitive impairments and psychotic disorder. This causal model implies that cognitive impairments decrease the capability to successfully adapt to stress in daily life, thereby increasing the risk for psychosis. A parallel model would suggest that cognitive impairments and altered reactivity to stress are two independent risk factors for psychosis. To test this causal versus parallel view, the association between cognitive impairments and stress-reactivity was investigated in the same sample of 42 patients with psychotic disorder in a state of clinical remission as described earlier (Myin-Germeys and others 2002). The results showed that in some instances cognitive functioning did not influence the emotional reaction to stress, whereas in other instances an inverse relationship was found, indicating that a better performance on tests of cognitive functioning was associated with a higher emotional reactivity to stress in daily life (Myin-Germeys and others 2002). The results of this study were replicated in a more recent study (Morrens and others 2007) and thus suggest that stress-reactivity is not on the causal pathway between cognitive impairments and psychosis, but rather constitutes a separate (affective) pathway to psychosis.

Based on the above findings it seems attractive to speculate that stress-reactivity and cognitive impairments are independent endophenotypes for psychosis, each related to different symptom dimensions (i.e. the positive and negative symptom dimension, respectively) of the disease as was suggested earlier in this chapter. Previous studies provided robust evidence for the notion that cognitive impairments are associated with the negative sub-syndrome of psychosis (Green 1998; van Os and Verdoux 2001), but not with positive symptoms of psychosis (Green 1998). Remarkably, there is little evidence for the association between emotional reactivity to stress and the positive sub-syndrome of psychosis. In one study, an inverse asso- 


\section{CMAPTER}

ciation was found between scores on the Behavioural Inhibition System (BIS), a neural motivational system which is sensitive to cues of threat, and scores on the negative syndrome scale of the Positive And Negative Syndrome Scale (PANSS) (Scholten and others 2006). However, no association was found with scores on the positive syndrome scale of the PANSS (Scholten and others 2006). The main goal of the study presented in CHAPTER 4 was to investigate the hypothesis that stressreactivity is an independent risk factor leading to the good outcome, positive syndrome of psychosis.

Additionally, as presented earlier in this chapter, first degree relatives of schizophrenia patients also show increased stress-reactivity (Myin-Germeys and others 2001). This suggests that stress-reactivity as possible endophenotype is transmitted within families. If this were the case, then one would expect this area of vulnerability to cluster within families. The study presented in CHAPTER 5 was designed to investigate in a semi-genetically sensitive sample of 47 sib-pairs ( 47 patients and 47 sibs) whether stress-reactivity clusters within families.

\section{Childhood trauma}

One of the many risk factors associated with psychosis that may play a role within the affective pathway to psychosis is the experience of traumatic events in childhood or early adolescence. Several lines of research suggest an association between trauma in childhood and the development of clinical or sub-clinical symptoms of psychosis in adolescence or adulthood (Bebbington and others 2004; Janssen and others 2004; Read and others 2001; Read and others 2005; Spauwen and others 2006). The study presented in CHAPTER 6 aimed at replicating these findings in a general population sample of young adolescents. Moreover, not only in patients with psychotic disorder but also in patients with other diagnoses, childhood trauma is especially associated with the positive symptoms, such as paranoid ideation, thought insertion, visual hallucinations and hearing voices (Butler and others 1996; Hammersley and others 2003; Heins and others 1990; Putnam and others 1986; Read and Argyle 1999; Sansonnet-Hayden and others 1987). It is often hypothesized that the experience of traumatic events, by means of elevated cortisol levels, creates changes in the hypothalamus-pituitary-adrenal axis, the main stress-circuitry in the brain (Read and others 2005). In line with this way of reasoning, it may be attractive to speculate that childhood trauma changes the underlying sensitivity to stress, thereby increasing the liability to develop psychotic symptoms later in life.

In a study from our group, the impact of a history of trauma on moment-to-moment emotions and experiences in the flow of daily life was investigated in 90 frequent attendees of general practitioners (Glaser and others 2006). It was found that subjects with a history of childhood trauma showed significantly increased stressreactivity. Moreover, this effect was found to be stronger for those subjects who had experienced childhood trauma before the age of 10 . The results of this study, 


\section{ON THE PATHWAY FROM STRESS TO PSYCMOSIS}

thus, confirm that the experience of childhood trauma has an effect on the way individuals respond to small stressors in the flow of daily life (Glaser and others 2006). Hence, trauma has its effect on the affective pathway to psychosis by increasing emotional reactivity to stress in daily life.

\section{Outline and aims of the thesis}

The first part of the thesis will focus on finding evidence for a continuum model of psychosis with genetic risk factors impacting on a broadly distributed and transitory population expression of psychosis during development. The second part will focus on finding evidence for an affective pathway to psychosis with stress-reactivity as underlying endophenotype leading to a good outcome, positive psychotic syndrome.

1) The first aim was to investigate a continuum model of psychosis with genetic risk factors impacting on a broadly distributed and transitory population expression of psychosis during development (CHAPTER 2). This was investigated in a general population twin sample. It was hypothesized that self-reported psychotic experiences would be genetically continuous with interview-based psychotic symptoms, meaning that self-reported psychotic experiences in one twin would be associated with interview-based psychotic symptoms in the other twin and that this association would be stronger in twins that are more genetically alike. Second, it was hypothesized that this genetic relationship would be strongly age-dependent, showing developmental specificity.

2) Our second aim was to collect evidence for a so called "affective pathway to psychosis". Stress-reactivity is hypothesized to be the core vulnerability marker within this pathway to a good outcome type with high levels of positive symptoms. A crosstrait, cross-twin design was used in the same general population twin sample as described above. It was investigated whether emotional reactivity to stress in daily life is an unconfounded indicator of risk for developing psychosis (CHAPTER 3). The same hypothesis was also tested in a semi genetically sensitive sample of patients with non-affective psychosis and their siblings (CHAPTER 5). In order to replicate findings on stress-reactivity and cognition as (partially) independent risk factors for the disorder, a clinical sample of patients with non-affective psychotic disorder was used (CHAPTER 4). Additionally, in the same clinical sample, the association between stress-reactivity and the positive and negative symptom dimension of psychosis was investigated (CHAPTER 4). It was hypothesized that stress-reactivity would show strong associations with the positive but not the negative symptoms of psychosis. To explore whether stress-reactivity also clusters within families, a semi genetically sensitive sample of patients with non-affective psychosis and their sib- 


\section{CHAPER}

lings was used (CHAPTER 5). A within-trait, cross-sib design was used to test the hypothesis that stress-reactivity in the sibling is associated with stress reactivity in the patient. Finally, childhood victimization/ trauma was explored as additional risk factor for psychosis in a general population sample of young adolescents (CHAPTER 6). It was hypothesized that, next to additional risk factors such as female sex and Life Events (LE), childhood victimization has an impact within the affective pathway. 
ONTHE PATHWAYFROM STMESTO PYCHOSIS

Figure 1. Arrows: cross-twin, cross-trait associations: examination of the association between trait 1 and trait 2 across genetically related individuals (twins). If the cross-trait, cross-twin association is greater in monozygotic than in dizygotic twins, a genetic contribution to the observed association may be inferred (Wichers et al., 2007).

TWIN 1

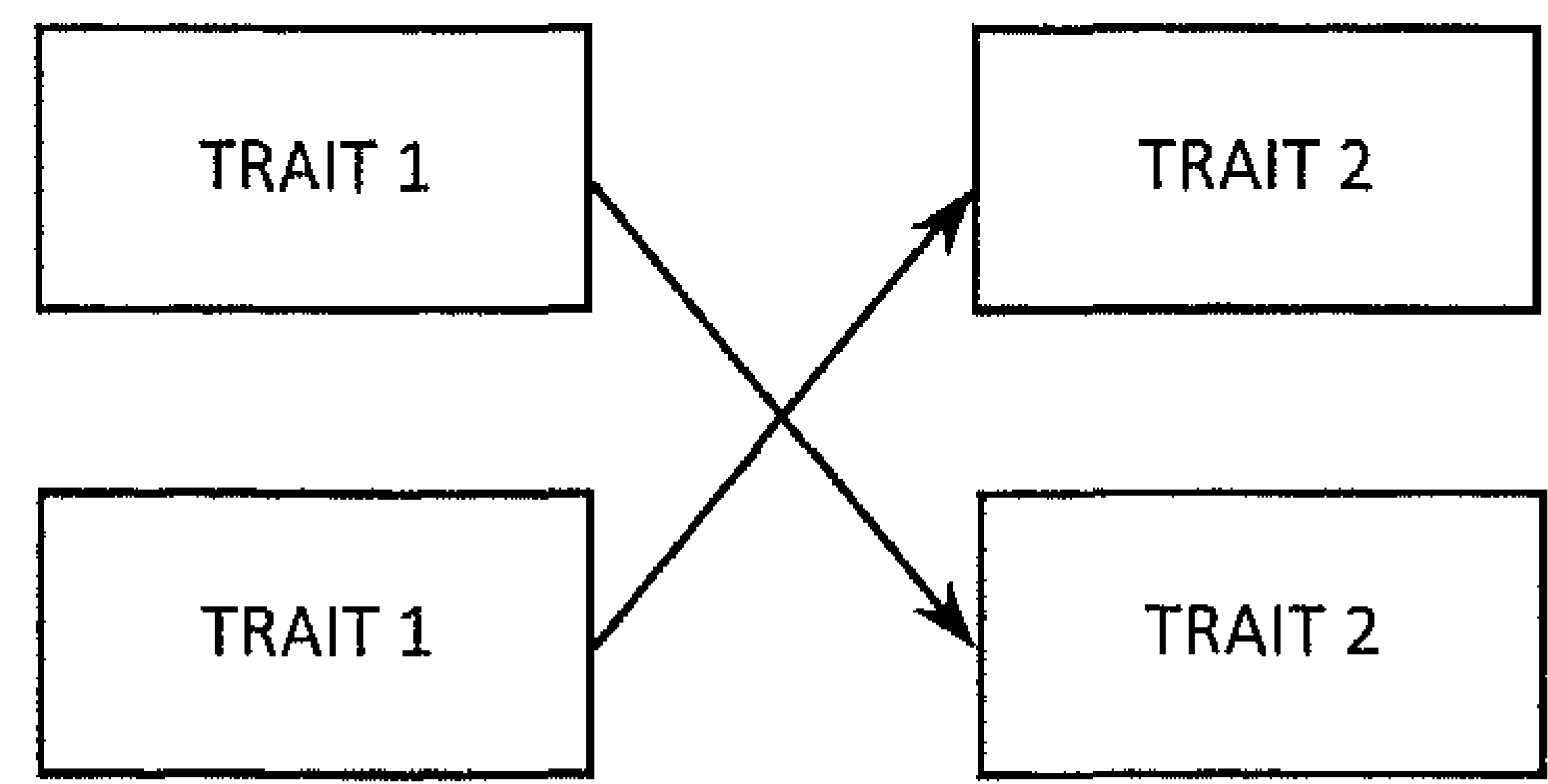

TWIN 2

$$
\text { TRAIT } 1
$$




\section{CHAPTER 1}

\section{References}

Allardyce J, Gaebel W, Zielasek J, van Os J. 2007a. Deconstructing Psychosis conference February 2006: the validity of schizophrenia and alternative approaches to the classification of psychosis. Schizophr Bull 33(4):863-7.

Allardyce J, Suppes T, Van Os J. 2007b. Dimensions and the psychosis phenotype. Int J Methods Psychiatr Res 16 Suppl 1 2007:\$34-40.

Andreasen NC. 1985. Positive vs. negative schizophrenia: a critical evaluation. Schizophr Bull 11(3):380-9.

APA. 1994. Diagnostic and Statistical Manual of Mental Disorders, Fourth Edition: Washington, DC: American Psychiatric Association.

Bebbington P, Kuipers L. 1994. The predictive utility of expressed emotion in schizophrenia: an aggregate analysis. Psychol Med 24(3):707-18.

Bebbington P, Wilkins S, Jones P, Foerster A, Murray R, Toone B, Lewis S. 1993. Life events and psychosis. Initial results from the Camberwell Collaborative Psychosis Study. Br J Psychiatry 162:72-9.

Bebbington P, Wilkins S, Sham P, Jones P, van Os J, Murray R, Toone B, Lewis S. 1996. Life events before psychotic episodes: do clinical and social variables affect the relationship? Soc Psychiatry Psychiatr Epidemiol 31(3-4):122-8.

Bebbington PE, Bhugra D, Brugha T, Singleton N, Farrell M, Jenkins R, Lewis G, Meltzer H. 2004. Psychosis, victimisation and childhood disadvantage: evidence from the second British National Survey of Psychiatric Morbidity. British Journal of Psychiatry 185:220-226.

Bijl RV, Ravelii A, van Zessen G. 1998. Prevalence of psychiatric disorder in the general population: results of The Netherlands Mental Health Survey and Incidence Study (NEMESIS). Soc Psychiatry Psychiatr Epidemiol 33(12):587-95.

Brockington I. 1992. Schizophrenia: Yesterday's concept. European Psychiatry 7:203-207.

Butler RW, Mueser KT, Sprock J, Braff DL. 1996. Positive symptoms of psychosis in posttraumatic stress disorder. Biol Psychiatry 39(10):839-44.

Butzlaff RL, Hooley JM. 1998. Expressed emotion and psychiatric relapse: a meta-analysis. Arch Gen Psychiatry 55(6):547-52.

Carpenter WT, Jr., Heinrichs DW, Wagman AM. 1988. Deficit and nondeficit forms of schizophrenia: the concept. Am J Psychiatry 145(5):578-83.

Carr V, Halpin S, Lau N, O'Brien S, Beckmann J, Lewin T. 2000. A risk factor screening and assessment protocol for schizophrenia and related psychosis. Aust N Z J Psychiatry 34 Suppl:S170-80.

Claridge G. 1994. Single indicator of risk for schizophrenia: probable fact or likely myth? Schizophr Bull 20(1):151-68.

Cosway R, Byrne M, Clafferty R, Hodges A, Grant E, Abukmeil SS, Lawrie SM, Miller P, Jahnstone EC. 2000. Neuropsychological change in young people at high risk for schizophrenia: results from the first two neuropsychological assessments of the Edinburgh High Risk Study. Psychol Med 30(5):1111-21.

Cougnard A, Marcelis M, Myin-Germeys I, De Graaf R, Vollebergh W, Krabbendam L, Lieb R, Wittchen HU, Henquet $C$, Spauwen $J$ and others. 2007. Does normal developmental expression of psychosis combine with environmental risk to cause persistence of psychosis? A psychosis proneness-persistence model. Psychol Med 37(4):513-27.

Crow TJ. 1980. Positive and negative schizophrenic symptoms and the role of dopamine. Br J Psychiatry 137:383-6.

Cuesta MJ, Peralta V, Zarzuela A, Zandio M. 2006. Insight dimensions and cognitive function in psychosis: a longitudinal study. BMC Psychiatry 6:26.

Delespaul PAEG. 1995. Assessing schizophrenia in daily life. Maastricht: Universitaire Pers.

deVries M. 1992. The Experience of Psychopathology: Investigating Mental Disorders in their Natural Settings. Cambridge, NY: Cambridge University Press.

Frith CD, Corcoran R. 1996. Exploring 'theory of mind' in people with schizophrenia. Psychol Med 26(3):521-30. 


\section{ON THE PATHWAY FPOM STPESSTO PSYCHOSIS}

Glaser JP, van Os J, Portegijs PJ, Myin-Germeys I. 2006. Childhood trauma and emotional reactivity to daily life stress in adult frequent attenders of general practitioners. J Psychosom Res 61(2):229-36.

Gottesman, II, Gould TD. 2003. The endophenotype concept in psychiatry: etymology and strategic intentions. Am J Psychiatry 160(4):636-45.

Green MF. 1996. What are the functional consequences of neurocognitive deficits in schizophrenia? Am J Psychiatry 153(3):321-30.

Green MF. 1998. Schizophrenia from a neurocognitive perspective: Probing the impenetrable darkness. Boston: Allyn and Bacon.

Gur RE, Keshavan MS, Lawrie SM. 2007. Deconstructing psychosis with human brain imaging. Schizophr Bull 33(4):921-31.

Hammersley P, Dias A, Todd G, Bowen-Jones K, Reilly B, Bentall RP. 2003. Childhood trauma and hallucinations in bipolar affective disorder: preliminary investigation. Br J Psychiatry 182:543-7.

Hanssen M, Bak M, Bijl R, Vollebergh W, van Os J. 2005. The incidence and outcome of subclinical psychotic experiences in the general population. Br J Clin Psychol 44(Pt 2):181-91.

Harvey PD, Davidson M, White L, Keefe RS, Hirschowitz J, Mohs RC, Davis KL. 1996. Empirical evaluation of the factorial structure of clinical symptoms in schizophrenia: effects of typical neuroleptics on the brief psychiatric rating scale. Biol Psychiatry 40(8):755-60.

Harvey PD, Howanitz E, Parrella M, White L, Davidson M, Mohs RC, Hoblyn J, Davis KL. 1998. Symptoms, cognitive functioning, and adaptive skills in geriatric patients with lifelong schizophrenia: a comparison across treatment sites. Am J Psychiatry 155(8):1080-6.

Heins T, Gray A, Tennant M. 1990. Persisting hallucinations following childhood sexual abuse. Aust N Z J Psychiatry 24(4):561-5.

Hulshoff Pol HE, Kahn RS. 2008. What happens after the first episode? A review of progressive brain changes in chronically ill patients with schizophrenia. Schizophr Bull 34(2):354-66.

Jabben N, van Os J, Janssen I, Versmissen D, Krabbendam L. 2007. Cognitive alterations in groups at risk for psychosis: neutral markers of genetic risk or indicators of social disability? Acta Psychiatr Scand 116(4):253-62.

Jablensky A, Sartorius N, Ernberg G, Anker M, Korten A, Cooper JE, Day R, Bertelsen A. 1992. Schizophrenia: manifestations, incidence and course in different cultures. A World Health Organization tencountry study. Psychol Med Monogr Suppl 20:1-97.

Janssen I, Hanssen M, Bak M, Bijl RV, de Graaf R, Vollebergh W, McKenzie K, van Os J. 2003. Discrimination and delusional ideation. Br J Psychiatry 182:71-6.

Janssen I, Krabbendam L, Bak M, Hanssen M, Vollebergh W, De Graaf R, Van Os J. 2004. Childhood abuse as a risk factor for psychotic experiences. Acta Psychiatrica Scandinavica 109(1):38-45.

Johns LC, van Os J. 2001. The continuity of psychotic experiences in the general population. Clin Psychol Rev 21(8):1125-41.

Joyce EM, Roiser JP. 2007. Cognitive heterogeneity in schizophrenia. Curr Opin Psychiatry 20(3):268-72.

Katschnig H. 1991. Vulnerability models for schizophrenia: Discussion. In: (eds.) HHWFG, editor. Search for the causes of schizophrenia. Berlin: Springer-Verlag.

Keefe RS, Eesley CE, Poe MP. 2005. Defining a cognitive function decrement in schizophrenia. Biol Psychiatry 57(6):688-91.

Kendell R, Jablensky A. 2003. Distinguishing between the validity and utility of psychiatric diagnoses. American Journal of Psychiatry 160(1):4-12.

Kendler KS, Gallagher TJ, Abelson JM, Kessler RC. 1996. Lifetime prevalence, demographic risk factors, and diagnostic validity of nonaffective psychosis as assessed in a US community sample. The National Comorbidity Survey. Arch Gen Psychiatry 53(11):1022-31.

Kendler KS, McGuire M, Gruenberg AM, Walsh D. 1995. Schizotypal symptoms and signs in the Roscommon Family Study. Their factor structure and familial relationship with psychotic and affective disorders. Arch Gen Psychiatry 52(4):296-303.

Krabbendam L, van OS J. 2005. Schizophrenia and urbanicity: a major environmental influence-conditional on genetic risk. Schizophr Bull 31(4):795-9. 


\section{CHB⿵冂卄}

Kraepelin E. 1919. Dementia Preaecox and Paraphrenia. GM. TbBRebR, editor. New York: Robert E Krieger, 1971.

Liddle PF. 1987. The symptoms of chronic schizophrenia. A re-examination of the positive-negative dichotomy. Br J Psychiatry 151:145-51.

McGorry PD, Bell RC, Dudgeon PL, Jackson HJ. 1998. The dimensional structure of first episode psychosis: an exploratory factor analysis. Psychol Med 28(4):935-47.

Morrens M, Krabbendam L, Bak M, Delespaul P, Mengelers R, Sabbe B, Hulstijn W, van Os J, MyinGermeys 1. 2007. The relationship between cognitive dysfunction and stress sensitivity in schizophrenia: a replication study. Soc Psychiatry Psychiatr Epidemiol 42(4):284-7.

Murray RM, Lewis SW. 1988. Is schizophrenia a neurodevelopmental disorder? Br Med J (Clin Res Ed) 296(6614):63.

Murray RM, O'Callaghan E, Castle DJ, Lewis SW. 1992. A neurodevelopmental approach to the classification of schizophrenia. Schizophr Bull 18(2):319-32.

Myin-Germeys I, Krabbendam L, Jolles J, Delespaul PA, van OS J. 2002. Are cognitive impairments associated with sensitivity to stress in schizophrenia? An experience sampling study. Am J Psychiatry 159(3):443-9.

Myin-Germeys I, Oorschot, M., Collip, D., Lataster, J., Delespaul, P., van Os, J. (2009). Experience sampling research in psychopathology: opening the black box of daily life. Psych Med, epub ahead of print.

Myin-Germeys I, Peeters F, Havermans R, Nicolson NA, DeVries MW, Delespaul P, Van Os J. 2003. Emotional reactivity to daily life stress in psychosis and affective disorder: an experience sampling study. Acta Psychiatr Scand 107(2):124-31.

Myin-Germeys I, van Os J. 2007. Stress-reactivity in psychosis: evidence for an affective pathway to psychosis. Clin Psychol Rev 27(4):409-24.

Myin-Germeys I, van Os J, Schwartz JE, Stone AA, Delespaul PA. 2001. Emotional reactivity to daily life stress in psychosis. Arch Gen Psychiatry 58(12):1137-44.

Nuechterlein KH, Dawson ME. 1984. A heuristic vulnerability/stress model of schizophrenic episodes. Schizophr Bull 10(2):300-12.

Putnam FW, Guroff JJ, Silberman EK, Barban L, Post RM. 1986. The clinical phenomenology of multiple personality disorder: review of 100 recent cases. J Clin Psychiatry 47(6):285-93.

Read J. 1997. Child abuse and psychosis: A literature review and implications for professional practice. Professional Psychology: Research-and-Practice 28(5):448-456.

Read J. 1998. Child abuse and severity of disturbance among adult psychiatric inpatients. Child Abuse \& Neglect 22(5):359-368.

Read J, Agar K, Argyle N, Aderhold V. 2003. Sexual and physical abuse during childhood and adulthood as predictors of hallucinations, delusions and thought disorder. Psychological Psychotherapy 76(Pt 1):122.

Read J, Argyle N. 1999. Hailucinations, delusions, and thought disorder among adult psychiatric inpatients with a history of child abuse. Psychiatr Serv 50(11):1467-72.

Read J, Perry BD, Moskowitz A, Connolly J. 2001. The contribution of early traumatic events to schizophrenia in some patients: a traumagenic neurodevelopmental model. Psychiatry 64(4):319-45.

Read J, van Os J, Morrison AP, Ross CA. 2005. Childhood trauma, psychosis and schizophrenia: a literature review with theoretical and clinical implications. Acta Psychiatr Scand 112(5):330-50.

Robins E, Guze SB. 1970. Establishment of diagnostic validity in psychiatric illness: its application to schizophrenia. American Journal of Psychiatry 126(7):983-987.

Rose G, Barker DJ. 1978. Epidemiology for the uninitiated. What is a case? Dichotomy or continuum? $\mathrm{Br}$ Med J 2(6141):873-4.

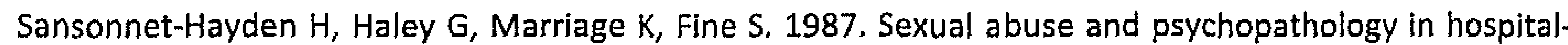
ized adolescents. J Am Acad Child Adolesc Psychiatry 26(5):753-7. 


\section{ONTHE PATHWAY FHOMSTESSTOPSYCHOSIS}

Sartorius N, Jablensky A, Korten A, Ernberg G, Anker M, Cooper JE, Day R. 1986. Early manifestations and first-contact incidence of schizophrenia in different cultures. A preliminary report on the initial evaluation phase of the WHO Collaborative Study on determinants of outcome of severe mental disorders. Psychol Med 16(4):909-28.

Scholten MR, van Honk J, Aleman A, Kahn RS. 2006. Behavioral inhibition system (BIS), behavioral activation system (BAS) and schizophrenia: relationship with psychopathology and physiology. J Psychiatr Res 40(7):638-45.

Spauwen J, Krabbendam L, Lieb R, Wittchen HU, van OS J. 2004. Does urbanicity shift the population expression of psychosis? J Psychiatr Res 38(6):613-8.

Spauwen J, Krabbendam L, Lieb R, Wittchen HU, van Os J. 2006. Impact of psychological trauma on the development of psychotic symptoms: relationship with psychosis proneness. Br J Psychiatry 188:52733.

Staal WG, Hulshoff Pol HE, Kahn RS. 1999. Outcome of schizophrenia in relation to brain abnormalities. Schizophr Bull 25(2):337-48.

Tsuang MT. 2001. Defining alternative phenotypes for genetic studies: what can we learn from studies of schizophrenia? Am J Med Genet 105(1):8-10.

van Os J. 2008. A salience dysregulation syndrome. British Journal of Psychiatry in press.

van Os J, Fahy TA, Jones P, Harvey I, Sham P, Lewis S, Bebbington P, Toone B, Williams M, Murray R. 1996. Psychopathological syndromes in the functional psychoses: associations with course and outcome. Psychol Med 26(1):161-76.

Van Os J, Gilvarry C, Bale R, Van Horn E, Tattan T, White I, Murray R. 1999a. A comparison of the utility of dimensional and categorical representations of psychosis. UK700 Group. Psychol Med 29(3):595-606.

van Os J, Hanssen M, Bak M, Bijl RV, Vollebergh W. 2003. Do urbanicity and familial liability coparticipate in causing psychosis? Am J Psychiatry 160(3):477-82.

van Os J, Hanssen M, Bijl RV, Ravelli A. 2000. Strauss (1969) revisited: a psychosis continuum in the general population? Schizophr Res 45(1-2):11-20.

van Os J, Hanssen M, Bijl RV, Vollebergh W. 2001. Prevalence of psychotic disorder and community level of psychotic symptoms: an urban-rural comparison. Arch Gen Psychiatry 58(7):663-8.

van Os J, Selten JP. 1998. Prenatal exposure to maternal stress and subsequent schizophrenia. The May 1940 invasion of The Netherlands. Br I Psychiatry 172:324-6.

van Os J, Verdoux H. 2001. Diagnosis and classification of schizophrenia: Categories versus dimensions, distributions versus disease. In: Murray RM, Jones PB, Susser E, van Os J, Cannon M, editors. The epidemiology of schizophrenia. Cambridge: Cambridge University Press.

van Os J, Verdoux H, Maurice-Tison S, Gay B, Liraud F, Salamon R, Bourgeois M. 1999b. Self-reported psychosis-like symptoms and the continuum of psychosis. Soc Psychiatry Psychiatr Epidemiol 34(9):459-63.

Weickert TW, Goldberg TE, Gold JM, Bigelow LB, Egan MF, Weinberger DR. 2000. Cognitive impairments in patients with schizophrenia displaying preserved and compromised intellect. Arch Gen Psychiatry 57(9):907-13.

Weinberger DR. 1999. Schizophrenia: new phenes and new genes. Biol Psychiatry 46(1):3-7

WHO. 1992. International classification of diseases, 10th edn. Geneva: World Health Organisation.

Wichers M, Myin-Germeys I, Jacobs N, Peeters F, Kenis G, Derom C, Vlietinck R, Delespaul P, Van Os J, 2007. Genetic risk of depression and stress-induced negative affect in daily life. $\mathrm{Br} J$ Psychiatry 191:218-23.

Wichers MC, Myin-Germeys 1, Jacobs N, Kenis G, Derom C, Vlietinck R, Delespaul P, Mengelers R, Peeters $F$, Nicolson $N$ and others, 2008. Susceptibility to depression expressed as alterations in cortisol day curve: a cross-twin, cross-trait study. Psychosom Med 70(3):314-8.

Zubin J, Spring B. 1977. Vulnerability--a new view of schizophrenia. J Abnorm Psychol 86(2):103-26. 


\section{CHAPTER 2}

\section{Evidence that self-reported psychotic experiences represent the transitory developmental expression of genetic liability to psychosis in the general population}

Tineke Lataster ${ }^{1}$, Inez Myin-Germeys ${ }^{1,4}$, Catherine Derom ${ }^{2}$, Evert Thiery ${ }^{5}$, Jim van $0 s^{1,3}$

\footnotetext{
${ }^{1}$ Department of Psychiatry and Neuropsychology, South Limburg Mental Health Research and Teaching Network, EURON, Maastricht University Medical Centre, Maastricht, The Netherlands 'Department of Human Genetics, University Hospital Gasthuisberg, Katholieke Universiteit Leuven, B-3000 Leuven, Belgium

${ }^{3}$ Division of Psychological Medicine, Institute of Psychiatry, London SE5 8AF, UK

${ }^{4}$ School of Psychological Sciences, University of Manchester, UK

${ }^{5}$ Association for Scientific Research in Multiple Births, Ghent, Belgium.
}

American Journal of Medical Genetics Part B: Neuropsychiatric Genetics, in press 


\section{ONTHE PATHWA PROM STRESSTO PSYCHOSIS}

\section{ABSTRACT}

Background: It has been suggested that self-reported, common, non-clinical psychotic experiences may represent the transitory developmental expression of distributed genetic risk for psychosis.

Methods: In a sample of female MZ (176 pairs) and DZ twins (113 pairs), cross-twin, cross-trait analyses were conducted to investigate the association between repeated continuous measures of self-reported psychotic experiences (PE-three measures over 18 months), assessed with the CAPE, in one twin and clinical interview categorical measures of psychotic symptoms (PS), assessed with SCID-I, in the other twin.

Results: The results showed that in $M Z$ but not $D Z$ pairs (interaction: $\chi 2=7.9, d f=1$, $P=0.005$ ), the cross-twin association between $P E$ and $P S$ was large and significant (standardized effect size: $0.26,95 \% \mathrm{Cl}: 0.10-0.42$ ) and of similar magnitude as the within-twin PE-PS association (standardized effect size: $0.28,95 \% \mathrm{Cl}: 0.10-0.45$ ), demonstrating both PE validity and genetic effects. In addition, the cross-twin association between PE and PS was significantly larger (interaction: $\chi 2=20.3, \mathrm{df}=1, \mathrm{P}<$ 0.0001 ) for younger $\mathrm{MZ}$ twins (standardized effect size: $0.67,95 \% \mathrm{Cl}: 0.44-0.90$ ) than older MZ twins (standardized effect size: $-0.05,95 \% \mathrm{Cl}:-0.26$ to 0.16 ), demonstrating developmental effects.

Discussion: This study indicates that self-reported psychotic experiences in the general population may represent the developmental expression of population genetic risk for psychosis. 


\section{Introduction}

Epidemiological restearch indicates that self reported, sublimical pspchotic experi. ences, or posive "schootupal" experiences, induding mallucinatory expericences and experiences resembling frst rank symptoms of schophrenia, are common in the general population Uohns and others 2004; Van os and others 2000). Follow-up of individuals with these experences has shown that for the great majority of ind. viduals, these phenomeria are a transitory developmental phenomenon (Cougnard and others 2007; Hanssen and others 20051

In apparent contrast to their transtory and benign nature, there is evidence suggesting that subclinical psychotic experiences are continuous with psychotic dis. orders such as schizophrema. For example, the non.ill relatives of patients with schizophrenia have higher levels of subclinical psychotic experiences, suggesting familial continuity (Kendler and others 1995). Similarly, environmental risk factors associated with psychotic disorder, such as ethnic minority group, urbanicity and cannabis, are also associated, independently, with subclinical psychotic experiences (Sharpley and Peters 1999; van Os and others 2002; van Os and others 2001), suggesting aetiological continuity (Johns and van 052001 ). Self-reported subclinical psychotic experiences are associated with an increased risk of developing psychotic disorder later in life, suggesting temporal continuity (Poulton and others 2000b). Finally, both clinical psychotic disorders and subclinical psychotic experiences are associated with specific developmental stages in that their population expression is mostly restricted to adolescence and early adulthood (Peters and others 1999; Verdoux and others 1998b).

Given these findings, it has been suggested that self-reported subclinical psychotic experiences represent a broadly distributed phenotype that is the developmental expression of genetic liability to psychosis (Cougnard and others 2007), in much the same way as the distributed personality trait neuroticism, or negative affectivity, is associated genetically with major depressive disorder (Kendler and others 1993). In the current study, this hypothesis was put to the test using a twin sample consisting of monozygote (MZ: 100\% shared genes) and dizygote (DZ: 50\% shared genes) twin pairs. It was hypothesized that self-reported psychotic experiences would be genetically continuous with interview-based psychotic symptoms, meaning that selfreported psychotic experiences in one twin would be associated with interview. based psychotic symptoms in the other twin and that this association would be stronger in twins that are more genetically alike. Second, it was hypothesized that this genetic relationship would be strongly age-dependent, showing developmental specificity. 


\section{Materials and Methods}

Sample

The sample used for the present study was drawn from a sample collected as part of a larger research project investigating gene-environment interactions in vulnerability for mental disorders. Given likely sex-specific genetic effects on psychopathology (Jacobs and others 2006), only women were selected in the first wave. Participants were recruited from birth registers of Flemish municipalities and from the East Flanders Prospective Twin Survey in Belgium. This population-based survey has prospectively recorded all multiple births in the province of East Flanders since 1964 (Derom and others 2006; Jacobs and others 2006; Jacobs and others 2007; Simons and others 2007). The project was approved by the Local Medical Ethics Committee and all participants gave written informed consent. The sample initially included 621 subjects ( 575 female twins and 46 of their non-twin sisters). For the current study, all 46 non-twin sisters were excluded from the analyses and 3 participants were excluded due to missing zygosity. Thus, the final sample consisted of 572 subjects, who were part of 289 different twin-pairs (176 MZ and $113 \mathrm{DZ}$ pairs). Six probands participated without their co-twin. These 6 subjects were excluded from the crosstrait, cross-twin analyses. Thus, the sample for the cross-trait, cross-twin analyses consisted of 566 subjects, who were part of 283 different twin-pairs (174 MZ and $109 \mathrm{DZ}$ pairs). Mean age of the final sample was 27 years ( $S D=8$; range $18-46$ ), 63\% had a higher education, $35 \%$ had followed higher secondary school, and $2 \%$ had finished only primary education. The majority (62.7\%) were employed, while $32.3 \%$ were students, $2.4 \%$ were unemployed, $2.2 \%$ were housewives, and $0.4 \%$ were on sick leave.

\section{Assessment of psychotic symptoms}

Psychotic symptoms (PS) were measured with the Structured Clinical Interview for DSM-IV Axis-I Disorders (SCID-I) (First and others 2002). The SCID is a structured interview for, amongst others, psychotic and affective disorders, yielding standardized DSM-IV (APA 1994) diagnoses. For the present study, symptoms pertaining to the psychosis section of the SCID.I were used and positive lifetime interview ratings of delusions and hallucinations were combined into one categorical measure of PS $(0=$ no delusions or hallucinations present, $1=$ one delusion or hallucination present, $2=$ two or more delusions or hallucinations present). Interviews were conducted by psychological test assistants (4 year training at academic level) with specific SCID-I training and additional training in the assessment of psychotic symptoms. 
Assessment of subclinical psychotic experiences

All subjects were followed up over an 18 month period. During this period, at three different moments, each approximately six months apart, continuous self-reported subclinical psychotic experiences (PE) in the affective and non-affective domains were assessed with the previously validated Community Assessment of Psychic Experiences (CAPE) (Hanssen and others 2003; Konings and others 2006; Stefanis and others 2002) (http://www.cape42.homestead.com/). Frequency scores were measured on a 4-point scale from 'never [1]', 'sometimes [2]', 'often [3]' to 'nearly always [4]'. Mean standardized frequency scores, with mean zero and unity standard deviation, on the positive psychotic experiences dimension of the CAPE were calculated for each of the three measurement occasions. Previous research with the CAPE has shown discriminative validity across groups of individuals with schizophrenia, affective and anxiety disorders and individuals from the general population (Hanssen and others 2003), as well as concurrent (Stefanis and others 2002) and predictive validity (Konings and others 2006). The CAPE positive symptom dimension encompasses 20 items.

\section{Analyses}

The current data set has a hierarchical structure: multiple observations (i.e. the repeated CAPE measurements) (level 1) were nested within subjects (level 2), who were part of twin pairs (level 3 ). In order to take the two-level grouping structure of the data (CAPE measurements at three different moments, subject, twin pair) into account, multilevel random regression analysis (Snijders and Bosker 1999) was applied in STATA, version 9.2 (Statacorp 2005), using the XTMIXED command to fit linear mixed models of the continuous psychosis outcome. Mixed models contain both fixed and random effects. The fixed effects are analogous to standard regression coefficients (B) and are estimated directly. The grouping structure of the data in XTMIXED may consist of multiple levels of nested groups.

\section{Are self-reported PE valid?}

Given genetic effects on psychotic experiences (Kendler and Hewitt 1992; Linney and others 2003; MacDonald and others 2001), a strict test of the hypothesis that self-reported PE are a valid reflection of PS, is to test whether the association between PE and PS can be replicated within and across genetically identical MZ twins, using both cross-trait within twin, and cross-trait cross-twin analyses (Figure 1, page 33). In a cross-trait within-twin analysis, the association between trait $x$ and $y$ is tested within one person. However, since both traits are assessed within the same person, trait $x$ may be contaminated by trait $y$ or both traits may be moderated by other traits of that person. Therefore, cross-trait cross-twin have been used as well, in which trait $x$ in the proband is associated with trait $y$ in the co-twin. Since trait $y$ is now assessed in a different person, trait $x$ cannot be contaminated by trait $y$. This 
ON THE PATHWAY FROM STRESS TO PSYHOSIS

method thus ensures that the association between $x$ and $y$ - in this case PE and PS is uncontaminated. In order to test whether the association between PE and PS could be replicated within and across genetically identical $M Z$ twins, multilevel linear regression analysis was performed for the group of $M Z$ twins using the XTMIXED command (within-twin regression model: $P S=B O+B 1 P E+$ residual; across-twin regression model: $\mathrm{PS}$-proband $=\mathrm{BO}+\mathrm{B} 1 \mathrm{PE}-$ cotwin + residual).

Are self-reported PE and interview-based PS genetically continuous?

In order to investigate the hypothesis that self-reported PE would be genetically continuous with interview-based PS, the association between proband PS and cotwin PE was compared between $M Z$ twins who share $100 \%$ of their genes and $D Z$ twins who share only $50 \%$ of their genes. A two-way interaction between co-twin PS and zygosity in the model of proband PE was fitted and evaluated using the XTMIXED command (regression model: proband $P E=B O+B 1$ co-twin $P S+B 2$ cotwin PS x zygosity + residual).

Is any genetic continuity between PE and PS age-dependent?

In order to test the age-dependency (i.e. the association between PS in the proband and $P E$ in the co-twin is greater for younger than for older subjects) of any genetic continuity between $\mathrm{PE}$ and $\mathrm{PS}$, another two-way interaction was fitted and evaluated using the XTMIXED command with age entered in the model as a dichotomous variable, separated around the sample median age of 25 years $(0=$ age $>25$ years, $1=$ age $<26$ years) (regression model: proband $P E=B O+B 1$ co-twin $P S+B 2$ co-twin PS $x$ age + residual).

\section{Results}

\section{Descriptives}

Out of 572 subjects in the final sample, a risk set was analysed consisting of 566 subjects with non-missing PS, PE, age, and zygosity (174 MZ and $109 \mathrm{DZ}$ pairs). The mean frequency score on self-reported PE was $1.14(S D=0.21)$. Of the total sample, 497 (88\%) subjects reported no delusions/ hallucinations on the SCID, 47 (8\%) reported one delusion/ hallucination, and $22(4 \%)$ reported more than two delusions/ hallucinations. More detailed descriptives of the risk set are depicted in Table 1 (page 33).

Are self-reported PE valid?

The multilevel linear regression analysis, performed to investigate the association between PE and PS within and across $M Z$ twins, showed a significant association of similar magnitude both within ( $B=0.26,95 \% C l: 0.10-0.42 ; p=0.001)$ and across $M Z$ twins $(B=0.28,95 \% \mathrm{Cl}: 0.10-0.45 ; p=0.002)$, indicating $P E$ validity. 


\section{CHAPER2}

Are self-reported PE and interview-based PS genetically continuous?

A significant interaction was found between zygosity and cotwin PS in the model of proband $P E(X 2=7.9, d f=1, P=0.005)$, indicating that the association between $P E$ and PS was significantly stronger in $\mathrm{MZ}(\mathrm{B}=0.28,95 \% \mathrm{Cl}: 0.10-0.45 ; \mathrm{p}=0.002)$ than $\mathrm{DZ}$ $(B=-0.08,95 \% \mathrm{Cl}:-0.25-0.10 ; p=0.393)$ twin pairs (Figure 2, page 34). This means that common self-reported $\mathrm{PE}$ are continuous with rarer clinical psychotic symptoms in an unconfounded fashion.

Is any genetic link between PE and PS age-dependent?

Additionally, in the group of $M Z$ twins, a significant interaction was found between age and cotwin $P S$ in the model of PE $(\chi 2=20.3, d f=1, p<0.0001)$, indicating that the association between $P E$ and $P S$ was significantly stronger for younger ( $B=0.67,95 \%$ $\mathrm{Cl}: 0.44-0.90 ; p=0.000)$ than for older $(B=-0.05,95 \% \mathrm{Cl}:-0.26-0.16 ; p=0.657) \mathrm{MZ}$ twins, indicating age-dependency of the genetic association between subclinical PE and clinical PS (Figure 3, page 35). This is in line with a neurodevelopmental approach to the aetiology of psychotic disorders, with a physiological neurodevelopmental stage favouring the expression of subclinical PE in normal subjects

\section{Discussion}

\section{Findings}

First, a significant association was found between subclinical PE and clinical PS both within and across genetically identical $M Z$ twins, suggesting that common selfreported PE are continuous with rarer clinical psychotic symptoms in an unconfounded fashion. Second, the cross-trait, cross-twin analyses showed that the association between subclinical PE and clinical PS was much larger in $M Z$ than in $D Z$ twins. These findings are in line with recent studies suggesting that subclinical psychotic experiences represent a broadly distributed phenotype that is the developmental expression of genetic liability to psychosis (Cougnard and others 2007).

Third, a strong age-dependency of the association between subclinical PE and clinical PS was found, evidenced by a much stronger association being apparent in the younger half of the sample. This is in line with a neurodevelopmental approach to the aetiology of psychotic disorders, with a physiological neurodevelopmental stage favouring the expression of subclinical PE in normal subjects (Verdoux and others 1998). It is attractive to suggest that psychotic symptoms arise during early adolescence as a result of the interaction between these normal brain maturational processes and the abnormal brain development associated with the genetic and nongenetic aetiology of psychotic disorder (Cougnard and others 2007). 


\section{ON THE PATHWAY FROM STRESS TO PSYCHOSIS}

Psychotic experiences and symptoms are genetically continuous: possible mechanisms

Several studies have suggested that the sensitisation of the dopamine (DA) system might mediate the expression of psychosis (Kapur 2003; Laruelle and Abi-Dargham 1999; Laruelle and others 1999). It has been suggested that this sensitisation of mesolimbic dopamine neurotransmission may result from a synergistic effect of genes and environment (Collip and others 2008; Featherstone and others 2007; van Os and others 2008). Genetic risk for psychosis has been with alterations in the dopamine system (van Os and others 2008), including increased dopamine synaptic availability (Hirvonen and others 2005), increased striatal dopamine synthesis (Huttunen and others 2008; Meyer-Lindenberg and others 2002), and increased dopamine reactivity to stress (Brunelin and others 2008; Myin-Germeys and others 2005a). Similarly, Murray and colleagues (2002) have suggested that environmental stressors may contribute to dopamine sensitisation during development. In animal studies, it was found that a disruption in postnatal rearing conditions can lead to profound and long lasting changes in the dopamine response to stress and psychostimulants (Brake and others 2004; Hall and others 1999; Pani and others 2000). Results of studies in humans suggest that similar mechanisms exist that may explain differential DA reactivity in subjects with and without psychosis liability (MyinGermeys and others 2005b; Soliman and others 2007). Low early life maternal care, for instance, may influence mesolimbic dopamine release as a response to psychological stress (Pruessner and others 2004). In addition to early life stress exposure, agonist drug use may also cause sensitisation of dopamine systems (Boileau and others 2006; Laruelle 2000; Pani and others 2000).

Kapur (2003) suggested that a dysregulated, hyperdopaminergic state may lead to stimulus-independent release of DA, which may take over the normal process of contextually driven salience attribution and leads to aberrant assignment of salience to external objects and internal representations. A recent study on subjects genetically at risk for psychosis suggested that a hyperreactive DA system may underlie the intensity of psychotic experiences in response to stress in daily life (MyinGermeys and others 2005a; Myin-Germeys and others 2005b). Preliminary analyses from our group showed that persistence of subclinical psychotic experiences over time is predictive of eventual transition to clinical psychosis. Cougnard and others (2007) suggested that a genetic predisposition to sensitisation of the dopamine system is related to a tendency to express subclinical PE that in most individuals will only be transitory. However, in the case of exposure to additional environmental risk factors, such as cannabis use, childhood trauma or environmental risk factors associated with urbanicity, the dopamine system may become abnormally sensitized and transitory subclinical psychotic experiences may become more persistent and eventually progress to a clinical psychotic disorder (Cougnard and others 2007). 


\section{CHAPTER}

The link between psychotic experiences and symptoms is developmental: possible mechanisms

Weinberger (1987) stated that "early adulthood may be a critical period of vulnerability for the expression of psychotic behaviour, whatever the underlying brain disease". Verdoux and colleagues (1998) hypothesized that there may be a physiological neurodevelopmental stage favouring the expression of subclinical psychotic experiences in the general population. For example, the maturation of the dopamine system in the brain may mediate the expression of positive psychotic experiences and symptoms in adolescence and early adulthood (Verdoux and others 1998), given the increase in dopaminergic neurotransmission around that age (Benoit-Marand and O'Donnell 2008; Chambers and others 2003; Weinberger 1987).

Genes that increase the risk for schizophrenia may impact directly or indirectly on a final common pathway involving dopamine regulation. To date, however, no consistent evidence exists for any molecular genetic variation in the aetiology of schizophrenia (van Os 2008).

\section{Limitations}

The results should be viewed in the light of several methodological issues. First, the CAPE questionnaire is based on subjective reports. Therefore, it can be argued that the results are not psychometrically precise. However, although subjective reports are considered less reliable (e.g., do all subjects interpret or answer the questions identically?), previous research implies that subjective reports can be valid, and that the validity of objective reports should not be taken for granted (Strauss 1994). The SCID questionnaire, which is used to assess the psychotic symptoms, on the other hand, is based on observant reports. The use of different approaches to assess psychotic experiences and psychotic symptoms could possibly introduce error. However, this could not explain the difference in association between $M Z$ and $D Z$ twins. In fact, one could argue that the finding of a positive association between PE and PS, despite coming from different sources of information, may provide even stronger evidence for a continuity of psychosis, since lower correlations would be expected between data coming from different instruments.

Second, as suggested by Verdoux et al. (1998), it is possible that the influence of age on the association between subclinical PE and clinical PS could be explained by elderly people being more reluctant in reporting unusual ideas or experiences. In this study, however, emphasis was put on the fact that all information would be kept confident and processed in an anonymous fashion, and the oldest person was 46 years of age. Additionally, Peters et al. (1999) suggest that increased conservatism with age might explain that people are less likely to present with unusual ideas as they get older instead of in fact experiencing fewer unusual thoughts. It can be argued, however, that increased conservatism with age conceptually does not differ 
from decreased proneness to present with non-conventional ideas (Verdoux and others 1998).

Third, the psychotic symptoms (PS) in this sample are neither clinically relevant nore producing need for care. A next step would be to reproduce these findings in a clinical sample.

Finally, the current sample was part of a larger sample collected to investigate the relationship between stress and psychopathology. Given sex-specific genetic and non-genetic effects on psychopathology (Bolger and others 1989; Fujita and others 1991), the first wave comprised only women. Therefore, it may be possible that the results of the present study cannot be generalized to the male population.

\section{Acknowledgments}

Tineke Lataster was supported by the Royal Dutch Academy of Scientific Research (Van Walree grant). Inez Myin-Germeys was supported by a 2006 NARSAD Young Investigator award and by the Dutch Medical Council (VENI and VIDI grant). 
CMAPTER 2

Table I. Mean scores on self-reported subclinical Psychotic Experiences (PE) and interview-based Psychotic Symptoms (PS) percentages for the different age groups.

\begin{tabular}{|c|c|c|c|c|c|}
\hline & $\begin{array}{l}M Z \\
\text { age<26 }\end{array}$ & $\begin{array}{l}M Z \\
\text { age>25 }\end{array}$ & $\begin{array}{l}D Z \\
\text { age<26 }\end{array}$ & $\begin{array}{l}D Z, \\
\text { age }>25\end{array}$ & Total $N$ \\
\hline \multirow[t]{2}{*}{$\begin{array}{l}\text { PE (measured at baseline, } 6 \text { month, } \\
\text { and } 18 \text { month follow-up), Mean (SD) }\end{array}$} & $\begin{array}{l}1.12 \\
(0.20)\end{array}$ & $\begin{array}{l}1.13 \\
(0.19)\end{array}$ & $\begin{array}{l}1.15 \\
(0.20)\end{array}$ & $\begin{array}{l}1.15 \\
(0.23)\end{array}$ & 566 \\
\hline & $N=184$ & $N=160$ & $N=101$ & $N=121$ & \\
\hline \multicolumn{6}{|l|}{ PS(baseline) } \\
\hline \multirow[t]{2}{*}{ No delusions/hallucinations } & $92.85 \%$ & $86.25 \%$ & $87.13 \%$ & $84.30 \%$ & $88 \%$ \\
\hline & $N=169$ & $N=138$ & $N=88$ & $N=102$ & 497 \\
\hline \multirow[t]{2}{*}{1 delusion/ hallucination } & $4.35 \%$ & $9.38 \%$ & $11.88 \%$ & $9.92 \%$ & $8 \%$ \\
\hline & $N=8$ & $\mathrm{~N}=15$ & $N=12$ & $N=12$ & 47 \\
\hline \multirow[t]{2}{*}{2 or more delusions/ hallucinations } & $3.80 \%$ & $4.38 \%$ & $0.99 \%$ & $5.79 \%$ & $4 \%$ \\
\hline & $N=7$ & $N=7$ & $N=1$ & $N=7$ & 22 \\
\hline Total N & 184 & 160 & 101 & 121 & 566 \\
\hline
\end{tabular}

Figure 1. Solid arrows: Cross-twin, cross-trait associations; examination of the association between selfreported subclinical psychotic experiences (PE) (trait 1) and interview-based clinical psychotic symptoms (PS) (trait 2) across genetically related individuals (twins). If the cross-trait, cross-twin association is greater in monozygotic than in dizygotic twins, a genetic contribution to the observed association may be inferred (Wichers et al., 2007). Dotted arrows: Within-twin, cross-trait associations.

TRAIT 1

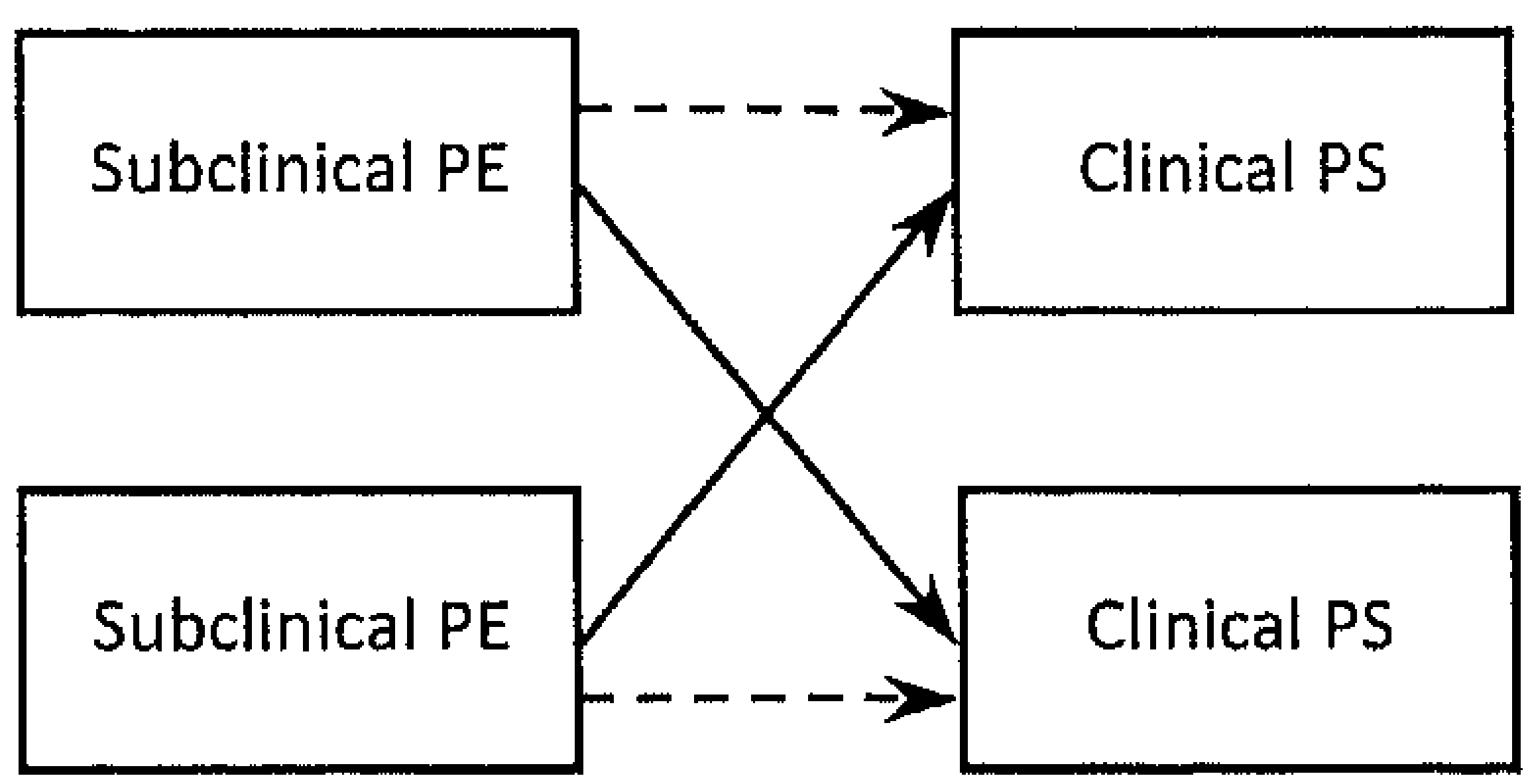


Figure 2. Continuity between subclinical Psychotic Experiences (PE) and Psychotic Symptoms (PS) using a twin-design. Significant interaction between zygosity and cotwin PS in the model of proband PE, indicating that the association between PE and PS was significantly stronger in MZ than DZ twin pairs.

** $p<0.01$

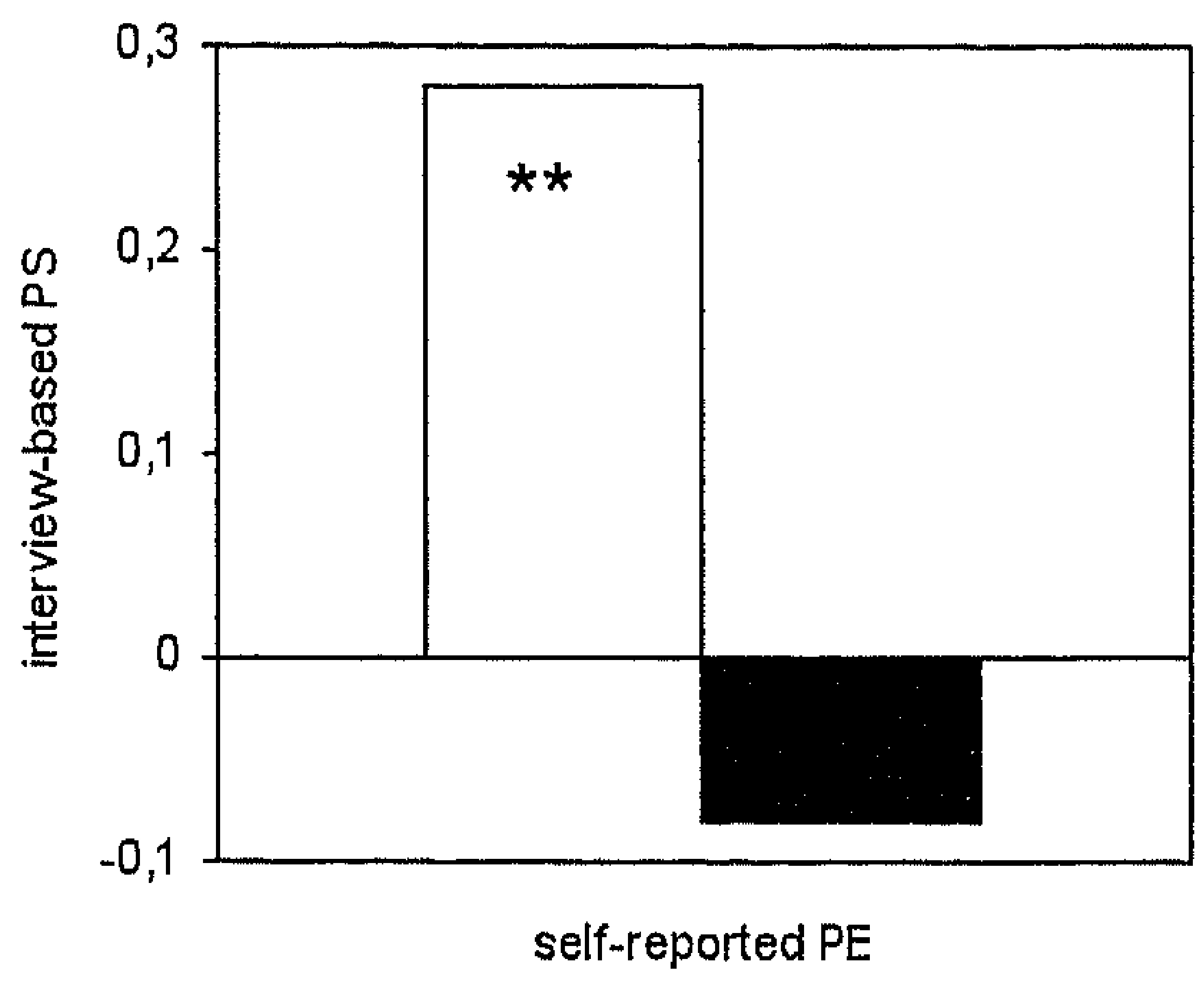

$\square \mathrm{MZ}$ twins

DZ twins 


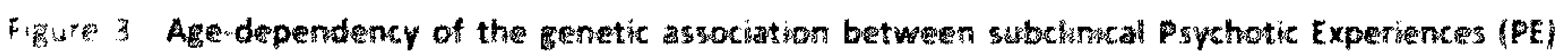

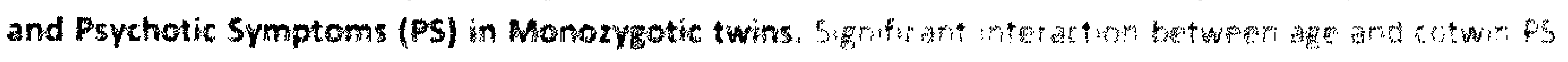

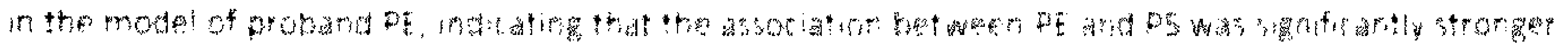

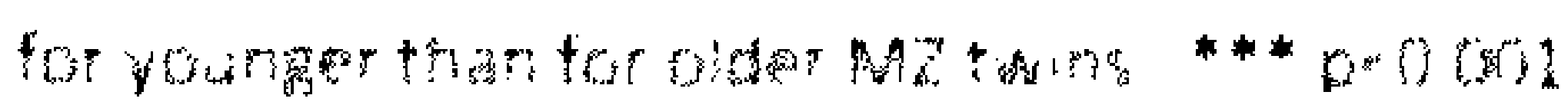

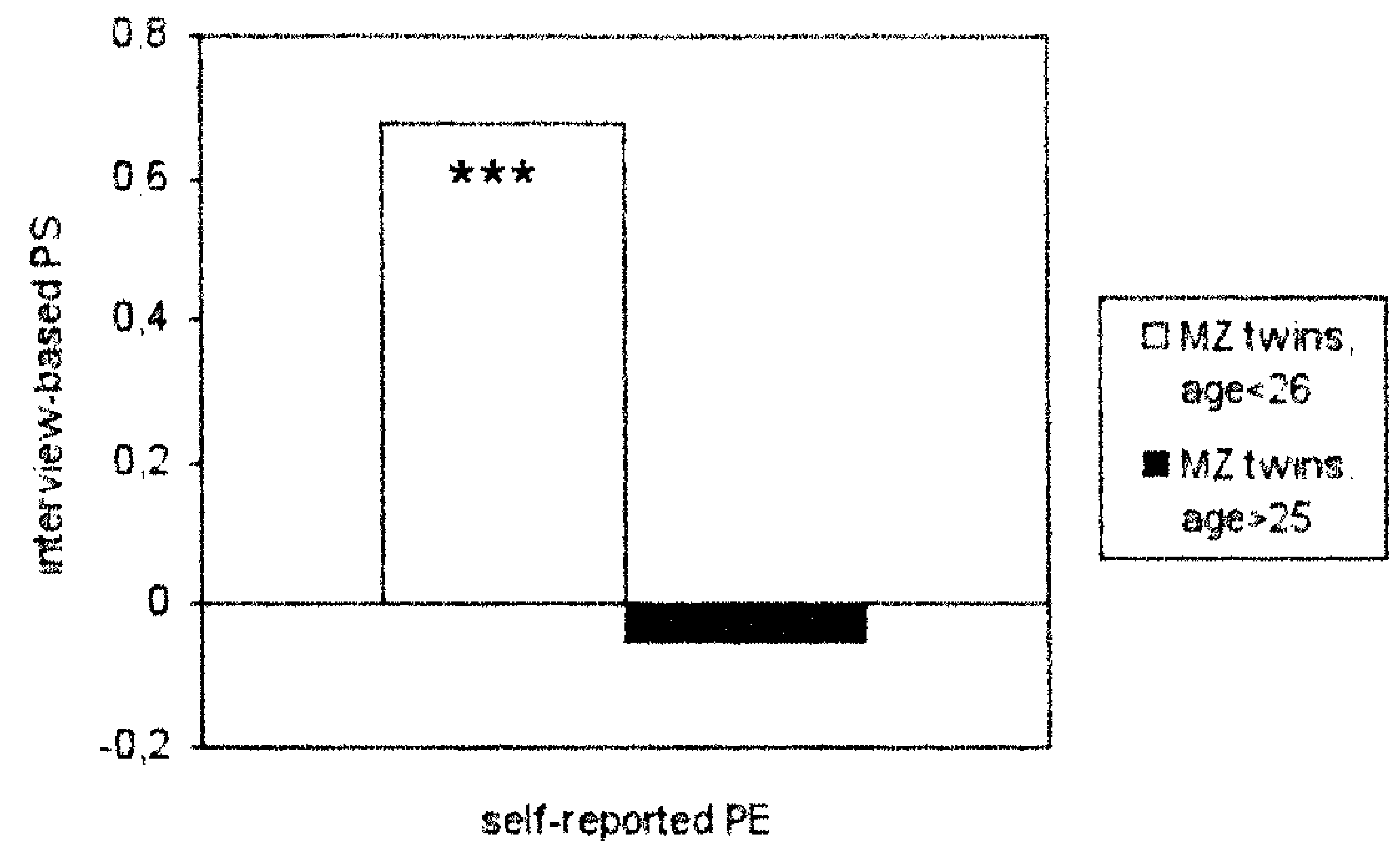




\section{ON THE PATHWAY FROM STRESS TO PSYCHOSIS}

\section{References}

APA. 1994. Diagnostic and Statistical Manual of Mental Disorders, Fourth Edition. Association AP, editor. Washington, DC.

Benoit-Marand M, O'Donnell P. 2008. D2 dopamine modulation of corticoaccumbens synaptic responses changes during adolescence. Eur $\rfloor$ Neurosci 27(6):1364-72.

Boileau I, Dagher A, Leyton M, Gunn RN, Baker GB, Diksic M, Benkelfat C. 2006. Modeling sensitization to stimulants in humans: an [11C]raclopride/positron emission tomography study in healthy men. Arch Gen Psychiatry 63(12):1386-95.

Bolger N, DeLongis A, Kessler RC, Schilling EA. 1989. Effects of daily stress on negative mood. J Pers SoC Psychol 57(5):808-18.

Brake WG, Zhang TY, Diorio J, Meaney MJ, Gratton A. 2004. Influence of early postnatal rearing conditions on mesocorticolimbic dopamine and behavioural responses to psychostimulants and stressors in adult rats. Eur J Neurosci 19(7):1863-74.

Brunelin J, d'Amato T, van Os J, Cochet A, Suaud-Chagny MF, Saoud M. 2008. Effects of acute metabolic stress on the dopaminergic and pituitary-adrenal axis activity in patients with schizophrenia, their unaffected siblings and controls. Schizophr Res 100(1-3):206-11.

Chambers RA, Taylor JR, Potenza MN. 2003. Developmental neurocircuitry of motivation in adolescence: a critical period of addiction vulnerability. Am J Psychiatry 160(6):1041-52.

Collip D, Myin-Germeys I, Van Os 1. 2008. Does the concept of "sensitization" provide a plausible mechanism for the putative link between the environment and schizophrenia? Schizophr Bull 34(2):220-5.

Cougnard A, Marcelis M, Myin-Germeys I, De Graaf R, Vollebergh W, Krabbendam L, Lieb R, Wittchen HU, Henquet $C$, Spauwen J and others. 2007. Does normal developmental expression of psychosis com bine with environmental risk to cause persistence of psychosis? A psychosis proneness-persistence model. Psychol Med 37(4):513-27.

Derom CA, Vlietinck RF, Thiery EW, Leroy FO, Fryns JP, Derom RM. 2006. The East Flanders Prospective Twin Survey (EFPTS). Twin Res Hum Genet 9(6):733-8.

Featherstone RE, Kapur S, Fletcher PJ. 2007. The amphetamine-induced sensitized state as a model of schizophrenia. Prog Neuropsychopharmacol Biol Psychiatry 31(8):1556-71.

First MB, Spitzer RL, Gibbon M, Williams JBW. 2002. Structured Clinical Interview for DSM-IV Axis I Disorders-Patient Edition (SCID-I/P), 11-2002 revision. New York: Biometrics Research Department, New York State Psychiatric Institute.

Fujita F, Diener E, Sandvik E. 1991. Gender differences in negative affect and well-being: the case for emotional intensity. J Pers Soc Psychol 61(3):427-34.

Hall FS, Wilkinson LS, Humby T, Robbins TW, 1999. Maternal deprivation of neonatal rats produces enduring changes in dopamine function. Synapse 32(1):37-43.

Hanssen $M$, Bak M, Bijl R, Vollebergh $W$, van Os J. 2005. The incidence and outcome of subclinical psychotic experiences in the general population. Br J Clin Psychol 44(Pt 2):181-91.

Hanssen M, Peeters F, Krabbendam L, Radstake S, Verdoux $H$, van Os J. 2003. How psychotic are individuals with non-psychotic disorders? Soc Psychiatry Psychiatr Epidemiol 38(3):149-54.

Hirvonen J, van Erp TG, Huttunen J, Aalto S, Nagren K, Huttunen M, Lonnqvist J, Kaprio J, Hietala J, Cannon TD. 2005. Increased caudate dopamine D2 receptor availability as a genetic marker for schizophrenia, Arch Gen Psychiatry 62(4):371-8.

Huttunen J, Heinimaa M, Svirskis T, Nyman M, Kajander J, Forsback S, Solin O, llonen T, Korkeila J, Ristkari $T$ and others. 2008. Striatal dopamine synthesis in first-degree relatives of patients with schizophrenia. Biol Psychiatry 63(1):114-7.

Jacobs N, Kenis G, Peeters F, Derom C, Vlietinck R, van OS J. 2006. Stress-related negative affectivity and genetically altered serotonin transporter function: evidence of synergism in shaping risk of depression. Arch Gen Psychiatry 63(9):989-96. 


\section{CHAPTER 2}

Jacobs N, Myin-Germeys I, Derom C, Delespaul P, van Os J, Nicolson NA. 2007. A momentary assessment study of the relationship between affective and adrenocortical stress responses in daily life. Biol Psychol 74(1):60-6.

Johns LC, Cannon $M$, Singleton N, Murray RM, Farrell M, Brugha $T$, Bebbington $P$, Jenkins R, Meltzer $H$. 2004. Prevalence and correlates of self-reported psychotic symptoms in the British population. $\mathrm{Br} J$ Psychiatry 185:298-305.

Johns LC, Van Os J. 2001. The continuity of psychotic experiences in the general population. Clin Psychol Rev 21(8):1125-41.

Kapur S. 2003. Psychosis as a state of aberrant salience: a framework linking biology, phenomenology, and pharmacology in schizophrenia. Am J Psychiatry 160(1):13-23.

Kendler KS, Hewitt J. 1992. The structure of self-report schizotypy in twins. Journal of Personality disorders 6:1-17.

Kendler KS, McGuire M, Gruenberg AM, Walsh D. 1995. Schizotypal symptoms and signs in the Roscommon Family Study. Their factor structure and familial relationship with psychotic and affective disorders. Arch Gen Psychiatry 52(4):296-303.

Kendler KS, Neale MC, Kessler RC, Heath AC, Eaves U. 1993. A longitudinal twin study of personality and major depression in women. Arch Gen Psychiatry 50(11):853-62.

Konings M, Bak M, Hanssen M, van Os J, Krabbendam L. 2006. Validity and reliability of the CAPE: a selfreport instrument for the measurement of psychotic experiences in the general population. Acta Psychiatr Scand 114(1):55-61.

Laruelle M. 2000. The role of endogenous sensitization in the pathophysiology of schizophrenia: implications from recent brain imaging studies. Brain Res Brain Res Rev 31(2-3):371-84.

Laruelle M, Abi-Dargham A. 1999. Dopamine as the wind of the psychotic fire: new evidence from brain imaging studies. S Psychopharmacol 13(4):358-71.

Laruelle M, Abi-Dargham A, Gil R, Kegeles L, Innis R. 1999. Increased dopamine transmission in schizophrenia: relationship to illness phases. Biol Psychiatry 46(1):56-72.

Linney YM, Murray RM, Peters ER, MacDonald AM, Rijsdijk F, Sham PC. 2003. A quantitative genetic analysis of schizotypal personality traits. Psychol Med 33(5):803-16.

MacDonald AW, 3rd, Pogue-Geile MF, Debski TT, Manuck S. 2001. Genetic and environmental influences on schizotypy: a community-based twin study. Schizophr Bull 27(1):47-58.

Meyer-Lindenberg A, Miletich RS, Kohn PD, Esposito G, Carson RE, Quarantelli M, Weinberger DR, Berman KF. 2002. Reduced prefrontal activity predicts exaggerated striatal dopaminergic function in schizophrenia. Nat Neurosci 5(3):267-71.

Murray RM, McDonald C, Bramon E. 2002. Neurodevelopmental impairment, dopamine sensitisation, and social adversity in schizophrenia. World Psychiatry 1(3):137-45.

Myin-Germeys I, Delespaul P, van Os J. 2005a. Behavioural sensitization to daily life stress in psychosis. Psychol Med 35(5):733-41.

Myin-Germeys I, Marcelis M, Krabbendam L, Delespaul P, van Os J. 2005b. Subtle fluctuations in psychotic phenomena as functional states of abnormal dopamine reactivity in individuals at risk. Biol Psychiatry 58(2):105-10.

Pani L, Porcella A, Gessa GL. 2000. The role of stress in the pathophysiology of the dopaminergic system. Mol Psychiatry 5(1):14-21.

Peters ER, Joseph SA, Garety PA. 1999. Measurement of delusional ideation in the normal population: introducing the PDI (Peters et al. Delusions Inventory). Schizophr Bull 25(3):553-76.

Poulton R, Caspi A, Moffitt TE, Cannon M, Murray R, Harrington H. 2000. Children's self-reported psychotic symptoms and adult schizophreniform disorder: A 15-year longitudinal study [In Process Citation]. Arch Gen Psychiatry 57(11):1053-8.

Pruessner JC, Champagne F, Meaney MJ, Dagher A. 2004. Dopamine release in response to a psychological stress in humans and its relationship to early life maternal care: a positron emission tomography study using [11C]raclopride. J Neurosci 24(11):2825-31. 


\section{OP THE PATHWAY FROM STRESTO PSYCHOSIS}

Sharpley MS, Peters ER. 1999. Ethnicity, class and schizotypy. Soc Psychiatry Psychiatr Epidemiol 34(10):507-12

Simons $\mathrm{CJ}$, Jacobs N, Jolles J, van Os J, Krabbendam L. 2007. Subclinical psychotic experiences and cognitive functioning as a bivariate phenotype for genetic studies in the general population. Schizophr Res 92(1-3):24-31.

Snijders T, Bosker R. 1999. Multilevel analysis: an introduction to basis and advanced multilevel modeling.

Soliman A, O'Driscoll GA, Pruessner J, Holahan AL, Boileau I, Gagnon D, Dagher A. 2007. Stress-Induced Dopamine Release in Humans at Risk of Psychosis: a [(11)C]Raclopride PET Study. Neuropsychopharmacology 33(8):2033-41.

Statacorp. 2005. STATA Statistical Software: Release 9.1 Texas, College Station.

Stefanis NC, Hanssen M, Smirnis NK, Avramopoulos DA, Evdokimidis IK, Stefanis CN, Verdoux H, Van Os J. 2002. Evidence that three dimensions of psychosis have a distribution in the general population. Psychol Med 32(2):347-58.

Strauss JS. 1994. The person with schizophrenia as a person. Il: Approaches to the subjective and complex. Br J Psychiatry Suppl. 23:103-107.

van Os J. 2008. Schizophrenia aetiology: Do gene-environment interactions hold the key? Comment on Tandon et al. Schizophr Res 102(1):21-26.

Van Os J, Bak M, Hanssen M, Bijl RV, de Graaf R, Verdoux H. 2002. Cannabis use and psychosis: a longitudinal population-based study. Am J Epidemiol 156(4):319-27.

Van Os J, Hanssen M, Bijl R-V, Ravelli A. 2000. Straus (1969) revisited: A psychosis continuum in the general population? Schizophrenia Research 45(1-2):11-20.

Van Os J, Hanssen M, Bijl RV, Vollebergh W. 2001. Prevalence of psychotic disorder and community level of psychotic symptoms: an urban-rural comparison. Arch Gen Psychiatry 58(7):663-8.

van Os J, Rutten BP, Poulton R. 2008. Gene-environment interactions in schizophrenia: review of epidemiological findings and future directions. Schizophr Bull 34(6):1066-82.

Verdoux H, Van Os J, Maurice-Tison S, Gay B, Salamon R, Bourgeois M. 1998. Is early adulthood a critical developmental stage for psychosis proneness? A survey of delusional ideation in normal subjects. Schizophr Res 29(3):247-54.

Weinberger DR. 1987. Implications of normal brain development for the pathogenesis of schizophrenia. Arch Gen Psychiatry 44(7):660-9. 


\section{Chapter 3}

\section{Does reactivity to stress cosegregate with subclinical psychosis? Findings from a general population twin study}

T. Lataster ${ }^{1}$, M. C. Wichers ${ }^{1}$, N. Jacobs ${ }^{1,2}$, R. Mengelers ${ }^{1}$, C. Derom ${ }^{3}$, E. Thiery ${ }^{4}$, J. van Os ${ }^{1,4}$, I. Myin-Germeys ${ }^{1,5}$

\footnotetext{
${ }^{1}$ Department of Psychiatry and Neuropsychology, South Limburg Mental Health Research and Teaching Network, EURON, Maastricht University, the Netherlands

2 Department of Psychology, Open University of the Netherlands, PO Box 2960, 6401 DL. Heerlen, the Netherlands

${ }^{3}$ Department of Human Genetics, University Hospital Gasthuisberg, Katholieke Universiteit Leuven, B3000 Leuven, Belgium

${ }^{4}$ Association for Scientific Research and Multiple Births, Ghent, Belgium

${ }^{5}$ Division of Psychological Medicine, Institute of Psychiatry, London, UK

${ }^{6}$ School of Psychological Sciences, University of Manchester, UK
}

Acta Psychiatrica Scandinavica 2009: 119: 45-53 
ONTHE PATHWAY FROM STRESS TO PSYCHOSIS

\section{ABSTRACT}

Background: The current study assessed the relationship between stress reactivity (trait 1) and psychosis (trait 2) across genetically related persons (cross-twin, crosstrait design) in order to examine whether stress reactivity is an uncontaminated and unconfounded familial marker of psychosis risk.

Methods: Reactivity to stress and subclinical psychotic experiences were assessed in 289 female, general population twin-pairs. Cross-trait, within-twin associations investigating the association between stress reactivity and subclinical psychotic experiences in each person, were calculated. In addition, cross-trait, cross-twin associations were calculated to assess whether stress reactivity in one twin was moderated by subclinical psychotic experiences in the co-twin.

Results: Cross-trait, within-twin showed significant associations between stressreactivity and subclinical psychotic experiences within each person. In addition, the cross-trait cross-twin analyses showed that stress-reactivity in twin 1 was significantly moderated by subclinical experiences in the co-twin.

Discussion: The results suggest that the psychosis phenotype cosegregates with increased emotional reactivity to stress in daily life. 


\section{Introduction}

Several studies have demonstrated that patients with schizophrenia are vulnerable to the effects of stress (Horan and others 2005; Norman and Malla 1993; Ventura and others 1989; Ventura and others 2000). In particular the category of smaller daily stressful events is associated with relapse rates in schizophrenia (Malla and others 1990; Norman and Malla 1991; Norman and Malla 1994; Nuechterlein and others 1994). In a series of previous studies, momentary assessment technology (techniques to measure responses in the flow of daily life) was used to examine whether emotional reactivity to daily life stress constituted a familial marker of psychosis (Myin-Germeys and others 2003a; Myin-Germeys and others 2003b; Myin-Germeys and others 2001). It was demonstrated that patients with psychosis in a state of clinical remission reported larger increases in negative affect (NA) in reaction to daily stressors compared to control subjects. Similar results were found in first-degree relatives of patients with a psychotic disorder (Myin-Germeys and others 2001), suggesting that subtle alterations in the way persons interact with their environment may constitute part of the vulnerability to psychosis.

These studies, however, did not resolve the issue of measurement contamination, since the marker (stress reactivity) may be contaminated by the presence residual symptoms in patients or by subclinical psychotic experiences in relatives. Subjects with current subclinical psychotic experiences may report more emotional reactivity to stress, suggesting that increased stress reactivity is the result of psychotic experiences rather than a familial marker of risk of developing psychosis. Therefore, the current study used a general population twin sample to examine whether emotional experiences in the face of stress can truly be considered an uncontaminated and unconfounded indicator of the risk of developing psychosis. Cross-twin, cross-trait associations (see figure 1, page 51) were established between stress reactivity (trait 1), measured in the proband twin, and the risk of developing psychosis (trait 2), as indicated by a history of subclinical psychotic experiences in the co-twin. The study of psychosis-like experiences in non-clinical populations may constitute a sensitive approach to elucidate causal mechanisms associated with the psychosis phenotype (Corcoran and others 2001; Hanssen and others 2005; Krabbendam and others 2005; Poulton and others 2000).

\section{Aims of the study}

To investigate whether emotional reactivity to stress is an uncontaminated and unconfounded indicator of the risk of developing psychosis. 


\section{Methods}

Sample

The sample used for the present study was drawn from a sample collected as part of a larger research project investigating gene-environment interactions in vulnerability to mental disorders (Jacobs and others 2006; Jacobs and others 2007; Simons and others 2007). Because sex-specific genetic effects on psychopathology are likely and often observed (Jacobs and others 2006), only women were selected in the first wave. Participants were recruited from birth registers of Flemish municipalities and from the East Flanders Prospective Twin Survey in Belgium. This population-based survey has prospectively recorded all multiple births in the province of East Flanders since 1964 (Derom and others 2002; Loos and others 1998). The project was approved by the Local Medical Ethics Committee and all participants gave written informed consent. The sample initially included 621 subjects ( 575 female twins and 46 of their non-twin sisters). For the current study, all 46 non-twin sisters were excluded from the analyses and 3 participants were excluded due to missing zygosity. Thus, the final sample consisted of 572 subjects, who were part of 289 different twin-pairs (176 MZ and $113 \mathrm{DZ}$ pairs). Six probands participated without their co-twin. These 6 subjects were excluded from the cross-trait, cross-twin analyses. Thus, the sample for the cross-trait, cross-twin analyses consisted of 566 subjects, who were part of 283 different twin-pairs (174 MZ and $109 \mathrm{DZ}$ pairs). Mean age of the final sample was 27 years ( $S D=8$; range $18-46$ ), $63 \%$ had a higher education, $35 \%$ had followed higher secondary school, and $2 \%$ had finished only primary education. The majority (62.7\%) were employed, while $32.3 \%$ were students, $2.4 \%$ were unemployed, $2.2 \%$ were housewives, and $0.4 \%$ were on sick leave.

\section{Experience sampling method}

The experience sampling method (ESM) was used to measure the emotional reaction to stress in the flow of daily life (hereafter: "stress reactivity"). ESM is a withinday, momentary self-assessment technique. Subjects received a digital wristwatch and self-assessment forms collated in a booklet for each day. Ten times a day on five consecutive days, the watch emitted a signal (beep) at unpredictable moments between 7:30 a.m. and 10:30 p.m. Subjects were asked to report immediately after each beep their thoughts, current context (activity, persons present, location), appraisals of the current situation, and mood. All self-assessments were rated on 7 point Likert scales. Subjects were informed about the ESM procedure during an initial briefing session. A practice form was completed to confirm that the subjects were able to understand the 7-point Likert scale format. Subjects were instructed to complete their reports immediately after the beep, thus minimizing memory distortion, and to record the time at which they completed the form. Research staff called 
each subject several times during the actual sampling period to assess whether they were complying with the instructions. In order to determine the reliability of the completed reports, the times at which the watch emitted a signal and the times at which subjects completed the reports were compared. All reports completed more than 15 minutes after the beep were excluded from the analyses. Previous research (Delespaul 1995) has shown that reports completed after this interval are less reliable and consequently less valid. Similarly, subjects with fewer than 17 valid reports (out of 50) were excluded from the analysis (Delespaul 1995).

\section{Assessment of mood and stress}

Measures of mood and stress were derived from the ESM reports as follows.

Assessment of mood. ESM negative affect (NA) was assessed at each beep with 6 mood-related adjectives (down, guilty, insecure, lonely, anxious, suspicious) rated on 7-point Likert scales ( $1=$ not at all, 7=very). Factor analysis on the raw withinsubject scores identified one factor with eigenvalue greater than 1 . Weighted factor scores were used in the analyses (Cronbach's $\alpha=0.87$ ).

Assessment of stress. In accordance with previous work, stress was conceptualized as the subjectively appraised stressfulness of distinctive events (event-related stress) as well as of minor disturbances that continually happen in the flow of daily life (activity-related stress) (Myin-Germeys and others 2001). In order to measure event-related stress, the subject was asked to report after each beep the most important event that had happened between the current and the previous report. This event was subsequently rated on a bipolar Likert scale (-3=very unpleasant, $0=$ neutral, $3=$ very pleasant). The responses were recoded to allow high scores to reflect stress $(-3=$ very pleasant, $0=$ neutral, $3=$ very unpleasant).

In order to measure activity-related stress, after each beep the subject judged the current activity on three self-report items scored on 7-point Likert scales (1=not at all, 7=very). The two items "I would rather do something else" and "This activity requires effort" formed the activity-related stress scale (Cronbach's $\alpha=0.59$ )

\section{Assessment of subclinical psychotic experiences}

Self-reported subclinical psychotic experiences in the affective and non-affective domains were assessed with the previously validated Community Assessment of Psychic Experiences (CAPE) (Hanssen and others 2003; Konings and others 2006; Stefanis and others 2002) (http://www.cape42.homestead.com/). Frequency scores were measured on a 4-point scale (1=never, 2=sometimes, 3=often, and 4=nearly always). Mean frequency scores, on the positive and negative symptom dimensions of the CAPE were log-transformed to shape the data into a normal distribution. Three previous studies have investigated discriminative and predictive validity of the CAPE (Hanssen and others 2003; Stefanis and others 2002). The first investigated scores on the CAPE across groups of individuals with schizophrenia, affective 


\section{ON THE PATHWAY FOOM STRESSTO PSYCHOSIS}

and anxiety disorder (Hanssen and others 2003). It was found that patients with schizophrenia have the greatest difference in positive psychosis items when compared to healthy control subjects (Hanssen and others 2003). Patients with mood and anxiety disorders had the highest depressive symptom scores, and positive symptom scores that were intermediate to those of healthy controls subjects and patients with schizophrenia (Hanssen and others 2003). In the second study it was shown that the associations between the three symptom dimensions of the CAPE on the one hand and scores on established scales measuring these symptoms on the other are high (Stefanis and others 2002). In a third study it was found that baseline self-report measures of psychosis, assessed with the CAPE, were specifically and independently associated with their equivalent interview-based dimension at follow-up, showing predictive validity (Konings and others 2006). The CAPE positive and negative symptom dimensions encompass 20 and 14 items, respectively.

\section{Analyses}

Multilevel linear random regression models were tested. Multilevel or hierarchical linear modeling techniques are a variant of the more often used unilevel linear regression analyses and are ideally suited for the analysis of ESM data consisting of multiple observations within one person who is part of a twin pair, i.e. at 3 levels (ESM-beep level, subject level and twin level). Since - in ESM - observations from the same subject are more similar than observations from different subjects, and observations from subjects within a twin pair are more similar than over twin pairs, the residuals are not independent. Conventional regression techniques do not take into account the variance components at three different levels. Data were analyzed with the XTMIXED module in STATA (StataCorp 2001). The B is the fixed regression coefficient of the predictor in the multilevel model and can be interpreted identically to the estimate in a unilevel linear regression analysis.

\section{Stress reactivity}

Using ESM data, stress reactivity was defined as the increase in NA in reaction to stress. In order to investigate the association between stress and NA in the flow of daily life (i.e., stress reactivity), multilevel linear regression analyses were conducted (regression model: $\mathrm{NA}=\mathrm{BO}+\mathrm{B} 1$ stress + residual).

\section{Cross-trait, within-twin analyses}

In the cross-trait, within-twin (see figure 1, page 51) analyses, we investigated within each individual whether subclinical psychotic experiences moderated the effect of stress on NA. Multilevel linear regression analyses were conducted with NA as the dependent variable, and stress and psychosis as well as their interaction as independent variables. Separate analyses were conducted for the positive and negative symptom dimensions of psychosis. The interaction term was the focus of 


\section{CHAPTER 3}

the analysis, since the hypothesis centered on the question whether the association between daily stress and intensity of NA varies with underlying psychosis levels within each person.

Cross-trait, cross-twin analyses

In the cross-trait, cross-twin (see figure 1, page 51) analyses, we investigated whether subclinical psychotic experiences in twin 2 moderated the effect of stress on NA in twin 1. Multilevel linear regression analyses were conducted with "NA in twin 1" as dependent variable. The independent variables were "stress in twin 1" and "psychosis in twin 2" as well as their interaction term. Separate analyses were conducted for the positive and negative dimension of psychosis. All analyses were adjusted for the corresponding dimension of psychosis in twin 1.

Again, the interaction term was the focus of the analysis, since the hypothesis centered on the question whether familial vulnerability to psychosis (i.e., psychosis in twin 2) moderates the association between stress and intensity of NA in twin 1.

\section{Results}

\section{Descriptives}

Of the 572 subjects in the final sample, 556 completed ESM reports yielding a total of 13,973 ESM observations with a mean of 40 beeps per subject. Of the subjects, 21 were excluded because they had fewer than 17 valid ESM self-reports (i.e., 535 subjects remained). The mean score on ACTIVITY STRESS was $1.76(S D=0.48)$ and the mean score on EVENT STRESS was -1.13 ( $S D=0.73$ ). The mean weighted negative affect score was $0.82(S D=0.22)$. The mean score on the CAPE positive symptom dimension was $1.8(S D=0.13)$ and on the CAPE negative symptom dimension 1.5 $(S D=0.21$ ). Correlations between the scores on the CAPE positive and negative symptom dimension and EVENT and ACTIVITY STRESS levels are shown in table 1 (page 50).

\section{Stress reactivity analyses}

Multilevel analyses showed a significant main effect of both ACTIVITY STRESS $(\beta=0.05,95 \% \mathrm{Cl}: 0.05-0.06, p=0.00)$ and EVENT STRESS $(\beta=0.04,95 \% \mathrm{Cl}: 0.03-0.04$, $p=0.00$ ) in the model of NA.

Cross-trait, within-twin analyses

The cross-trait, within-twin analyses (see figure 1, page 51) showed within each individual a significant interaction effect between the positive dimension of psychosis and both ACTIVITY and EVENT STRESS (table 2, page 50). A similar result was found for the negative psychosis dimension (table 2, page 50). These results, thus, 
suggest that increased vulnerability to psychosis is associated with increased emotional reactivity to stress in daily life within each person.

\section{Cross-trait, cross twin analyses}

The cross-trait, cross-twin analyses (see figure 1, page 51 ) were conducted to investigate whether psychosis in twin 2 moderated the association between stress and NA in twin 1. The analysis showed no significant interaction effect between the positive psychotic experiences in twin 2 and ACTIVITY STRESS in twin 1 in the model of NA (table 3, page 51). However, after controlling for positive psychotic symptoms in twin 1, a statistical trend was found. Additionally, a statistical trend was found for the interaction between the positive psychosis dimension in twin 2 and EVENT STRESS in twin 1 in the model of NA (table 3, page 51). This trend became significant after controlling for positive psychotic symptoms in twin 1 (table 3 , page 51). For the negative symptom dimension in twin 2, significant interactions were found with ACTIVITY STRESS and EVENT STRESS in twin 1 in the model of NA. These results remained the same after controlling for negative symptoms in twin 1 (table 3, page 51).

\section{Discussion}

\section{Findings}

First, cross-trait, within-twin analyses showed that stress reactivity was associated with both the positive and the negative subclinical psychosis phenotype in a general population twin sample. These findings show that subjects from the general population with an increased psychometric risk for psychosis (i.e. higher scores on the CAPE) show higher stress-reactivity. This is in line with findings that relatives of patients who are genetically at risk to develop psychosis (Myin-Germeys and others 2001) also report more stress-reactivity, suggesting that increased liability to psychosis cosegregates with increased emotional reactivity to stress in daily life.

Second, stress reactivity in twin 1 was associated with the positive and negative subclinical psychosis dimension in the co-twin, indicating familial association between stress reactivity and the subclinical psychosis phenotype at the level of the general population and suggestive of stress reactivity as an unconfounded and uncontaminated familial marker of psychosis.

Both within and between subjects analyses show a significant association between stress reactivity on the one hand and both positive and negative subclinical psychotic experiences. These results are not in line with the hypothesis that increased stress reactivity, as a marker of genetic risk, is part of an affective pathway to psychosis that may underlie a more episodic, reactive, good-outcome type of psychosis mainly characterized by positive symptoms (Myin-Germeys and van Os 2007). However, Stefanis et al. (Stefanis and others 2002) suggested that the correlation be- 
tween the positive and negative dimension was higher in a general population sample (correlations of around 0.70) compared with numbers found in clinical samples (0.2-0.6) (Peralta and Cuesta 1998; Peralta and others 1994). They conclude that the CAPE questionnaire was not sensitive enough to discriminate between the much more attenuated symptom dimensions in the general population, resulting in high correlations in the general population (Stefanis and others 2002).

Effect sizes were small. However, since we assessed frequently occurring exposures to stress in daily life, the cumulative effects of which may be considerable, these effect sizes are not negligible.

\section{The informative value of psychometric high-risk samples}

The present study aimed to identify individuals at psychometric risk of developing psychosis. The psychometric high-risk strategy may aid in understanding the etiology of the disorder by allowing the examination of etiological factors without the confounds associated with the consequences of the illness (Gooding and others 2005). The psychosis phenotype is thought to be expressed also at levels well below its clinical manifestation, which is commonly referred to as psychosis proneness, psychotic experiences, schizotypy, or at-risk mental states (Chapman and others 1994; Kwapil 1998; Meehl 1962; Stefanis and others 2002; van Os and others 2000; Verdoux and others 1998a; Vollema and others 2002; Yung and others 2003). It has been noted that the dimensions of this variously labeled subclinical psychosis phenotype closely resemble those that have been identified in schizophrenia, suggesting continuity between the clinical and non-clinical phenotypes (Gruzelier and Kaiser 1996; Mata and others 2003; Vollema and Hoijtink 2000; Vollema and van den Bosch 1995). Apart from strong evidence of phenomenological continuity in form and structure, continuity between community sampled clinical and subclinical phenotypes is further suggested by i) similar associations with demographic factors in epidemiological studies, in particular the negative association with age and the positive association with single marital status and social disadvantage (Johns and van Os 2001; Peters and others 1999; van Os and others 2000; Verdoux and others 1998 b); ii) high rates of transitions over time from the subclinical to the clinical, even over periods longer than 15 years (Chapman and others 1994; Hanssen and others 2005; Poulton and others 2000); iii) familial co-clustering of the clinical and the subclinical (Kendler and Diehl 1993); iv) strong dose-response effects of the urban environment on both the clinical and subclinical phenotype (Corcoran and others 2001); v) sharing of cognitive and motor deficits (Krabbendam and others 2005; Lenzenweger and Korfine 1994; Matsui and others 2004; Neumann and Walker 2003; Voglmaier and others 2000), although this may not hold for all cognitive measures (Johnson and others 2003; Lenzenweger and Gold 2000); vi) sharing of risk genes (Stefanis and others 2004) and sharing of environmental risk factors such as cannabis use (Arseneault and others 2002; Fergusson and others 2003; van 


\section{ON THE PATHWAY FROM STRESTO PSYCHOSIS}

Os and others 2002) and childhood trauma (Bak and others 2005; Janssen and others 2004; Read and others 2005).

Thus, establishing cross-trait, within-twin associations and cross-trait, cross-twin associations in our general population twin sample enabled us to examine the relationship between the subclinical psychosis phenotype on the one hand and stress reactivity on the other, without having the confounding influence of causes or consequences of the disease.

\section{Resolving the issue of state contamination}

The current study resolved the issue of within-person confounding by establishing cross-trait, cross-twin associations between proband stress reactivity and the cotwin subclinical psychosis phenotype, controlling for the possible contamination of psychotic experiences in the proband. However, one could argue that increased CAPE scores may correlate with increased stress-levels, even across twins. The Pearson correlation between the two stress measures and scores on the CAPE symptom dimensions showed no significant associations between the positive symptom dimension in twin 1 and stress levels in twin 2. For the negative symptom dimension, significant albeit low correlations were found, suggesting that these correlations may explain only a very small part of the association. Overall, the cross-trait crosstwin associations found in the present study confirm that stress reactivity may be considered an unconfounded and uncontaminated risk indicator for psychosis.

The cross-trait associations within and across twins suggest common etiological influences underlying stress reactivity and the subclinical psychosis phenotype, and clustering of these within families. This does not necessarily imply that the observed risk indicators are genetically transmitted. However, the findings do suggest a contribution of genes to the observed cross-trait, cross-twin associations for the positive psychosis dimension. These results are in line with the suggestion that familial vulnerability to psychosis derives mainly from the influence of shared genes rather than shared environment (Cardno and others 2002). Such an interpretation of the findings is in line with evidence suggesting that stress reactivity is a possible marker of the genetic predisposition to psychosis (Myin-Germeys and others 2001). Alternatively, however, stress reactivity may be due to the impact of environmental factors in interaction with genetic factors or, particularly in twins, due to epigenetic factors operating in the fetal period (Van Os and Sham 2003).

\section{Limitations}

The results should be viewed in the light of several methodological issues. First, both the CAPE questionnaire and the ESM measurements are based on subjective reports. Therefore, it can be argued that the results are not psychometrically precise. However, although subjective reports are considered less reliable (e.g., do all subjects interpret or answer the questions identically?), previous research implies 
that subjective reports may be more ecologically valid, and that the validity of objective reports such as clinical observations should not be taken for granted (Strauss 1994).

Second, the current study used ESM, a daily life assessment technique in which subjects have to comply with a paper-and-pencil diary protocol without the researcher being present. Recently, some authors have cast doubt on the reliability and subject compliance in paper-and-pencil ESM studies, favoring the use of electronic devices (Broderick and others 2003; Stone and others 2002). However, in a comparative study, Green and colleagues concluded that both methods yielded similar results (Green and others 2006). In addition, a recent study of our group using a signal-contingent random time sampling procedure with multiple observations per day - similar to the protocol used in the current study - found evidence that underscores the validity of the paper-and-pencil random time self-report data in the current study (Jacobs and others 2005).

Third, the current results are based on cross-sectional analyses. Therefore, the possibility of reversed causality cannot be excluded. There is a possibility that increased psychosis or increased negative affect might influence the subjective appraisal of the environment (e.g. subjects with higher scores on psychosis or negative affect measures might interpret the environment in a different way than subjects with lower scores on these measures). It has been well described, for instance, that people with psychosis often use an external attribution style (e.g. they attribute the cause of a negative event to other people or to the environment rather than to themseives) (Bentall et al., 2001). The overall effect, however, would still be for the individual to experience psychosis associated with an environmental event.

Fourth, the current sample was part of a larger sample collected to investigate the relationship between stress and psychopathology. Because sex-specific genetic effects on psychopathology are likely and often observed (Bolger and others 1989; Fujita and others 1991), the first wave comprised only women. Previous research in psychosis has shown, however, that women report significantly higher emotional reactivity to stress in daily life than men do (Myin-Germeys and others 2004). They report more intense affect (Fujita and others 1991) and greater distress as a reaction to stressors in daily life (Bolger and others 1989). Nevertheless, the present design may also be productive in investigating stress reactivity as an underlying etiologic mechanism for psychosis in men. 
ONTHEATHWAY FOM STRESTO PSYCHOSIS

Table 1. Pearsons correlation between CAPE positive and negative symptom dimension and EVENT and ACTIVITY stress measures. * $p<0.05, * * p<0.01$

\begin{tabular}{lll}
\hline & \multicolumn{1}{l}{ Event stress twin 1 } & Activity stress twin 1 \\
\hline CAPE positive twin 1 & 0.02 & $0.14^{* *}$ \\
CAPE negative twin 1 & $0.20^{* *}$ & $0.19^{* *}$ \\
CAPE positive twin 2 & 0.03 & 0.06 \\
& & $0.10^{*}$ \\
CAPE negative twin 2 & $0.14^{* *}$ & \\
\end{tabular}

Table 2. Cross-trait, within-twin analyses, assessing the interaction between daily stress and psychotic experiences in the model predicting negative affect (NA). The focus of the analysis was the interaction term, as the hypothesis centered on the question whether the association between daily stress and intensity of NA varies with level of underlying psychosis levels within the person.

\begin{tabular}{|c|c|c|c|c|c|c|c|c|}
\hline \multirow{3}{*}{$\begin{array}{l}\text { ESM } \\
\text { stress measure }\end{array}$} & \multicolumn{4}{|c|}{$\begin{array}{l}\text { CAPE positive psychosis } \\
\text { dimension }\end{array}$} & \multicolumn{4}{|c|}{$\begin{array}{l}\text { CAPE negative psychosis } \\
\text { dimension }\end{array}$} \\
\hline & \multicolumn{8}{|c|}{ Stress reactivity $x$ psychosis interaction term } \\
\hline & $\mathrm{N}$ & $\mathrm{B}$ & $95 \% \mathrm{Cl}$ & $\mathrm{P}$ & $\mathrm{N}$ & B & $95 \% \mathrm{Cl}$ & $P$ \\
\hline Activity-stress & 529 & 0.40 & $0.32-0.48$ & 0.00 & 529 & 0.26 & $0.21-0.31$ & 0.00 \\
\hline Event-stress & 522 & 0.28 & $0.22-0.35$ & 0.00 & 522 & 0.17 & $0.13-0.21$ & 0.00 \\
\hline
\end{tabular}




\section{CHAPTER 3}

Table 3. Cross-trait, cross-twin analyses, assessing the interaction between daily stress in twin 1 and psychotic experiences in the co-twin in the model predicting negative affect in twin 1 (NA). The focus of the analysis was the interaction term, since the hypothesis centered on the question whether familial vulnerability to psychosis (i.e., psychosis in the co-twin) moderates the association between stress and intensity of NA in twin1.

\begin{tabular}{|c|c|c|c|c|c|c|c|c|}
\hline \multicolumn{9}{|c|}{ Stress reactivity $x$ psychosis interaction term } \\
\hline \multirow{2}{*}{$\begin{array}{l}\text { ESM } \\
\text { stress } \\
\text { measure }\end{array}$} & \multicolumn{4}{|c|}{ CAPE positive psychosis dimension } & \multicolumn{4}{|c|}{ CAPE negative psychosis dimension } \\
\hline & $N$ & $\mathrm{~B}^{\mathrm{a}}$ & $95 \% \mathrm{Cl}^{\wedge}$ & $\mathrm{P}$ & $N$ & $\mathrm{~B}^{\mathrm{a}}$ & $95 \% \mathrm{Cl}$ & $\mathrm{P}$ \\
\hline $\begin{array}{l}\text { Activity } \\
\text { stress }\end{array}$ & 512 & 0.07 & $-0.014-0.15$ & 0.11 & 512 & 0.15 & $0.09-0.20$ & 0.00 \\
\hline \multirow[t]{2}{*}{$\begin{array}{l}\text { Event } \\
\text { stress }\end{array}$} & 505 & 0.06 & $-0.003-0.13$ & 0.06 & 505 & 0.13 & $0.09-0.18$ & 0.00 \\
\hline & $N$ & $\mathrm{~B}^{\mathrm{b}}$ & $95 \% \mathrm{Cl}$ & $\mathrm{P}$ & $N$ & $\mathrm{~B}^{\mathrm{b}}$ & $95 \% \mathrm{Cl}$ & $P$ \\
\hline $\begin{array}{l}\text { Activity } \\
\text { stress }\end{array}$ & 508 & 0.08 & $-0.003-0.16$ & 0.06 & 508 & 0.15 & $0.10-0.20$ & 0.00 \\
\hline $\begin{array}{l}\text { Event } \\
\text { stress }\end{array}$ & 501 & 0.08 & $0.01-0.14$ & 0.03 & 501 & 0.13 & $0.09-0.18$ & 0.00 \\
\hline
\end{tabular}

${ }^{a}$ Unadjusted $B$

${ }^{b} B$ adjusted for corresponding psychosis dimension in the twin 1.

Figure 1. Solid arrows: Cross-twin, cross-trait associations; examination of the association between stress-reactivity (trait 1) and subclinical psychotic experiences (trait 2) across genetically related individuals (twins). If the cross-trait, cross-twin association is greater in monozygotic than in dizygotic twins, a genetic contribution to the observed association may be inferred (Wichers et al., 2007). Dotted arrows: Within-twin, cross-trait associations.

TRAIT 1

TRAIT 2

TWIN 1

TWIN 2

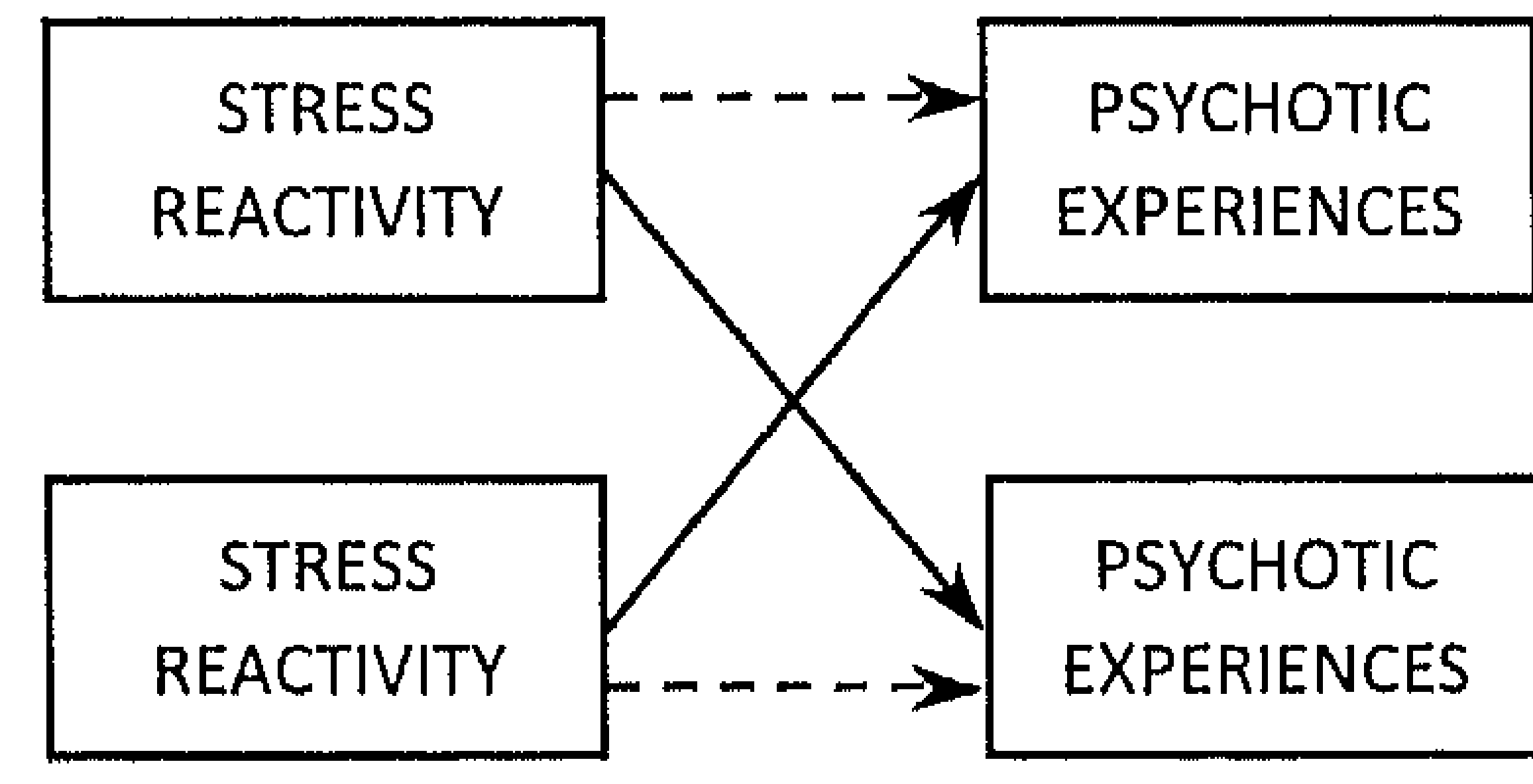


ON TME PATHWAY FROMSTPESTOPSYCHOSIS

\section{References}

Arseneault L, Cannon M, Poulton R, Murray R, Caspi A, Moffitt TE. 2002. Cannabis use in adolescence and risk for adult psychosis: longitudinal prospective study. Bmj 325(7374):1212-3.

Bak M, Krabbendam L, Janssen I, de Graaf R, Vollebergh W, van Os J. 2005. Early trauma may increase the risk for psychotic experiences by impacting on emotional response and perception of control. Acta Psychiatr Scand 112(5):360-6.

Bentall RP, Corcoran R, Howard R, Blackwood N, Kinderman P. 2001. Persecutory delusions: a revies and theoretical integration. Clin Psych Rev 21: 1143-1192.

Bolger N, DeLongis A, Kessler RC, Schilling EA. 1989. Effects of daily stress on negative mood. J Pers Soc Psychol 57(5):808-18.

Broderick JE, Schwartz JE, Shiffman S, Hufford MR, Stone AA. 2003. Signaling does not adequately improve diary compliance. Ann Behav Med 26(2):139-48.

Cardno AG, Rijsdijk FV, Sham PC, Murray RM, McGuffin P. 2002. A twin study of genetic relationships between psychotic symptoms. Am J Psychiatry 159(4):539-45.

Chapman U, Chapman JP, Kwapil TR, Eckblad M, Zinser MC. 1994. Putatively psychosis-prone subjects 10 years later. J Abnorm Psychol 103(2):171-83.

Corcoran C, Gallitano A, Leitman D, Malaspina D. 2001. The neurobiology of the stress cascade and its potential relevance for schizophrenia. J Psychiatr Pract 7(1):3-14.

Delespaul PAEG. 1995. Assessing schizophrenia in daily life. Maastricht: Universitaire Pers.

Derom C, Vlietinck R, Thiery E, Leroy F, Fryns JP, Derom R. 2002. The East Flanders Prospective Twin Survey (EFPTS). Twin Res 5(5):337-41.

Fergusson DM, Horwood $\amalg$, Swain-Campbell NR. 2003. Cannabis dependence and psychotic symptoms in young people. Psychol Med 33(1):15-21.

Fujita F, Diener E, Sandvik E. 1991. Gender differences in negative affect and well-being: the case for emotional intensity. J Pers Soc Psychol 61(3):427-34.

Gooding DC, Tallent KA, Matts CW. 2005. Clinical status of at-risk individuals 5 years later: further validation of the psychometric high-risk strategy. J Abnorm Psychol 114(1):170-5.

Green AS, Rafaeli E, Bolger N, Shrout PE, Reis HT. 2006. Paper or plastic? Data equivalence in paper and electronic diaries. Psychol Methods 11(1):87-105.

Gruzelier $\mathrm{JH}$, Kaiser J. 1996. Syndromes of schizotypy and timing of puberty. Schizophr Res 21(3):183-94.

Hanssen M, Bak M, Bijl R, Vollebergh W, van Os J. 2005. The incidence and outcome of subctinical psychotic experiences in the general population. Br J Clin Psychol 44(Pt 2):181-91.

Hanssen M, Peeters F, Krabbendam L, Radstake S, Verdoux H, van Os J. 2003. How psychotic are individuals with non-psychotic disorders? Soc Psychiatry Psychiatr Epidemiol 38(3):149-54.

Horan WP, Ventura J, Nuechterlein KH, Subotnik KL, Hwang S5, Mintz J. 2005. Stressful life events in recent-onset schizophrenia: reduced frequencies and altered subjective appraisals. Schizophr Res 75(2-3):363-74.

Jacobs N, Kenis G, Peeters F, Derom C, Vlietinck R, van Os J. 2006. Stress-related negative affectivity and genetically altered serotonin transporter function: evidence of synergism in shaping risk of depression. Arch Gen Psychiatry 63(9):989-96.

Jacobs N, Myin-Germeys I, Derom C, Delespaul P, van Os J, Nicolson NA. 2007. A momentary assessment study of the relationship between affective and adrenocortical stress responses in daily life. Biol Psychol 74(1):60-6.

Jacobs N, Nicolson NA, Derom C, Delespaul P, van Os J, Myin-Germeys I, 2005. Electronic monitoring of salivary cortisol sampling compliance in daily life. Life Sci 76(21):2431-43.

Janssen I, Krabbendam L, Bak M, Hanssen M, Vollebergh W, de Graaf R, van Os J. 2004. Childhood abuse as a risk factor for psychotic experiences. Acta Psychiatr Scand 109(1):38-45.

Johns LC, van Os J. 2001. The continuity of psychotic experiences in the general population. Clinical Psychology Review 21(8):1125-41. 


\section{CMAPER}

Johnson JK, Tuulio-Henriksson A, Pirkola T, Huttunen MO, Lonnqvist J, Kaprio J, Cannon TD. 2003. Do schizotypal symptoms mediate the relationship between genetic risk for schizophrenia and impaired neuropsychological performance in co-twins of schizophrenic patients? Biol Psychiatry 54(11):12004.

Kendler KS, Diehl SR. 1993. The genetics of schizophrenia: a current, genetic-epidemiologic perspective. Schizophr Bull 19(2):261-85.

Konings $M$, Bak M, Hanssen $M$, van Os J, Krabbendam L. 2006. Validity and reliability of the CAPE: a selfreport instrument for the measurement of psychotic experiences in the general population. Acta Psychiatr Scand 114(1):55-61.

Krabbendam L, Myin-Germeys I, Hanssen M, van Os J. 2005. Familial covariation of the subclinical psychosis phenotype and verbal fluency in the general population. Schizophr Res 74(1):37-41.

Kwapil TR. 1998. Social anhedonia as a predictor of the development of schizophrenia-spectrum disorders. J Abnorm Psychol 107(4):558-65.

Lenzenweger MF, Gold JM. 2000. Auditory working memory and verbal recall memory in schizotypy. Schizophr Res 42(2):101-10.

Lenzenweger MF, Korfine L. 1994. Perceptual aberrations, schizotypy, and the Wisconsin Card Sorting Test. Schizophr Bull 20(2):345-57.

Loos R, Derom C, Vlietinck R, Derom R. 1998. The East Flanders Prospective Twin Survey (Belgium): a population-based register. Twin Res 1(4):167-75.

Malla AK, Cortese L, Shaw TS, Ginsberg B. 1990. Life events and relapse in schizophrenia. A one year prospective study. Soc Psychiatry Psychiatr Epidemiol 25(4):221-4.

Mata I, Gilvarry CM, Jones PB, Lewis SW, Murray RM, Sham PC. 2003. Schizotypal personality traits in nonpsychotic relatives are associated with positive symptoms in psychotic probands. Schizophr Bull 29(2):273-83.

Matsui M, Sumiyoshi T, Kato K, Yoneyama E, Kurachi M. 2004. Neuropsychological profile in patients with schizotypal personality disorder or schizophrenia. Psychol Rep 94(2):387-97.

MeehI PE. 1962. Schizotaxia, schizotypy, schizophrenia. American Psychologist 17(12):827-838.

Myin-Germeys I, Krabbendam L, Delespaul PA, Van Os J. 2003a. Do life events have their effect on psychosis by influencing the emotional reactivity to daily life stress? Psychol Med 33(2):327-33.

Myin-Germeys I, Krabbendam L, Delespaul PA, van Os J. 2004. Sex differences in emotional reactivity to daily life stress in psychosis. J Clin Psychiatry 65(6):805-9.

Myin-Germeys I, Peeters F, Havermans R, Nicolson NA, DeVries MW, Delespaul P, Van Os J. 2003b. Emotional reactivity to daily life stress in psychosis and affective disorder: an experience sampling study. Acta Psychiatr Scand 107(2):124-31.

Myin-Germeys 1, van Os J. 2007. Stress-reactivity in psychosis: evidence for an affective pathway to psychosis. Clin Psychol Rev 27(4):409-24.

Myin-Germeys I, van Os J, Schwartz JE, Stone AA, Delespaul PA. 2001. Emotional reactivity to daily life stress in psychosis. Arch Gen Psychiatry 58(12):1137-44.

Neumann CS, Walker EF. 2003. Neuromotor functioning in adolescents with schizotypal personality disorder: associations with symptoms and neurocognition. Schizophr Bull 29(2):285-98.

Norman RM, Malla AK. 1.991. Subjective stress in schizophrenic patients. Soc Psychiatry Psychiatr Epidemiol 26(5):212-6.

Norman RM, Malla AK. 1993. Stressful life events and schizophrenia. I: A review of the research. Br J Psychiatry 162:161-6.

Norman RM, Malla AK. 1994. A prospective study of daily stressors and symptomatology in schizophrenic patients. Soc Psychiatry Psychiatr Epidemiol 29(6):244-9.

Nuechterlein KH, Dawson ME, Ventura J, Gitlin M, Subotnik KL, Snyder KS, Mintz J, Bartzokis G. 1994. The vulnerability/stress model of schizophrenic relapse: a longitudinal study. Acta Psychiatr Scand Suppl 382:58-64.

Peralta V, Cuesta MJ. 1998. Factor structure and clinical validity of competing models of positive symptoms in schizophrenia. Biol Psychiatry 44(2):107-14. 


\section{ON THE PATHWAY FROM STPESSTO PSYCMOSIS}

Peralta V, Cuesta MJ, de Leon J. 1994. An empirical analysis of latent structures underlying schizophrenic symptoms: a four-syndrome model. Biol Psychiatry 36(11):726-36.

Peters ER, Joseph SA, Garety PA. 1999. Measurement of delusional ideation in the normal population: introducing the PDI (Peters et al. Delusions Inventory). Schizophr Bull 25(3):553-76.

Poulton R, Caspi A, Moffitt TE, Cannon M, Murray R, Harrington H. 2000. Children's self-reported psychotic symptoms and adult schizophreniform disorder: a 15-year longitudinal study. Archives of General Psychiatry 57(11):1053-1058.

Read J, van Os J, Morrison AP, Ross CA. 2005. Childhood trauma, psychosis and schizophrenia: a literature review with theoretical and clinical implications. Acta Psychiatr Scand 112(5):330-50.

Simons $\mathrm{Cl}$, Jacobs $\mathrm{N}$, Jolles J, van OS J, Krabbendam L. 2007. Subclinical psychotic experiences and cognitive functioning as a bivariate phenotype for genetic studies in the general population. Schizophr Res 92(1-3):24-31.

StataCorp. 2001. STATA Statistical Software: Release 7.0. Texas: College Station.

Stefanis NC, Hanssen M, Smirnis NK, Avramopoulos DA, Evdokimidis IK, Stefanis CN, Verdoux H, Van Os J. 2002. Evidence that three dimensions of psychosis have a distribution in the general population. Psychol Med 32(2):347-58.

Stefanis NC, Van Os 1, Avramopoulos D, Smyrnis N, Evdokimidis I, Hantoumi I, Stefanis CN. 2004. Variation in catechol-o-methyltransferase val158 met genotype associated with schizotypy but not cognition: a population study in 543 young men. Biol Psychiatry 56(7):510-5.

Stone AA, Shiffman S, Schwartz JE, Broderick JE, Hufford MR. 2002. Patient non-compliance with paper diaries. Bmj 324(7347):1193-4.

Strauss JS. 1994. The person with schizophrenia as a person. II: Approaches to the subjective and complex. Br J Psychiatry Suppl(23):103-7.

van Os J, Bak M, Hanssen M, Bijl RV, de Graaf R, Verdoux H. 2002. Cannabis use and psychosis: a longitudinal population-based study. Am J Epidemiol 156(4):319-27.

van Os J, Hanssen M, Bijl RV, Ravelli A. 2000. Strauss (1969) revisited: a psychosis continuum in the general population? Schizophr Res 45(1-2):11-20.

Van Os J, Sham P. 2003. Gene-environment interactions. In: Murray PBJRM, Susser E, Os IV, Cannon M, editors. The Epidemiology of Schizophrenia. Cambridge: Cambridge University Press. p 235-254.

Ventura J, Nuechterlein KH, Lukoff D, Hardesty JP. 1989. A prospective study of stressful life events and schizophrenic relapse. I Abnorm Psychol 98(4):407-11.

Ventura J, Nuechterlein KH, Subotnik KL, Hardesty JP, Mintz J. 2000. Life events can trigger depressive exacerbation in the early course of schizophrenia. J Abnorm Psychol 109(1):139-44.

Verdoux H, Maurice-Tison S, Gay B, Van OS J, Salamon R, Bourgeois ML. 1998a. A survey of delusional ideation in primary-care patients. Psychol Med 28(1):127-34.

Verdoux H, van Os J, Maurice-Tison S, Gay B, Salamon R, Bourgeois M. 1998b. Is early adulthood a critical developmental stage for psychosis proneness? A survey of delusional ideation in normal subjects. Schizophr Res 29(3):247-54.

Voglmaier MM, Seidman L, Niznikiewicz MA, Dickey CC, Shenton ME, McCarley RW. 2000. Verbal and nonverbal neuropsychological test performance in subjects with schizotypal personality disorder. Am J Psychiatry 157(5):787-93.

Vollema MG, Hoijtink H. 2000. The multidimensionality of self-report schizotypy in a psychiatric population: an analysis using multidimensional Rasch models. Schizophr Bull 26(3):565-75.

Vollema MG, Sitskoorn MM, Appels MC, Kahn RS. 2002. Does the Schizotypal Personality Questionnaire reflect the biological-genetic vulnerability to schizophrenia? Schizophr Res 54(1-2):39-45.

Vollema MG, van den Bosch RJ. 1995. The multidimensionality of schizotypy. Schizophr Bull 21(1):19-31.

Wichers M, Myin-Germeys I, Jacobs N, et al, 2007. Genetic risk of depression and stress-induced negative affect in daily life. British Journal of Psychiatry. 191: 218-223.

Yung AR, Phillips W, Yuen HP, Francey SM, McFarlane CA, Hallgren M, McGorry PD. 2003. Psychosis prediction: 12-month follow up of a high-risk ("prodromal") group. Schizophr Res 60(1):21-32. 


\section{Chapter 4}

\section{Stress-reactivity and cognitive impairments: separate mechanisms underlying different symptoms in psychosis}

Tineke Lataster ${ }^{1}$, Lucia Valmaggia ${ }^{2}$, Mariëlle Lardinois ${ }^{1}$, Jim van $0 s^{1,2}$, Inez MyinGermeys $^{1,3}$

\footnotetext{
${ }^{1}$ Department of Psychiatry and Neuropsychology, South Limburg Mental Health Research and Teaching Network, EURON, P.O. box 616, 6200 MD, Maastricht University Medical Centre, The Netherlands. ${ }^{2}$ Division of Psychological Medicine \& Psychiatry, Institute of Psychiatry, King's College London, UK. ${ }^{3}$ School of Psychological Sciences, University of Manchester, UK.
}

Schizophrenia Research, submitted 
ONTHE PATHWAY FROM STRESSTO PSYCHOSIS

\section{ABSTRACT}

Background: The development of the DSM $V$ has fueled the discussion whether psychotic disorders may better be characterized using a dimensional approach, suggesting that symptom dimensions may constitute more homogeneous entities with unique underlying liabilities. Cognitive impairments and an altered stressreactivity in daily life are suggested to be independent mechanisms, possibly underlying different symptom dimensions. Aims of the study were to replicate the finding that stress-reactivity is not or inversely associated with cognitive performance in patients with psychotic disorder and to examine whether stress-reactivity is specifically associated with the positive psychotic symptom dimension.

Methods: Sixty-three patients with psychotic disorder were assessed using the Positive and Negative Syndrome Scale and a neuropsychological test battery. The Experience Sampling Method was used to measure stress-reactivity.

Results: The results showed that in some instances, cognitive functioning did not alter the emotional reaction to stress. In other instances, an inverse relationship was found, with better performance on cognitive tests being associated with greater stress-reactivity. Higher levels of stress-reactivity were associated with higher levels of positive symptoms and lower levels of negative symptoms.

Discussion: The findings suggest that increased stress-reactivity is a mechanism specifically related to positive psychotic symptoms, independent of cognition. 


\section{CHAPTE}

\section{Introduction}

The development of the Diagnostic Manual of Mental Disorders $V$ has fueled the discussion whether schizophrenia is a valid and useful entity. Several authors have favored a dimensional approach in which patients have more or less psychopathology rated on several symptom dimensions (Cuesta and others 2006; McGorry and others 1998). Symptom dimensions may constitute more homogeneous entities with similar symptom patterns, aetiology, prognosis and possibly treatment. They may thus be interesting phenotypes both for molecular genetic studies and for revealing patterns of unique liability specifically associated with single symptom dimensions. Cognitive impairments have been extensively studied as underlying mechanism associated with schizophrenia. They have consistently been linked to the negative, but not the positive, syndrome of psychosis (Dominguez and others 2008; van Os and Verdoux 2001). Reports on possible mechanisms underlying the positive symptoms of psychosis are less consistent. Previous work suggests that increased emotional reactivity to stress is a vulnerability marker for psychosis, as it has been identified both in subjects at genetic risk for psychosis (first-degree relatives and patients in clinical remission), as well as in subjects at psychometric risk for psychosis (subjects scoring high on a psychometric psychosis liability scale) (Lataster and others 2008; Myin-Germeys and others 2001). Interestingly, two studies reported that evidence of increased emotional reactivity was either not or even inversely associated with cognitive impairments, suggesting that alterations in stress-reactivity require intact cognitive functioning (Morrens and others, 2007; Myin-Germeys and others 2002). In addition, it was found that experiences of stress increased the intensity of positive psychotic experiences, both in patients in clinical remission and in healthy relatives of patients with psychosis (Myin-Germeys and others 2005). These findings make it attractive to hypothesize that altered stressreactivity is a mechanism underlying the positive symptoms of psychosis. This study had two aims. First, it attempted to replicate the finding that stress-reactivity is not or inversely associated with cognitive performance in patients with psychotic disorder. Second, the association between stress-reactivity and the positive and negative symptom dimensions of psychosis was investigated.

\section{Method}

Subjects

The sample consisted of 72 patients with a non-affective psychotic disorder recruited through in- and outpatient mental health service facilities in South-Limburg, The Netherlands and in Flanders, Belgium. All interviews were conducted by trained research assistants, a clinical/ neuropsychologist (M.L.) and a neuropsychologist 


\section{OMTHE PATHWAY RROM STHESTOPSYCHOSIS}

(T.L.). The Brief Psychiatric Rating Scale (Ventura and others 1993) and the Positive and Negative Syndrome Scale (Kay and others 1987) were used to assess psychiatric symptoms regarding the two weeks prior to study entry. The CASH (Andreasen and others 1992) was completed to assess symptom history over the past six months and lifetime, yielding DSM-IV diagnoses (APA 1994).

Inclusion criteria were: (1) lifetime occurrence of non-affective psychotic symptoms, according to DSM-IV criteria; (2) age 18 to 55 years; (3) sufficient command of the Dutch language. The exclusion criteria were: (1) brain disease, and (2) history of head injury with loss of consciousness. Written informed consent, confirming to local ethics committee guidelines, was obtained from all subjects.

\section{Experience sampling method}

The experience sampling method (ESM) was used to measure the emotional reaction to stress in the flow of daily life (hereafter: "stress reactivity"). ESM is a withinday, momentary self-assessment technique (Myin-Germeys and others 2009). Subjects received a digital wristwatch and self-assessment forms collated in a booklet for each day. Ten times a day on six consecutive days, the watch emitted a signal (beep) at unpredictable moments between 7:30 a.m. and 10:30 p.m. Subjects were asked to report immediately after each beep their thoughts, current context (activity, persons present, location), appraisals of the current situation, and mood. All self-assessments were rated on 7-point Likert scales. For more details on the procedure and reliability of this method, see (Delespaul 1995; Myin-Germeys and others 2009; Myin-Germeys and others 2007)

\section{Assessment of mood and stress}

Measures of mood and stress were derived from the ESM reports as follows.

Assessment of mood. ESM negative affect was assessed at each beep with 6 moodrelated adjectives (down, guilty, insecure, lonely, anxious, angry/ irritated) rated on 7-point Likert scales ( $1=$ not at all, $7=$ very). The six mood adjectives were reduced to one measure of Negative Affect (NA) by means of principal component factor analysis of the entire sample followed by varimax rotation, using STATA version 10 (Statacorp 2007). Based on the scree plot, a one-factor solution was chosen, accounting for $100 \%$ of the variance (factor loadings down: 0.84 , guilty: 0.78 , lonely: 0.72 , insecure: 0.79 , anxious: 0.79 , and angry/ irritated: 0.63 ). Weighted factor scores (NA) were used in the analyses. For this purpose, the score on each of the six mood adjectives was multiplied by its own factor loading and divided by the number of adjectives assessed per subject (with a minimum of three adjectives per subject) (Cronbach's $\alpha=0.85$ ).

Assessment of stress. In accordance with previous work, stress was conceptualized as the subjectively appraised stressfulness of distinctive events (event-related stress) as well as of minor disturbances that continually happen in the flow of daily 


\section{CMABTER}

life (activity-related stress) (Myin-Germeys and van Os 2007). In order to measure event-related stress, the subject was asked to report, after each beep, the most important event that had happened between the current and the previous report. This event was subsequently rated on a bipolar Likert scale $(-3=$ very unpleasant, $0=$ neutral, $3=$ very pleasant). The responses were recoded to allow high scores to reflect stress $(-3=$ very pleasant, $0=$ neutral, $3=$ very unpleasant).

In order to measure activity-related stress, the subject rated, after each beep, aspects relating to current activity using three self-report items scored on 7-point Likert scales ( $1=$ not at all, $7=$ very). The mean weighted factor score on the three items "I would rather do something else", "This is something I am good at", and "This activity requires effort" formed the activity-related stress scale (Cronbach's $\alpha=$ $0.54)$.

Assessment of symptoms: Positive and Negative Syndrome Scale All subjects were assessed with the Positive and Negative Syndrome Scale (PANSS) (Kay and others 1987) at the end of the ESM week. The PANSS constitutes a positive symptom scale, a negative symptom scale, and a general symptoms scale. For the present study we used the positive and negative symptoms scale each of which include seven items scored on a 7-point scale ( $1=$ absent, $7=$ extreme). The mean scores on both the positive and negative scale were used.

\section{Neuropsychological Assessment}

The neuropsychological assessment was directed at the following cognitive domains: episodic memory, sustained attention, speed of complex information processing (executive functioning), social cognition, and intelligence.

The Auditory Verbal Learning Task (Lezak 1995) was used to evaluate learning and retrieval of information in episodic memory. In three consecutive trials, a list of 15 words had to be memorized and reproduced. The measure used was the total number of words recalled over the three trials. The Continuous Performance Taskversion $\mathrm{HQ}$ (Nestor and others 1990) was used as a measure of sustained attention. The relevant variable was the total number of no-go errors (i.e. pressing the space bar when this was not required). The Flanker CPT (Cognitive Therapeutics Ltd.; http://www.cogtest.com) (Eriksen and Kann 1974) and Response Shifting Test (based on the Competing Programs Task (Bilder and others 1992) were applied to measure speed of complex information processing. Both tasks have congruent (simple) and incongruent (complex) trials. On both tasks, the mean reaction time on the incongruent trials was used as measure of executive functioning. The Hinting Task (Corcoran and others 1995), Facial Affect Recognition Task (van 't Wout and others 2007), and Benton Face Recognition Task (Benton and others 1978) were used to evaluate social cognition. The four subtasks (Performal IQ: Digit Symbol Substitution Test, and Block Design; Verbal IQ: Arithmetic's, and General Information) of the 
ONTHE PATHWAV FROM STRESS TO PSVCHOSIS

Wechsler Adult Intelligence Scale III-Revised (Wechsler 2001) were used to calculate total IQ scores.

Cognitive factors

The number of neuropsychological test variables was reduced by means of principal component factor analyses of the entire sample followed by varimax rotation. Based on the scree plot, a three-factor solution was chosen, accounting for $58 \%$ of the variance. Factor scores were used. The variables of the Auditory Verbal Learning Task (factor loading 0.76), the WAIS (factor loading -0.84), and the Hinting Task (factor loading 0.55 ) loaded strongly on the first factor, which was named General Cognition. The variables of the Flanker Test (factor loading 0.75), the Response Shifting Test (factor loading 0.74), and the Continuous Performance Test (factor loading 0.69 ) loaded strongly on the second factor, which was labelled Information Processing Speed. The variables of the Hinting Task (factor loading 0.47), the Facial Affect Recognition Task (factor loading 0.68), and Benton Face Recognition Task (factor loading 0.80 ) loaded on the third factor, which was labelled Social Cognition. For all factors, high values represent poor performance.

\section{Analyses}

ESM data have a hierarchical structure: Multiple observations (level 1) are nested within subjects (level 2), who were in some cases part of sib pairs (level 3). In order to take the 3-level grouping structure of the data (ESM beep level observations, subject, sib pair) into account, multilevel random regression analysis (Snijders and Bosker 1999) was applied in STATA, version 10.0 (Statacorp 2007), using the XTMIXED command. Mixed models are characterized as containing both fixed and random effects. The fixed effects are analogous to conventional regression coefficients $(B)$ and are estimated directly.

\section{Association between stress reactivity and neuropsychological performance}

In order to replicate previous findings, neuropsychological performance was assessed in a subsample of 52 patients. Multilevel linear regression analyses were conducted to examine the association between stress reactivity on the one hand and cognitive functioning on the other. For these analyses, Negative Affect (NA) was entered in the model as the dependent variable. The three measures of cognitive functioning (i.e. general cognition, information processing speed, and social cognition), the ratings on the two stress measures (i.e. event- and activity-related stress), and their interactions (stress $x$ cognitive functioning) were included as independent variables in separate models (general model: $N A=B O+B 1$ stress $+B 2$ cognitive functioning + B3stress $x$ cognitive functioning + residual). The interaction term is the focus of these analyses, since the hypothesis required testing whether cognitive functioning moderated the association between stress and the intensity of NA. 
Therefore, stratified analyses were conducted whenever a significant interaction effect was found. For these analyses, patients were divided into three groups conform previous work in this area (Myin-Germeys and others 2002): (1) low cognitive functioning (the $33 \%$ of the subjects with the lowest scores on the tests), (2) medium cognitive functioning (the $33 \%$ of the subjects who fell in the middle tertile), (3) high cognitive functioning (the $33 \%$ of patients with the highest scores on the tests). Stress reactivity was analyzed in the three groups separately (regression model: $\mathrm{NA}=\mathrm{BO}+\mathrm{B} 1$ stress + residual). All analyses were controlled for use of illicit drugs and alcohol measured at the beep level with the questions: "Since the last beep I used alcohol" ( $1=y e s, 0=$ no), and "Since the last beep I used cannabis or other drugs" (1=yes, $0=$ no).

\section{2) Association between stress reactivity and positive and negative symptoms}

Multilevel linear regression analyses were conducted to examine the association between stress reactivity on the one hand and the positive and negative symptoms of psychosis, measured with the PANSS, on the other. For these analyses, NA was entered in the model as the dependent variable, whereas mean scores on the positive and negative symptom scale, the ratings on the two stress measures (i.e. eventand activity-related stress), and their interactions (stress $x$ symptoms), were the independent variables (general model: $\mathrm{NA}=\mathrm{BO}+\mathrm{B} 1$ stress $+\mathrm{B} 2$ symptoms $+\mathrm{B} 3$ stress $x$ symptoms + residual). Again, the interaction term was the focus of these analyses, since the hypothesis required testing whether positive and negative symptoms moderated the association between stress and NA intensity.

\section{Results}

\section{Subjects and Descriptives}

The final sample consisted of 72 patients. Of these patients, 71 completed ESM reports ( 1 subject dropped out) yielding a total of 2560 beeps with a mean of 41 beeps per subject. A further 8 subjects were excluded because they had fewer than 20 valid ESM self-reports (i.e. 63 subjects remained). A sub-sample of 52 patients completed neuropsychological testing. The general cognition measure could be calculated for all 52 subjects. Due to missing data on the Facial Affect Recognition task, social cognition could be calculated for 41 participants. The cognitive speed/ executive functioning measure was only available for 34 subjects since a switch was made from the CPT-AX to the CPT-HQ, which turned out to be incompatible. Demographic and clinical statistics of the sample are shown in Table 1 (page 68), and the mean scores on the independent and dependent variables are shown in Table 2 (page 69). 


\section{OP THE PATHWAY FROM STRESS TO PSVCHOSIS}

\section{1) Association between stress reactivity and neuropsychological functioning}

The multilevel random regression analyses conducted to examine associations between stress reactivity on the one hand and cognitive functioning on the other showed no significant interaction effects with general cognition and speed of information processing for both event- and activity-related stress (Table 3, page 70), indicating that scores on these cognitive measures did not modify the moment-tomoment emotional reaction to stress in daily life. A significant negative interaction, indicating an inverse moderating effect, was found between social cognition and event-related stress, and a trend was found for social cognition and activity-related stress (Table 3, page 70). Controlling for use of alcohol and illicit drugs did not substantially change these results

Stratified analyses were conducted to further investigate the association between event-related stress and mood in relation to social cognition. The analyses showed that the group with the best performance on social cognition showed stronger emotional reactions to stress in daily life, with larger increases in negative affect compared to both the group with intermediate performance on social cognition and the group with the worst performance (Figure 1, page 72).

To assure that the results were not due to a lack of power, post-hoc power analyses were calculated by simulation adapted from STATA

www.stata.com/support/faqs/stat/power.html indicating that the current sample size yielded an overall power of $95 \%$ for General Cognition, of $79 \%$ for information Processing Speed, and of $86 \%$ for Social Cognition to detect significant 2-way interactions with an estimated effect size of 0.2 SD.

2) Association between stress reactivity and positive and negative psychotic symptoms

The multilevel random regression analyses conducted to examine the associations between stress reactivity on the one hand and scores on the positive and negative syndrome scale on the other, showed significant positive interaction effects for the positive syndrome scale, and significant negative or inverse interaction effects for the negative syndrome scale (Table 4, page 71), indicating that the emotional reactivity to stress in daily life is associated with high levels of positive symptoms and low levels of negative symptoms (Figure 2, page 73).

\section{Discussion}

This study is the first to demonstrate a direct association between increased levels of stress-reactivity and the positive symptoms of psychosis, suggesting that increased stress-reactivity is a mechanism specifically underlying the positive symptoms of psychosis. Furthermore, this study replicated the finding that cognitive 


\section{CHAPED}

impairments are not associated or inversely associated with a higher reactivity to stress in daily life.

\section{The affective pathway to psychosis}

The results of the present study suggest that altered stress-reactivity and cognitive deficits may be independent mechanisms underlying the symptoms of psychosis. Furthermore, altered stress-reactivity was associated specifically with the positive symptom dimension. In a dimensional view of psychosis, stress-reactivity could thus be argued to reflect a specific mechanism underlying the development of positive symptoms (Cuesta and others 2006; McGorry and others 1998). However, these findings also fit in with more traditional views of psychosis, which suggest that the extensive clinical heterogeneity in schizophrenia can be reduced to two main forms. The positive syndrome, or non-developmental, type I schizophrenia is characterized by a sudden onset, an episodic course, a good outcome, a good response to antipsychotic drug treatment and high levels of positive symptoms (Andreasen 1985; Murray and others 1992). It is suggested that alterations at the level of neurotransmitter signalling, for example mesolimbic hyperdopaminergia secondary to abnormal activation of the hypothalamic-pituitary-adrenal axis (HPA-axis), play an important role and that this subtype is more sensitive to aversive environmental influences (Murray and others 1992). The negative syndrome, or developmental, type II schizophrenia is characterized by a gradual onset, a chronic course, a poor outcome, resistance to drug treatment, high levels of negative symptoms and cognitive impairments (Andreasen 1985; Murray and others 1992). Structural brain abnormalities and cognitive dysfunction are thought to be most prevalent in this subsyndrome (Murray and others 1992). Within this line of reasoning, the present results, thus, support the notion that altered reactivity to stress in daily life and cognitive deficits represent partly independent syndromes caused by partly separable underlying aetiologies reflected in distinguishable endophenotypic pathways (Jacobs and others 2005; Murray and others 1992; Robins and Guze 1970).

Are stress-reactivity and cognitive impairments two independent pathways?

The data represent the third replication of the finding that cognitive impairments and emotional stress-reactivity to psychosis are statistically independent suggesting differential mechanisms underlying psychosis (Myin-Germeys and others 2002). Similar to previous results, the mean weighted factor scores on measures of general cognition and speed of information processing showed no significant interaction with stress-reactivity. Therefore, the evidence suggests that moment-to-moment reactivity to stress may not be a consequence of cognitive impairments, but rather may represent an independent underlying mechanism. The current study in addition extended these findings to the cognitive domain of social cognition. Some studies have suggested that social cognition is a compound of neurocognition (Vauth and 
others 2004), whereas other studies have shown that social cognition represents a separate area of cognition (Pinkham and others 2003). The results indicated that social cognition was significantly associated with emotional reactivity to stress in daily life, albeit inversely. In other words, better performance in social cognition was associated with higher reactivity to stress. This is in line with some of the neurocognitive results, where similar associations were found (Pinkham and others 2003). Although traditionally measures of social cognition are thought to be associated with positive symptoms and, by implication, with the stress-reactive form of psychosis the current finding, in the opposite direction, that better social cognition was associated with worse stress-reactivity is likely due to the nature of the tasks that were used to measure social cognition. A recent study from our group has shown that, unlike neurocognition, social cognition is a multidimensional construct encompassing various unrelated cognitive mechanisms (van Hooren and others 2008). In the present study, the Hinting task loaded on both the social and general cognition factor. This is in accordance with recent work showing that the Hinting task is strongly associated with neurocognitive measures (van Hooren and others 2008) and intelligence (Corcoran and others 1995). However, both the Benton Face Recognition Task and Facial Affect Recognition Task loaded solely on the social cognition factor. Thus, the social cognition factor used in the present study reflects in part neurocognitive capacity rather than social cognition. More research is needed on other dimensions of social cognition, such as source monitoring, reasoning biases, and attribution style, which are more closely linked to positive symptoms of psychosis (Janssen and others 2006).

How may stress-reactivity contribute to psychosis?

\section{Biological mechanisms}

There are several biological models that can account for the relationship between increased emotional reaction to stress and positive psychotic symptoms. A possible interpretation of the association is that minor stressors cause an increase in psychosis intensity. Since this effect would suggest an enduring increase of the behavioural response to environmental stress, it could be described as behavioural sensitization (Myin-Germeys and others 2005). It has been suggested in the past that exposure to environmental stressors resulting in a chronic heightened glucocorticoid release, may cause permanent changes in the HPA-axis (Walker and others 2008). Stressinduced dysregulation of the HPA-axis may then give rise to increased dopamine (DA) receptor densities and DA release (Walker and others 2008). These results, in turn, suggest that abnormalities in HPA-axis functioning may underlie the dopaminergic abnormalities that are generally thought to be involved in psychosis (Walker and others 2008). Additionally, Kapur (2003) suggested that a dysregulated, hyperdopaminergic state may lead to stimulus independent release of DA, which 
may take over the normal process of contextually driven salience attribution and leads to aberrant assignment of salience to external objects and internal representations.

\section{Psychological mechanisms}

Recent psychological models suggest that triggering events may lead to the development of positive psychotic symptoms. These models suggest that victimization experiences may lead to the formation of negative schemas about the self and the world (e.g., beliefs about the self as vulnerable to threat, or about others as dangerous) (Garety and others 2001) that facilitate external attributions, which may lead to the development of paranoid delusions (Bentall and others 2001). Additionally, a number of affective processes, in particular neuroticism, depression and anxiety, have been hypothesized to play a role in the formation of psychotic symptoms (Bentall and others 2001; Birchwood and others 2005). Additionally, Birchwood and colleagues (Birchwood and others 2005)suggest that it is the distress and depression that is experienced with and as a consequence of hallucinations and delusions that creates the problem, not the psychotic experiences themselves. They list a number of risk factors for depression in patients with non affective psychosis: (i) the appraisal of prosecutors as omnipotent and powerful, (ii) having fewer 'safety behaviours', and (iii) experiencing of their psychosis with greater 'loss', 'shame' and 'entrapment'.

The results of the current study would suggest that small daily events may trigger the type of affective disturbances that may facilitate the process whereby anomalous experiences may become psychotic symptoms.

\section{Clinical implications}

The current results suggest that there is an affective pathway to psychosis, in which increased reactivity to stress serves as an intermediate phenotype. Clearly, these results are still a long way from offering direct therapeutic insight. However, if stress-reactivity can truly be considered a specific area of vulnerability, it may be useful to tailor treatment aimed at reducing sensitivity to stress in daily life. One possible way to do so is by reducing stress in the social environment of the patient. In a meta-analysis it was shown that these family intervention techniques may be helpful in relapse prevention (Pilling and others 2002). Training patients to apply self-relaxation or -distraction techniques seems to improve emotional well-being in chronic schizophrenia patients but not in early psychosis (Hodel and others 1998). Previous studies have shown that Cognitive Behavioural Therapy (CBT) reduces psychotic symptoms (Pilling and others 2002), reduces distress caused by psychotic symptoms (Valmaggia and others 2005), and there are some studies suggesting that it might reduce relapse rates (Gumley and others 2006). However, in a recent study the effects of CBT and family intervention on relapse rates, symptoms and func- 


\section{ONTHE PTHWAY FOM STRESTO TEVCMOSIS}

tional outcome in patients with non affective psychosis were investigated (Garety and others 2008). The results showed no effects for family intervention. For CBT, however, beneficial effects were found on depression at 24 months follow up, delusional distress, and social functioning (Garety and others 2008). Thus, CBT seems to help for depression and emotional distress, but not for psychosis relapse. These findings are in accordance with what was proposed by Birchwood and Trower (Birchwood and Trower 2006), namely that CBT should focus primarily on the emotional dysfunction (i.e. affective symptoms) in psychosis rather than focus on improving psychotic symptoms. Extending this therapy in such a way that treatment is additionally focused on emotional sensitivity to stress in daily life may thus have positive effects on depression and distress that are experienced with psychotic symptoms, thereby improving functional outcome.

\section{Methodological issues}

The results should be viewed in the light of several methodological issues. The ESM measurements are based on subjective reports. Therefore, it can be argued that the results are not psychometrically precise. However, although subjective reports are considered less reliable (e.g., do all subjects interpret or answer the questions identically?), previous research implies that subjective reports can be valid, and that the validity of objective reports should not be taken for granted (Strauss 1994).

Second, the current study used ESM, a daily life assessment technique in which subjects have to comply with a paper-and-pencil diary protocol without the researcher being present. Recently, some authors have cast doubt on the reliability and subject compliance in paper-and-pencil ESM studies, favoring the use of electronic devices (Broderick and others 2003; Stone and others 2002). However, in a comparative study, Green and colleagues concluded that both methods yielded similar results (Green and others 2006). In addition, a recent study using a signalcontingent random time sampling procedure with multiple observations per day similar to the protocol used in the current study - found evidence that underscores the validity of the paper-and-pencil random time self-report data in the current study (Jacobs and others 2005).

Finally, stress-reactivity has been defined as the emotional reaction to subjective stress. The current results are based on cross-sectional analyses and therefore, the possibility of reverse causality cannot be excluded. There is a possibility that increased negative affect or increased levels of positive or negative symptoms influences the subjective appraisal of the environment. However, the individual would still experience psychosis or distress with an environmental event. 


\section{CMAPTER A}

\section{Funding}

This work was supported by the Royal Dutch Academy of Scientific Research [VWF/DA/977 to Tineke Lataster]; the Dutch Medical Council [Veni and Vidi grant to Inez Myin-Germeys]; and NARSAD [2006 Young Investigator Award to Inez MyinGermeys].

\section{Acknowledgments}

The authors wish to thank the research assistants of the GROUP project Maastricht who helped with the collection of the data. 


\section{ON THE PATMWAY FOOM STRESS TO PSYCHOSIS}

Table 1. Demographic and clinical characteristics.

\begin{tabular}{|c|c|c|c|c|}
\hline Charachteristic & & Mean & $S D$ & Range \\
\hline Age (years) & & 29.1 & 9.1 & $17-55$ \\
\hline \multicolumn{5}{|l|}{ Gender } \\
\hline Male & $65 \%$ & & & \\
\hline Female & $35 \%$ & & & \\
\hline \multicolumn{5}{|l|}{ Marital Status } \\
\hline Married or living together & $16 \%$ & & & \\
\hline Divorced & $5 \%$ & & & \\
\hline Never married & $79 \%$ & & & \\
\hline \multicolumn{5}{|l|}{ Work situation } \\
\hline Working & $13 \%$ & & & \\
\hline Unable to work & $69 \%$ & & & \\
\hline Working in protected environment & $5 \%$ & & & \\
\hline School/ education & $13 \%$ & & & \\
\hline \multicolumn{5}{|l|}{ Education } \\
\hline Elementary school & $6 \%$ & & & \\
\hline Secondary school & $65 \%$ & & & \\
\hline Higher Education & $29 \%$ & & & \\
\hline Total PANSS score & & 11.7 & 5.0 & $0-26$ \\
\hline Age at first psychotic episode (years) & & 23.1 & 7.1 & $13-44$ \\
\hline Number of episodes & & 2.2 & 1.3 & $1-6$ \\
\hline CASH DSM-IV Axis I diagnosis lifetime & $\mathrm{N}$ & & & \\
\hline Schizophrenia & 40 & & & \\
\hline Schizoaffective disorder & 9 & & & \\
\hline Psychotic disorder NOS & 6 & & & \\
\hline Brief psychotic disorder & 4 & & & \\
\hline Delusional disorder & 3 & & & \\
\hline Schizophreniform disorder & 1 & & & \\
\hline
\end{tabular}


CHADP

Table 2. Mean scores on the dependent and independent variables.

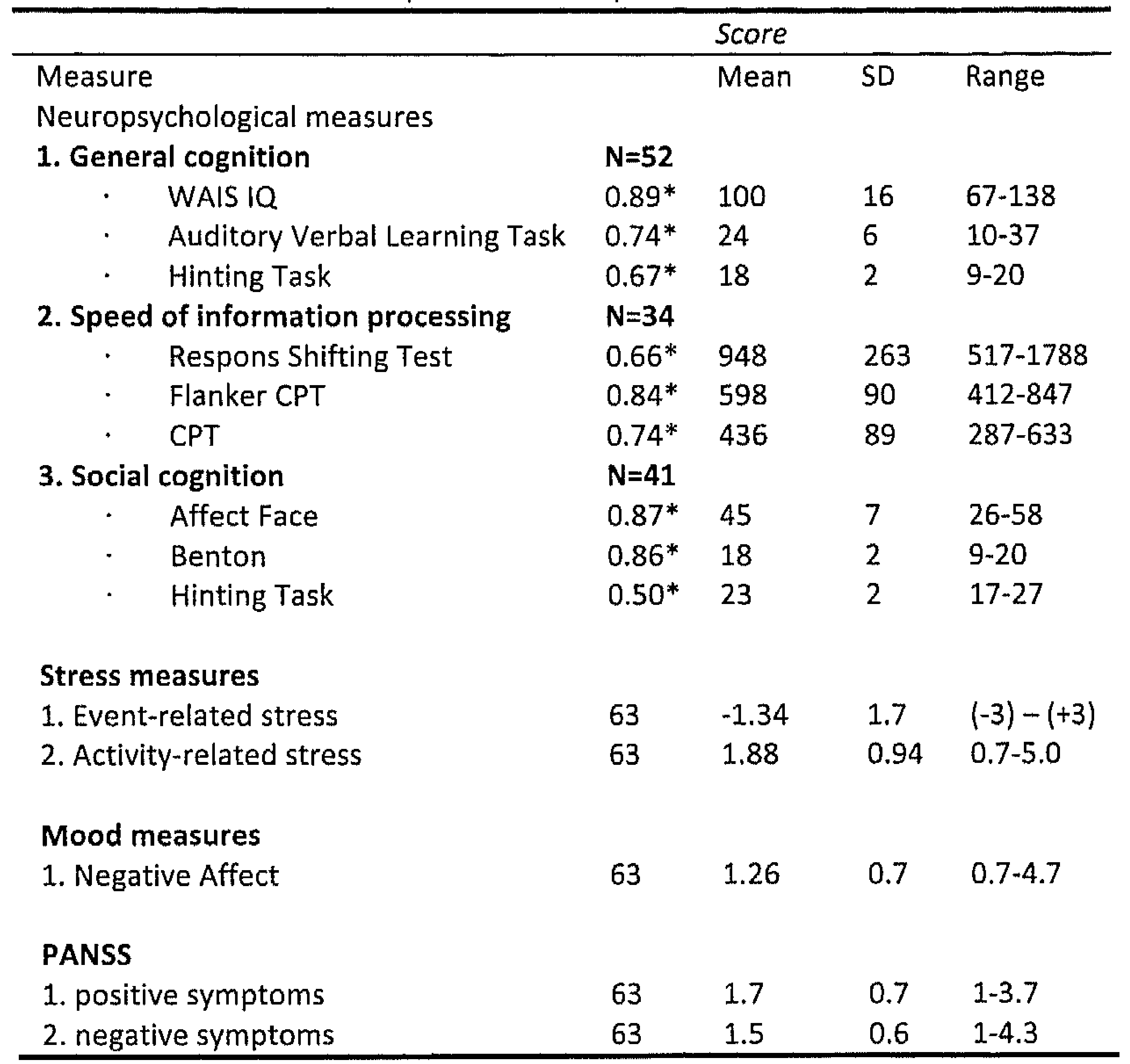

Factor loadings per cognitive test (these were used to calculate the factor scores for the analyses). Some of the factor loadings were inversely scored (negative value) in such a way that for all factor scores high values represent poor performance. 
ONTHE PATHWAY FROM STRESS TO PSYCHOSHS

Table 3. Multilevel regression analyses, investigating the effect of cognitive measures on the association between mood and stress (i.e. stress reactivity).

\begin{tabular}{|c|c|c|c|c|}
\hline & \multicolumn{4}{|c|}{ Negative Affect } \\
\hline & \multicolumn{4}{|c|}{ Event-related stress } \\
\hline & $\mathrm{N}^{*}$ & $\mathrm{~B}^{\mathrm{a}}$ & $95 \% \mathrm{Cl}^{\wedge}$ & $p^{5}$ \\
\hline General cognition & 52 & -0.0008 & $-0.004 ; 0.002$ & 0.640 \\
\hline Speed & 34 & 0.0001 & $-0.0001 ; 0.0003$ & 0.288 \\
\hline \multirow[t]{3}{*}{ Social Cognition } & 41 & -0.014 & $-0.0207 ;-0.008$ & 0.000 \\
\hline & \multicolumn{4}{|c|}{ Activity-related stress } \\
\hline & $\mathrm{N}^{*}$ & $\mathrm{~B}^{\mathrm{a}}$ & $95 \% \mathrm{Cl}^{\wedge}$ & $P^{S}$ \\
\hline General cognition & 52 & -0.004 & $-0.009 ; 0.0008$ & 0.096 \\
\hline Speed & 34 & 0.0001 & $-0.0002 ; 0.0004$ & 0.560 \\
\hline Social Cognition & 41 & -0.028 & $-0.0388 ;-0.017$ & 0.000 \\
\hline
\end{tabular}

* N: number of subjects included in the analyses

${ }^{a} \mathrm{~B}$ : regression coefficient representing the magnitude of the interaction term adjusted for use of alcohol and illicit drugs

$\wedge 95 \% \mathrm{Cl}: 95 \%$ confidence interval

swo-sided $P$ value 
CHAOTHA

Table 4. Multilevel linear regression analyses, assessing the association between stress-reactivity on the one hand and mean total scores on the positive and negative syndrome scale (PANSS) on the other.

\begin{tabular}{lllll}
\hline \multicolumn{5}{c}{ Negative Affect } \\
\hline \multicolumn{5}{c}{ Event-related stress } \\
PANSS & $N^{*}$ & B\# & $95 \% \mathrm{Cl}^{\wedge}$ & $\mathrm{P}^{\$}$ \\
Positive symptoms & 63 & 0.026 & $0.008 ; 0.044$ & 0.004 \\
Negative symptoms & 63 & -0.032 & $-0.051 ;-0.012$ & 0.002 \\
& & & & \\
PANSS & Activity-related stress & $p^{\$}$ \\
Positive symptoms & $N^{*}$ & B\# & $95 \% \mathrm{Cl} \wedge$ & 0.000 \\
Negative symptoms & 63 & 0.089 & $0.054 ; 0.123$ & 0.199 \\
\hline
\end{tabular}

* $N$ : number of subjects included in the analyses

\# B: regression coefficient representing the magnitude of the interaction term $\wedge 95 \% \mathrm{Cl}: 95 \%$ confidence interval

${ }^{5}$ two sided $P$ value 
ONTHE PATHWAY RROM STRESS TOPSYCHOSIS

Figure 1. Social Cognition and Stress-reactivity. Effect sizes of stressful events and activities on negative affect, stratified by level of performance on tests of social cognition in 41 patients with a diagnosis of schizophrenia or other psychosis.

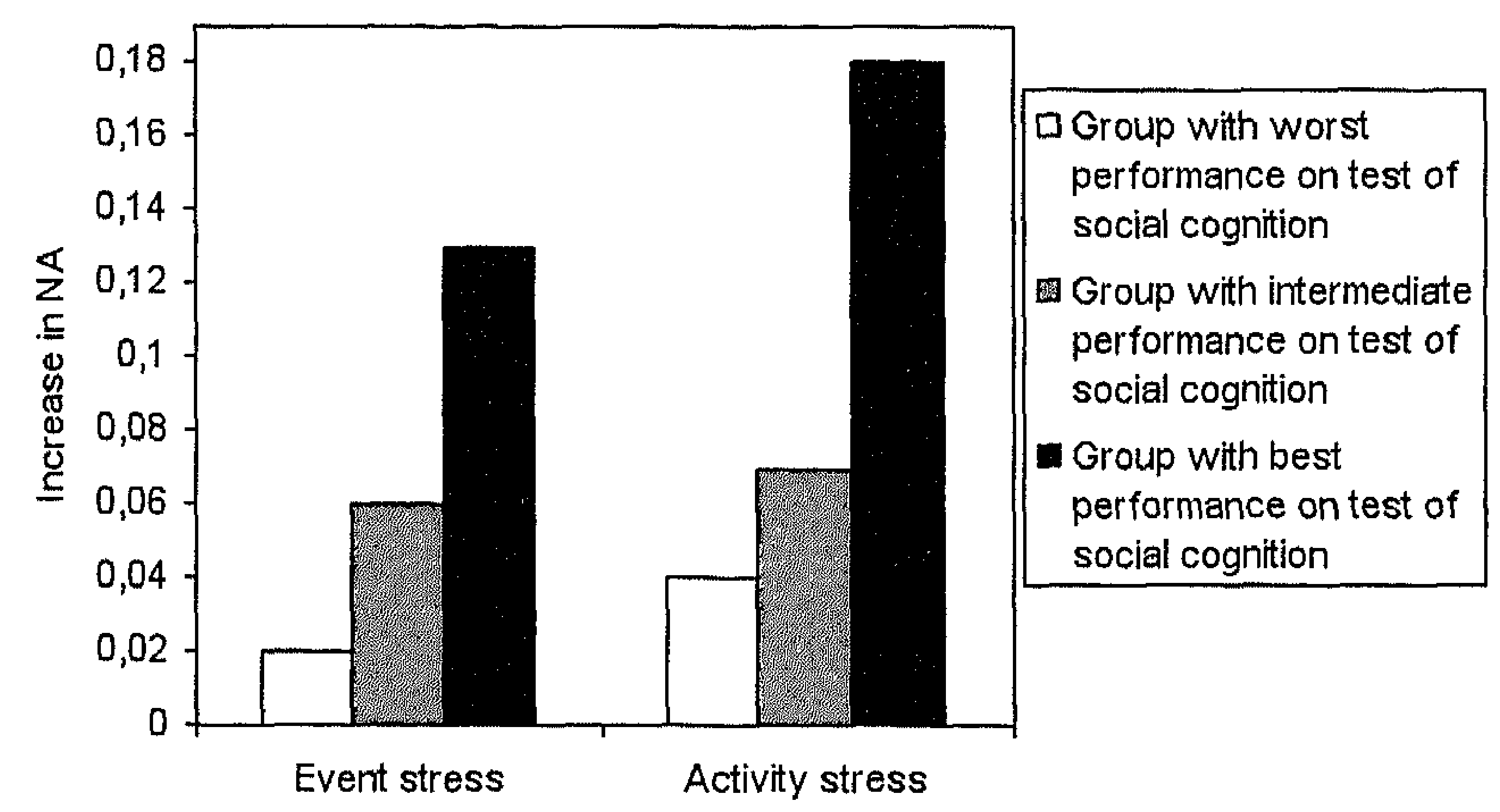


CHAPEA

Figure 2. Stress-reactivity and the positive and negative syndrome scale of the PANSS. Effect sizes of stressful events on negative affect: effect sizes of the affective response on stress levels 'pleasant' to 'very unpleasant' relative to the affective response of the reference category 'very pleasant', stratified by PANSS positive and negative syndrome score in 63 patients with a diagnosis of schizophrenia or other psychosis.

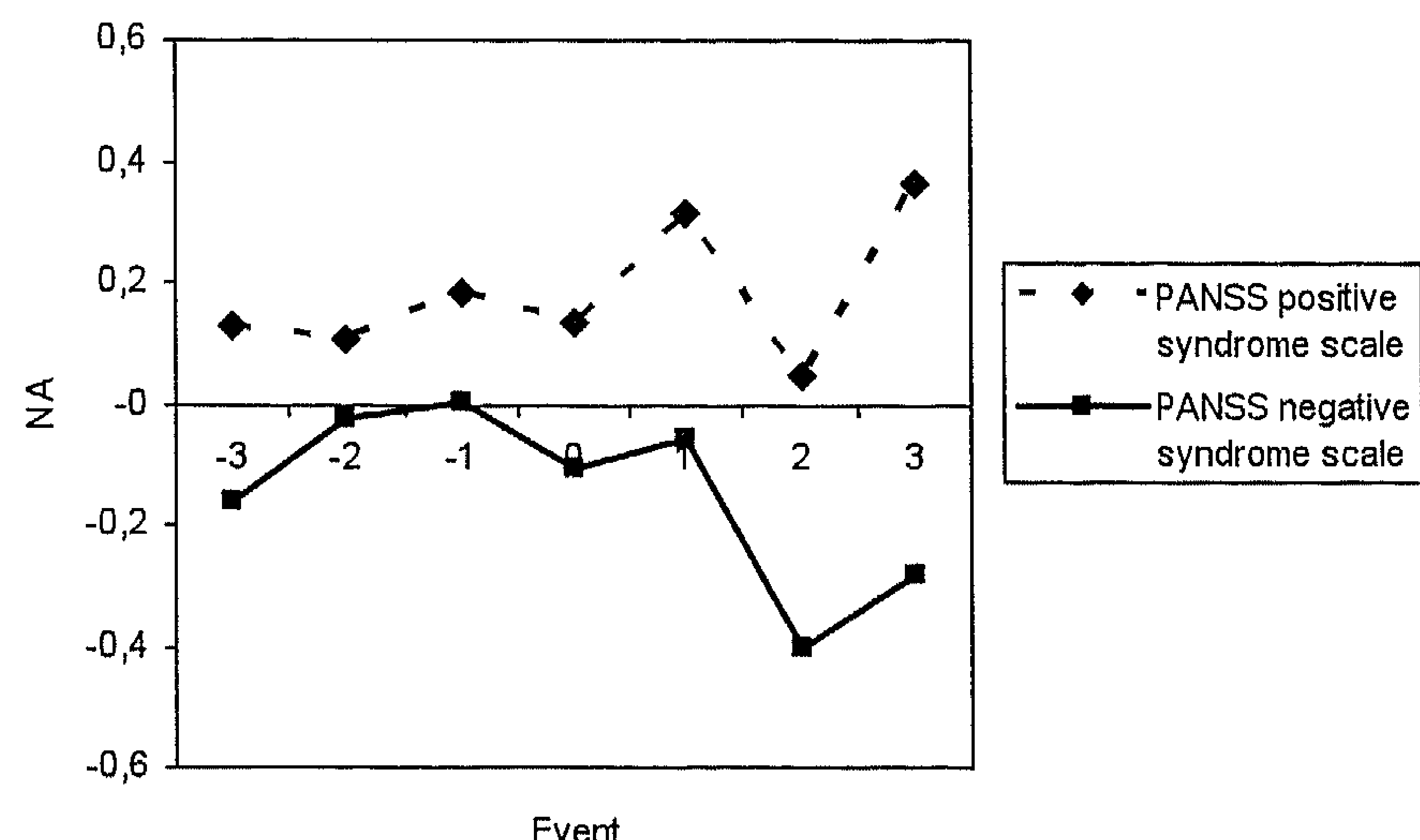




\section{References}

Andreasen N, Flaum M, Arndt S. 1992. The Comprehensive Assessment of Symptoms and History (CASH). An instrument for assessing diagnosis and psychopathology. Archives of General Psychiatry 49(8):615-623.

Andreasen NC. 1985. Positive vs. negative schizophrenia: a critical evaluation. Schizophr Bull 11(3):380-9. APA. 1994. Diagnostic and Statistica! Manual of Mental Disorders, Fourth Edition: Washington, DC: American Psychiatric Association.

Bentall RP, Corcoran R, Howard R, Blackwood N, Kinderman P. 2001. Persecutory delusions: a review and theoretical integration. Clin Psychol Rev 21(8):1143-92.

Benton AL, Sivan AB, Hamsher KS, Varney NR, Spreen O. 1978. Benton Facial Recognition. Stimulus and Multiple Choice Pictures.: Psichological Assessment Resources, Inc.

Bilder RM, Lipschutz-Broch L, Reiter G, Geisler SH, Mayerhoff DI, Lieberman JA. 1992. Intellectual deficits in first-episode schizophrenia: evidence for progressive deterioration. Schizophr Bull 18(3):437-48.

Birchwood M, lqbal Z, Upthegrove R, 2005. Psychological pathways to depression in schizophrenia: studies in acute psychosis, post psychotic depression and auditory hallucinations. Eur Arch Psychiatry Clin Neurosci 255(3):202-12.

Birchwood M, Trower P. 2006. The future of cognitive-behavioural therapy for psychosis: not a quasineuroleptic. Br J Psychiatry 188:107-8.

Broderick JE, Schwartz JE, Shiffman S, Hufford MR, Stone AA. 2003. Signaling does not adequately improve diary compliance. Ann Behav Med 26(2):139-48.

Corcoran R, Mercer G, Frith CD. 1995. Schizophrenia, symptomatology and social inference: investigating "theory of mind" in people with schizophrenia. Schizophr Res 17(1):5-13.

Cuesta MJ, Peralta V, Zarzuela A, Zandio M. 2006. Insight dimensions and cognitive function in psychosis: a longitudinal study. BMC Psychiatry 6:26.

Delespaul PAEG. 1995. Assessing schizophrenia in daily life. Maastricht: Universitaire Pers.

Dominguez MDG, Viechtbauer W, Simons, C.J.P., van Os J, Krabbendam L. 2008. Are psychotic psychopathology and neurocognition orthogonal? A systematic review of their associations. Psychological Bulletin submitted.

Eriksen B, Kann J. 1974. [Instruments of prevention]. Tandlaegebladet 78(16):670-6.

Garety PA, Fowler DG, Freeman D, Bebbington P, Dunn G, Kuipers E. 2008. Cognitive--behavioural therapy and family intervention for relapse prevention and symptom reduction in psychosis: randomised controlled trial. Br J Psychiatry 192(6):412-23.

Garety PA, Kuipers E, Fowler D, Freeman D, Bebbington PE. 2001. A cognitive model of the positive symptoms of psychosis. Psychol Med 31(2):189-95.

Green AS, Rafaeli E, Bolger N, Shrout PE, Reis HT. 2006. Paper or plastic? Data equivalence in paper and electronic diaries. Psychol Methods 11(1):87-105.

Gumley A, Karatzias A, Power K, Reilly J, McNay L, O'Grady M. 2006. Early intervention for relapse in schizophrenia: impact of cognitive behavioural therapy on negative beliefs about psychosis and selfesteem. Br J Clin Psychol 45(Pt 2):247-60.

Hodel B, Brenner HD, Merlo MC, Teuber JF. 1998. Emotional management therapy in early psychosis. Br J Psychiatry Suppl 172(33):128-33.

Jacobs N, Nicolson NA, Derom C, Delespaul P, van Os J, Myin-Germeys 1. 2005. Electronic monitoring of salivary cortisol sampling compliance in daily life. Life Sci 76(21):2431-43.

Janssen I, Versmissen D, Campo JA, Myin-Germeys I, van OS J, Krabbendam L. 2006. Attribution style and psychosis: evidence for an externalizing bias in patients but not in individuals at high risk. Psychol Med 36(6):771-8.

Kapur S. 2003. Psychosis as a state of aberrant salience: a framework linking biology, phenomenology, and pharmacology in schizophrenia. Am J Psychiatry 160(1):13-23. 


\section{CMAPERA}

Kay SR, Fiszbein A, Opler LA. 1987. The Positive and Negative Syndrome Scale (PANSS) for schizophrenia. . Schizophrenia Bulletin 13:261-276.

Lataster T, Wichers MC, Jacobs N, Mengelers R, Derom C, Thiery E, van Os J, Myin-Germeys I. 2008. Does reactivity to stress cosegregate with subclinical psychosis? Findings from a general population twin study. Acta Psychiatrica Scandinavica Submitted.

Lezak MD. 1995. Neuropsychological Assessment. New-York: Oxford University Press.

McGorry PD, Bell RC, Dudgeon PL, Jackson HJ. 1998. The dimensional structure of first episode psychosis: an exploratory factor analysis. Psychol Med 28(4):935-47.

Morrens M, Krabbendam L, Bak M, Delespauf P, Mengelers R, Sabbe B, Hulstijn W, van Os J, MyinGermeys I. 2007. The relationship between cognitive dysfunction and stress-sensitivity in schizophrenia. Social Psychiatry \& Psychiatric Epidemiology 42: 284-287.

Murray RM, O'Callaghan E, Castle DJ, Lewis SW. 1992. A neurodevelopmental approach to the classification of schizophrenia. Schizophr Bull 18(2):319-32.

Myin-Germeys I, Delespaul P, van Os J. 2005. Behavioural sensitization to daily life stress in psychosis. Psychol Med 35(5):733-41.

Myin-Germeys I, Krabbendam L, Jolles J, Delespaul PA, van Os J. 2002. Are cognitive impairments associated with sensitivity to stress in schizophrenia? An experience sampling study. Am J Psychiatry 159(3):443-9.

Myin-Germeys I, Oorschot M, Collip D, Lataster J, Delespaul, P, van Os, J. 2009. Experience sampling research in psychopathology: opening the black box of daily life. Psych Med, epbub ahead of print.

Myin-Germeys I, van Os J. 2007. Stress-reactivity in psychosis: evidence for an affective pathway to psychosis. Clin Psychol Rev 27(4):409-24.

Myin-Germeys I, van Os J, Schwartz JE, Stone AA, Delespaul PA. 2001. Emotional reactivity to daily life stress in psychosis. Arch Gen Psychiatry 58(12):1137-44.

Nestor PG, Faux SF, McCarley RW, Shenton ME, Sands SF. 1990. Measurement of visual sustained attention in schizophrenia using signal detection analysis and a newly developed computerized CPT task. Schizophr Res 3(5-6):329-32.

Pilling S, Bebbington P, Kuipers E, Garety P, Geddes J, Orbach G, Morgan C. 2002. Psychological treatments in schizophrenia: I. Meta-analysis of family intervention and cognitive behaviour therapy. Psychol Med 32(5):763-82.

Pinkham AE, Penn DL, Perkins DO, Lieberman J. 2003. Implications for the neural basis of social cognition for the study of schizophrenia. Am J Psychiatry 160(5):815-24.

Robins E, Guze SB. 1970. Establishment of diagnostic validity in psychiatric illness: its application to schizophrenia. American Journal of Psychiatry 126(7):983-987.

Snijders T, Bosker R. 1999. Multilevel analysis: an introduction to basis and advanced multilevel modeling.

Statacorp. 2007. STATA Statistical Software: Release 10.0 Texas, College Station.

Stone AA, Shiffman S, Schwartz JE, Broderick JE, Hufford MR. 2002. Patient non-compliance with paper diaries. Bmi 324(7347):1193-4.

Strauss JS. 1994. The person with schizophrenia as a person. If: Approaches to the subjective and complex. Br J Psychiatry Suppl(23):103-7.

Valmaggia LR, van der Gaag M, Tarrier N, Pijnenborg M, Slooff CJ. 2005. Cognitive-behavioural therapy for refractory psychotic symptoms of schizophrenia resistant to atypical antipsychotic medication. Randomised controlled trial. Br J Psychiatry 186:324-30.

van 't Wout M, Aleman A, Kessels RP, Cahn W, de Haan EH, Kahn RS. 2007. Exploring the nature of facial affect processing deficits in schizophrenia. Psychiatry Res 150(3):227-35.

van Hooren S, Versmissen D, Janssen I, Myin-Germeys I, J AC, Mengelers R, van OS J, Krabbendam L. 2008. Social cognition and neurocognition as independent domains in psychosis. Schizophr Res.

van Os J, Verdoux H. 2001. Diagnosis and classification of schizophrenia: Categories versus dimensions, distributions versus disease. In: Murray RM, Jones PB, Susser E, van Os J, Cannon M, editors. The epidemiology of schizophrenia. Cambridge: Cambridge University Press. 


\section{ON THE PATHWAY FOM SHRESTOPSYCHOSH}

Vauth R, Rusch N, Wirtz M, Corrigan PW. 2004. Does social cognition influence the relation between neurocognitive deficits and vocational functioning in schizophrenia? Psychiatry Res 128(2):155-65.

Ventura J, Green MF, Shaner A, Liberman RP. 1993. Training and quality assurance with the Brief Psychiatric Rating Scale: "the drift busters". Int J Methods Psychiatr Res 3:221-244.

Walker E, Mittal V, Tessner K. 2008. Stress and the hypothalamic pituitary adrenal axis in the developmental course of schizophrenia. Annu Rev Clin Psychol 4:189-216.

Wechsler D. 2001. Wechsler Adult Intelligence Scale III Manual. New-York: Psychological Corp. 


\section{Chapter 5}

\section{Increased reactivity to stress clusters within families of patients with non-affective psychosis}

T. Lataster ${ }^{1}$, D. Collip ${ }^{1}$, M. Lardinois ${ }^{1}$, J. van $0 s^{1,2}$, I. Myin-Germeys ${ }^{1,3}$

\footnotetext{
${ }^{1}$ Department of Psychiatry and Neuropsychology, South Limburg Mental Health Research and Teaching Network, EURON, P.O. box 616, 6200 MD, Maastricht University, The Netherlands.

${ }^{2}$ Division of Psychological Medicine \& Psychiatry, Institute of Psychiatry, King's College London, UK.

${ }^{3}$ School of Psychological Sciences, University of Manchester, UK.
}

American Journal of Medical Genetics Part B: Neuropsychiatric Genetics, submitted 
ONTHE PATHWAY FOM TRESSTO PSYCHOSIS

\section{ABSTRACT}

Background: Increased stress-reactivity has been reported in subjects who are at increased risk to develop psychosis. Moreover, it has been suggested that stressreactivity may be specifically related to the development of positive symptoms. To add evidence to the hypothesis that stress-reactivity is an endophenotype for a positive syndrome of psychosis, the present study examined: i) whether stressreactivity clusters within families of psychotic patients, and (ii) whether stressreactivity in relatives cosegregates with positive symptoms in patients.

Methods: The sample consisted of 47 patients with a diagnosis of psychotic disorder and their siblings $(n=47)$. The Experience Sampling Method (ESM - a structured diary technique) was used to measure stress-reactivity, defined as the increase in negative affect in reaction to stress in daily life. Positive symptoms in patients were measured with the Positive and Negative Syndrome Scale.

Results: Within-trait, cross-sib associations showed a significant association between stress-reactivity in the patient and stress reactivity in their first-degree relative. Additionally, significant cross-trait, cross-sib associations were established showing a significant association between the patient's positive symptoms and stress-reactivity in the first-degree relative.

Discussion: This study provided evidence for familial transmission of increased stress-reactivity. Furthermore, increased stress-reactivity levels in the sibling were associated with increased positive symptom intensity in the patients. These results thus suggest a possible genetic contribution to increased stress-reactivity, which is specifically underiying the positive dimension of psychosis. 


\section{Introduction}

The search for causal mechanisms of schizophrenia has lead to an increased interest in the study of intermediary phenotypes (Gottesman and Gould 2003; Tsuang 2001; Weinberger 1999). These risk indicators are more closely related to genetic aetiology and its interaction with environmental risk factors which makes them good candidates for revealing mechanisms that lead to the development of psychotic symptoms (Claridge 1994).

Emotional reactivity to stress seems a potent intermediary phenotype. Increased emotional reactivity to stress has been identified both in subjects at genetic risk for psychosis (first-degree relatives and patients in clinical remission), and in subjects at psychometric risk for psychosis (subjects scoring high on a psychosis liability scale) (Lataster and others 2008; Myin-Germeys and others 2001). However, a genetic contribution could not be inferred since previous studies used genetically unrelated subjects (Myin-Germeys and others 2003; Myin-Germeys and others 2002; MyinGermeys and others 2001).

Increased stress-reactivity has been specifically related to the development of positive psychotic symptoms (Lataster and others submitted). Patients with positive symptoms are characterized by an increased stress-sensitivity (Lataster and others submitted), and both patients and relatives tend to react with positive psychotic symptoms to small stresses that happen to them in daily life reality (Myin-Germeys and others 2005). In addition, this increased stress-reactivity is independent of cognitive performance (Lataster and others submitted; Morrens and others 2007; MyinGermeys and others 2002), another well-known intermediary phenotype.

The current study was designed to investigate a possible genetic contribution to stress-reactivity and its association with positive psychotic symptoms. Exploring familial covariation of these factors within affected families offers an elegant way to investigate the possible influence of genes, since covariance is suggestive of familial transmission. A semi-genetically sensitive sample of patients with psychosis and their siblings was used to examine (i) whether increased stress-reactivity in the patient is associated with increased stress-reactivity in the sibling (i.e. does stressreactivity cluster within families?), and (ii) whether increased stress-reactivity in the sibling is associated with the presence of positive symptoms in the patient.

\section{Method}

Subjects

The sample consisted of 72 patients with a psychotic disorder and 80 siblings (brothers and sisters) of these patients. Subjects were recruited through in- and outpatient mental health service facilities in South-Limburg, The Netherlands and in Flan- 
ders, Belgium. Prior to entering the study, all subjects were screened. All interviews were conducted by trained research assistants, a clinical/ neuropsychologist (M.L.) and a neuropsychologist (T.L.). The Brief Psychiatric Rating Scale (Overall and Gorham 1962; Ventura and others 1993) and the Positive and Negative Syndrome Scale (Kay and others 1987) were used to assess psychiatric symptoms regarding the two weeks prior to study entry. The CASH (Andreasen and others 1992) was completed to assess symptom history over the past six months and lifetime, yielding DSM-IV diagnoses (APA 1994).

Inclusion criteria for patients were: (1) lifetime occurrence of psychotic symptoms, according to DSM-IV criteria; (2) age 16 to 56 years; (3) sufficient command of the Dutch language. The inclusion criteria for siblings were: (1) age 18 to 55 years, and (2) sufficient command of the Dutch language. Patients were recruited through inpatient and outpatient mental health service facilities, and through patient associations in the southern part of the Netherlands and the northern part of Belgium. The sibling group was recruited by asking the patients to inform their brothers and sisters about the study. Written informed consent, confirming to local ethics committee guidelines, was obtained from all subjects.

\section{Experience sampling method}

The experience sampling method (ESM) was used to measure the emotional reaction to stress in the flow of daily life (hereafter: "stress reactivity") (Myin-Germeys and others 2003a; Myin-Germeys and van Os 2007). ESM is a within-day, momentary self-assessment technique (Myin-Germeys and others 2009). Subjects received a digital wristwatch and self-assessment forms collated in a booklet for each day. Ten times a day on six consecutive days, the watch emitted a signal (beep) at unpredictable moments between 7:30 a.m. and 10:30 p.m. Subjects were asked to report immediately after each beep their thoughts, current context (activity, persons present, location), appraisals of the current situation, and mood. All selfassessments were rated on 7-point Likert scales. Subjects were informed about the ESM procedure during an initial briefing session. A practice form was completed to confirm that subjects were able to understand the 7-point Likert scale format. Subjects were instructed to complete their reports immediately after the beep, thus minimizing memory distortion, and to record the time at which they completed the form. Research staff called each subject several times during the actual sampling period to assess whether they were complying with the instructions. In order to determine the reliability of the completed reports, the times at which the watch emitted a signal and the times at which subjects completed the reports were compared. All reports completed more than 15 minutes after the beep were excluded from the analyses. Previous research (Delespaul 1995) has shown that reports completed after this interval are less reliable and consequently less valid. For the same 


\section{CHAPER}

reason, subjects with fewer than 20 valid reports (out of 60 ) were excluded from the analysis (Delespaul 1995).

\section{Assessment of mood and stress}

Measures of mood and stress were derived from the ESM reports as follows.

Assessment of mood. ESM negative affect was assessed at each beep with 6 moodrelated adjectives (down, guilty, insecure, lonely, anxious, angry/ irritated) rated on 7-point Likert scales ( $1=$ not at all, $7=$ very). The six mood adjectives were reduced to one measure of Negative Affect (NA) by means of principal component factor analysis of the entire sample followed by varimax rotation, using STATA version 10 (Statacorp 2007). Based on the scree plot, a one-factor solution was chosen, accounting for $60 \%$ of the total variance (factor loadings down: 0.85 , guilty: 0.79 , lonely: 0.74 , insecure: 0.81 , anxious: 0.80 , and angry/ irritated: 0.62 ). Factor scores (NA) were used in the analyses. For this purpose, the score on each of the six mood adjectives was multiplied by its own factor loading (Cronbach's $\alpha=0.86$ ).

Assessment of stress. In accordance with previous work, stress was conceptualized as the subjectively appraised stressfulness of distinctive events (event-related stress) as well as of minor disturbances that continually happen in the flow of daily life (activity-related stress) (Myin-Germeys and van Os 2007). In order to measure event-related stress, the subject was asked to report, after each beep, the most important event that had happened between the current and the previous report. This event was subsequently rated on a bipolar Likert scale (-3=very unpleasant, $0=$ neutral, $3=$ very pleasant). The responses were recoded to allow high scores to reflect stress $(-3=$ very pleasant, $0=$ neutral, $3=$ very unpleasant $)$.

In order to measure activity-related stress, the subject rated, after each beep, aspects relating to current activity using three self-report items scored on 7-point Likert scales ( $1=$ not at all, $7=$ very). The mean weighted factor score on the three items "I would rather do something else", "This is something I am good at", and "This activity requires effort" formed the activity-related stress scale (Cronbach's $\alpha=$ $0.55)$.

Assessment of symptoms: Positive and Negative Syndrome Scale

All patients were assessed with the Positive and Negative Syndrome Scale (PANSS) (Kay and others 1987) at the end of the ESM week. The PANSS constitutes a positive symptom scale, a negative symptom scale, and a general symptom scale. For the present study we used the positive and negative symptoms scale each of which include seven items scored on a 7-point scale ( $1=a b s e n t, 7=e x t r e m e)$. The mean scores on both the positive and negative scale were used. 
ON THE PATHWAY ROM STRESS TOPSYCHOSIS

\begin{abstract}
Analyses
ESM data have a hierarchical structure: Multiple observations (level 1) are nested within subjects (level 2), who were in some cases part of sib pairs (level 3). In order to take the 3-level grouping structure of the data (ESM beep level observations, subject, sib pair) into account, multilevel random regression analysis (Snijders and Bosker 1999) was applied in STATA, version 10.0 (Statacorp 2007), using the XTMIXED command. Mixed models are characterized as containing both fixed and random effects. The fixed effects are analogous to conventional regression coefficients $(B)$ and are estimated directly.
\end{abstract}

\title{
1. Stress-reactivity
}

Using ESM data, stress-reactivity was defined as the increase in NA in reaction to stress. To investigate the association between stress and NA in the flow of daily life (i.e. stress reactivity), multilevel linear regression analyses were conducted (regression model: $N A=B O+B 1$ stress + residual)

\section{Within-trait, cross-sib stress-reactivity}

For each individual patient, a multilevel regression analysis was conducted over the multiple reports to calculate the individual stress reactivity level (regression model: $N A \_P=B O+B 1$ stress_P + residual). The regression coefficient was used as the stress-reactivity measure of the patient in the next analyses (Stress_reac_P).

To examine the association between stress reactivity in the sibling and stress reactivity in the patient, within-trait, cross-sib multilevel linear regression analyses (see Figure 1) were conducted with Negative Affect (NA_S) of the sibling as the dependent variable, the stress measure of the sibling (stress_S), the stress-reactivity measure of the patient (stress-reac_P) as well as their interactions (stress_S $x$ stress_reac_P) as the independent variables (general model: NA_S $=B 0+B 1$ stress_S + B2stress_reac_P + B3stress_S X stress_reac_P + residual). This model was fitted for both stress measures independently. The interaction term is the focus of these analyses, since the hypothesis required testing whether stress reactivity in the patient moderated the association between stress and the intensity of NA in the sibling.

\section{Cross-trait, cross-sib analyses}

Given genetic effects on psychotic experiences (Kendler and Hewitt 1992; Linney and others 2003; MacDonald and others 2001), a strict way of testing the hypothesis that stress-reactivity is an unconfounded and uncontaminated mechanisms underlying the positive symptoms of psychosis, is to test whether the association between stress-reactivity and positive symptom scores can be replicated within and across genetically related subjects, using both cross-trait within sib, and cross-trait cross-sib analyses (figure 2 , page 90 ). In a cross-trait within-sib analysis, the associa- 


\section{CHPTER}

tion between trait $x$ and $y$ is tested within one person. However, since both traits are tested within the same person, trait $x$ may be contaminated by trait $y$ or both traits may be moderated by other traits of that person. Therefore, cross-trait crosssib analyses have been used in this study, in which trait $x$ in the sibling is associated with trait $y$ in the patient. Since trait $y$ is now assessed in a different person, trait $x$ cannot be contaminated by trait $y$. This method thus ensures that the association between $x$ and $y$ - in this case stress-reactivity and positive psychotic symptoms - is uncontaminated. Cross-trait, cross-sib analyses were conducted to examine the association between stress reactivity in the sibling on the one hand and positive psychotic symptoms in the patient, measured with the PANSS, on the other. For these analyses, NA_S was entered in the model as the dependent variable, whereas mean scores on the positive symptom scale of the patient (symptoms_P), the ratings on the two stress measures of the siblings (stress_S), and their interactions (stress_S x symptoms_P), were the independent variables (general model: NA_S $=B 0$ + B1stress_S + B2 symptoms_P + B3stress_S x symptoms_P + residual). Again, the interaction term was the focus of these analyses, since the hypothesis required testing whether positive symptoms in the patient moderated the association between stress and NA intensity in the sibling. Stratified analyses were conducted whenever a significant interaction effect was found.

\section{Results}

\section{Subjects and Descriptives}

The final sample consisted of 72 patients and 80 relatives. Of this sample, 71 patients (one dropped out) and 80 relatives completed ESM reports yielding a total of 5992 beeps with a mean of 41 beeps per subject. A further 8 patients and 12 relatives were excluded because they had fewer than 20 valid ESM self-reports (i.e. 63 patients and 68 siblings remained). Of the remaining subjects, 34 patients participated with their sibling (e.g. brother or sister), 5 patients participated with two of their siblings, and one patient participated with three of his siblings. Thus, in the within-trait, cross-sib analyses a total of 47 patient-sibling pairs were included. Demographic and clinical statistics of the sample are shown in Table 1, and the mean scores on the independent and dependent variables are shown in Table 2.

\section{Stress-reactivity}

Multilevel analyses showed significant interaction effects between status and both stress measures in the model of NA (event stress: $B=0.04,95 \% \mathrm{Cl}: 0.19-0.06, P$ $=0.000$, and activity stress: $\mathrm{B}=0.08,95 \% \mathrm{Cl}: 0.04-0.12, \mathrm{P}=0.000)$. Stronger emotional reactions to daily life stress were found in patients compared to siblings (see Figure 1, page 90 ). 


\section{Within-trait, cross-sib stress-reactivity}

The within-trait, cross-sib multilevel random regression analyses (see Figure 2, page 90) showed a significant interaction effect between stress-reactivity in the sibling on the one hand and stress-reactivity in the patient on the other for both activity $(\beta=0.15,95 \% \mathrm{Cl}: 0.06-0.24, P=0.001)$ and event related stress $(\beta=0.13,95 \% \mathrm{Cl}: 0.02-$ $0.24, P=0.024)$, indicating that siblings of patients with high stress-reactivity are more reactive to stress in daily life themselves. These results indicate that stressreactivity indeed is transmitted within families.

\section{Cross-trait, cross-sib analyses}

The cross-trait, cross-sib multilevel random regression analyses (see Figure 2, page 90) showed a significant interaction effect between both activity- and event-related stress-reactivity in the sibling on the one hand and scores on the positive syndrome scale in the patient on the other $(\beta=0.055,95 \% \mathrm{Cl}: 0.023-0.086, P=0.001$ and $\beta=0.033,95 \% \mathrm{Cl}: 0.016-0.05, P=0.000$, respectively), indicating that the genetic contribution to the observed increased reactivity to stress in daily life is especially associated with positive symptoms of psychosis.

Stronger emotional reactions to stress in daily life, with larger increases in negative affect, were found in the siblings of patients with high and intermediate scores on the positive syndrome scale compared to patients with low scores on the positive syndrome scale of the PANSS (Figure 3, page 91).

\section{Discussion}

This study is the first to demonstrate that increased stress-reactivity clusters within families of patients with non-affective psychosis. Furthermore, the study found a significant association between increased stress-reactivity in the siblings and positive symptoms in the patients. These results suggest a possible genetic contribution to increased stress-reactivity, which is specifically underlying the positive dimension of psychosis.

\section{Stress-reactivity clusters within families}

The results of the present study show covariance of stress-reactivity within affected families. Increased stress-reactivity in sibling is associated with increased stressreactivity in the patient. These findings suggest common aetiological influences underlying stress-reactivity in the siblings and patients, and transmission of this intermediary phenotype within families. But what does this familial clustering of stress-reactivity tell us? Some have suggested that familial liability to psychosis mainly represents the influence of shared genes rather than shared environment (Cardno and others 2002). Most likely, however, an interplay between environmental factors and genetic factors underlies the familial transmission since both 
environmental factors, such as stressful life events and childhood trauma (Lardinois and others submitted; Myin-Germeys and others 2003b), and genetic factors (Jacobs and others 2006; Wichers and others 2007) give rise to an increased emotional reactivity to stress in daily life.

Evidence for a possible influence of genes can be found in studies showing an association between two functional polymorphisms, COMTVal158Met and BDNFVal66Met and increased psychotic reactions to stress in daily life. The catechol-O-methyltransferase gene (COMT Val158Met), a gene encoding for an important enzyme regulating prefrontal dopamine turnover, is predictive of increased dopamine synthesis in the midbrain and is generally thought to be involved in psychosis. Results from three recent studies suggest that this polymorphism may play a role in the emotional or psychotic reactions to stress in daily life (i.e. stressreactivity). One study showed a significant interaction effect between COMT Val158Met and the psychotic reactions to stress associated with entering the military (Stefanis and others 2007), with Val-allele carriers showing the largest increases in psychotic reactivity. Results from another study suggest that Val-allele carriers displayed more feelings of paranoia in response to event stress compared to Metallele carriers (Simons and others 2009), whereas the results of the other study (van Winkel and others 2008) suggested that patients with the Met-allele show the largest increase in psychotic experiences and negative affect in reaction to stress measured with ESM. The findings of these studies are thus far contradicting and more studies are needed to investigate the role of ComtVal158Met in stress-induced vulnerability to psychosis. Another functional polymorphism was recently identified in the Brain-Derived Neurotrophic Factor gene (BDNF Val66Met), a neurotrophin that promotes the growth and differentiation of developing neurons and the survival of neuronal cells in response to stress. It has been suggested that the $\mathrm{Val} / \mathrm{Val}$ variant is associated with higher BDNF secretion (Chen and others 2004), the $\mathrm{Val} /$ Met and Met/Met variant with decreased BDNF secretion. In line with this, the result of the study by Simons an colleagues (2009) suggest that BDNF Met-allele carriers respond with greater increases in psychotic reactivity to social stress in daily life when compared to Val-allele carriers.

Clustering of stress-reactivity within families may also result from the influence of epigenetic factors (Meaney and Szyf 2005; Weaver and others 2004). The term epigenetic refers to those gene-environment interactions where environmental factors impact on the DNA sequence or on DNA methylation. For example, it has been shown that early maternal behaviour in animals can affect offspring sensitivity to stress through altered DNA methylation of key neuronal receptor genes involved in the stress response (Meaney and Szyf 2005; Weaver and others 2004).

Additionally, clustering of stress-reactivity within sibling-pairs may be the results of genetic effects correlating with the environment, or purely by shared environmental 


\section{ON THE PATHWAY FROM STRESSTOPSYCHOSIS}

effects between siblings. However, as suggested earlier, this is unlikely to be the only explanation for the results found in the current study.

\section{An affective pathway to psychosis}

The results of the current study show that increased stress-reactivity in siblings is associated with increased levels of positive symptoms in the patients in an unconfounded and uncontaminated fashion. These findings add credence to the notion of an affective pathway to psychosis (Myin-Germeys and van Os 2007). Additionally, the current results are in line with findings from recent studies suggesting that increased stress-reactivity is an unconfounded, and partially independent, mechanism of risk specifically underlying the positive symptoms of psychosis (Lataster and others submitted; Lataster and others 2008). In a dimensional view of psychosis, stressreactivity could thus be argued to reflect a specific mechanism underlying the development of positive symptoms (Cuesta and others 2006; McGorry and others 1998). However, these findings also fit in with more traditional views of psychosis, which suggest that the extensive clinical heterogeneity in schizophrenia can be reduced to two main forms. The positive syndrome, or non-developmental, type I schizophrenia is characterized by a sudden onset, an episodic course, a good outcome, a good response to anti-psychotic drug treatment and high levels of positive symptoms (Andreasen 1985; Murray and others 1992). It is suggested that alterations at the level of neurotransmitter signalling, for example mesolimbic hyperdopaminergia secondary to abnormal activation of the hypothalamic-pituitary-adrenal axis (HPA-axis), play an important role and that this subtype is more sensitive to aversive environmental influences (Murray and others 1992).

\section{Limitations}

The results should be viewed in the light of several methodological issues. The ESM measurements are based on subjective reports. Therefore, it can be argued that the results are not psychometrically precise. However, although subjective reports are considered less reliable (e.g., do all subjects interpret or answer the questions identically?), previous research implies that subjective reports can be valid, and that the validity of objective reports should not be taken for granted (Strauss 1994).

Second, the current study used ESM, a daily life assessment technique in which subjects have to comply with a paper-and-pencil diary protocol without the researcher being present. Recently, some authors have cast doubt on the reliability and subject compliance in paper-and-pencil ESM studies, favoring the use of electronic devices (Broderick and others 2003; Stone and others 2002). However, in a comparative study, Green and colleagues concluded that both methods yielded similar results (Green and others 2006). In addition, a recent study using a signalcontingent random time sampling procedure with multiple observations per day similar to the protocol used in the current study - found evidence that underscores 


\section{CHAPEP}

the validity of the paper-and-pencil random time self-report data in the current study (Jacobs and others 2005).

Finally, stress-reactivity has been defined as the emotional reaction to subjective stress. The current results are based on cross-sectional analyses and therefore, the possibility of reverse causality cannot be excluded. There is a possibility that increased negative affect or increased levels of positive or negative symptoms influences the subjective appraisal of the environment. However, the individual would still experience psychosis or distress with an environmental event.

\section{Acknowledgments}

The authors wish to thank the research assistants of the GROUP project Maastricht who helped with the collection of the data. Tineke Lataster was supported by the Royal Dutch Academy of Scientific Research (2007 Van Walree grant). Inez MyinGermeys was supported by a 2006 NARSAD Young Investigator award and by the Dutch Medical Council (VENI and VIDI grant). 
ON THE PATHWAY ROM STRESTO PSYHOSIS

Table 1. Demographic and clinical characteristics.

\begin{tabular}{|c|c|c|c|c|c|}
\hline \multicolumn{2}{|c|}{ Charachteristic } & patients & siblings & $\begin{array}{l}\text { Mean } \\
(S D)\end{array}$ & Range \\
\hline \multirow{2}{*}{\multicolumn{2}{|c|}{ Age (vears) patients }} & & & 30.5 & $17-50$ \\
\hline & & & & $(9.4)$ & \\
\hline \multirow{2}{*}{\multicolumn{2}{|c|}{ siblings }} & & & 31.1 & $16-53$ \\
\hline & & & & $(9.4)$ & \\
\hline \multicolumn{6}{|c|}{ Gender } \\
\hline · & Male & $60 \%$ & $40 \%$ & & \\
\hline$\cdot$ & Female & $40 \%$ & $60 \%$ & & \\
\hline \multicolumn{6}{|c|}{ Marital Status } \\
\hline · & Married or living together & $16 \%$ & $53 \%$ & & \\
\hline · & Divorced & $5 \%$ & $1 \%$ & & \\
\hline · & Never married & $79 \%$ & $46 \%$ & & \\
\hline \multicolumn{6}{|c|}{ Work situation } \\
\hline$\cdot$ & Working & $13 \%$ & $62 \%$ & & \\
\hline · & Unable to work & $69 \%$ & $6 \%$ & & \\
\hline · & Working in protected environment & $5 \%$ & $1 \%$ & & \\
\hline · & School/ education & $13 \%$ & $31 \%$ & & \\
\hline \multicolumn{6}{|c|}{ Education } \\
\hline$\cdot$ & Elementary school & $6 \%$ & $1 \%$ & & \\
\hline · & Secondary school & $65 \%$ & $2 \%$ & & \\
\hline . & Higher Education & $29 \%$ & $97 \%$ & & \\
\hline \multirow{2}{*}{\multicolumn{2}{|c|}{ Total PANSS score patients $(n=40)$}} & & & 11.8 & $7-26$ \\
\hline & & & & $(4.4)$ & \\
\hline \multirow{2}{*}{\multicolumn{2}{|c|}{ Age at first psychotic episode (years) }} & & & 23.4 & $13-44$ \\
\hline & & & & $(7.3)$ & \\
\hline \multicolumn{2}{|c|}{ Number of episodes } & & & 2.4 & $1-6$ \\
\hline \multicolumn{2}{|c|}{ CASH DSM-IV Axis I diagnosis lifetime } & $N=40$ & $N=47$ & & \\
\hline$\cdot$ & Schizophrenia & 27 & - & & \\
\hline - & Schizoaffective disorder & 6 & - & & \\
\hline - & Psychotic disorder NOS & 3 & - & & \\
\hline - & Brief psychotic disorder & 3 & - & & \\
\hline • & Delusional disorder & 1 & - & & \\
\hline · & Major Depressive Disorder & - & 11 & & \\
\hline - & No Diagnosis or Condition on Axis I & - & 36 & & \\
\hline
\end{tabular}


CHPTER

Table 2. Mean scores on the dependent and independent variables.

\begin{tabular}{|c|c|c|c|c|}
\hline & & Score & & \\
\hline Measure & & Mean & SD & Range \\
\hline \multicolumn{5}{|l|}{ Stress measures } \\
\hline 1. Event-related stress patients & 40 & -1.3 & 1.6 & $(-3)-(+3)$ \\
\hline 2. Activity-related stress patients & 40 & 1.9 & 1.0 & $0.7-5.1$ \\
\hline 1. Event-related stress siblings & 47 & -1.5 & 1.5 & $(-3)-(+3)$ \\
\hline 2. Activity-related stress siblings & 47 & 1.7 & 0.8 & $0.7-5.1$ \\
\hline 1. Negative Affect patients & 40 & 1.44 & 0.9 & $0.8-5.4$ \\
\hline 1. Negative Affect siblings & 47 & 0.99 & 0.5 & $0.8-4.1$ \\
\hline \multicolumn{5}{|l|}{ PANSS } \\
\hline 1. positive symptoms patients & 40 & 1.7 & 0.6 & $1-3.7$ \\
\hline
\end{tabular}


Figure 1. Stress-reactivity for different levels of vulnerability. Effect sizes of stressful events and activities on negative affect, stratified by status level ( $0=$ =iblings, $1=$ patients).

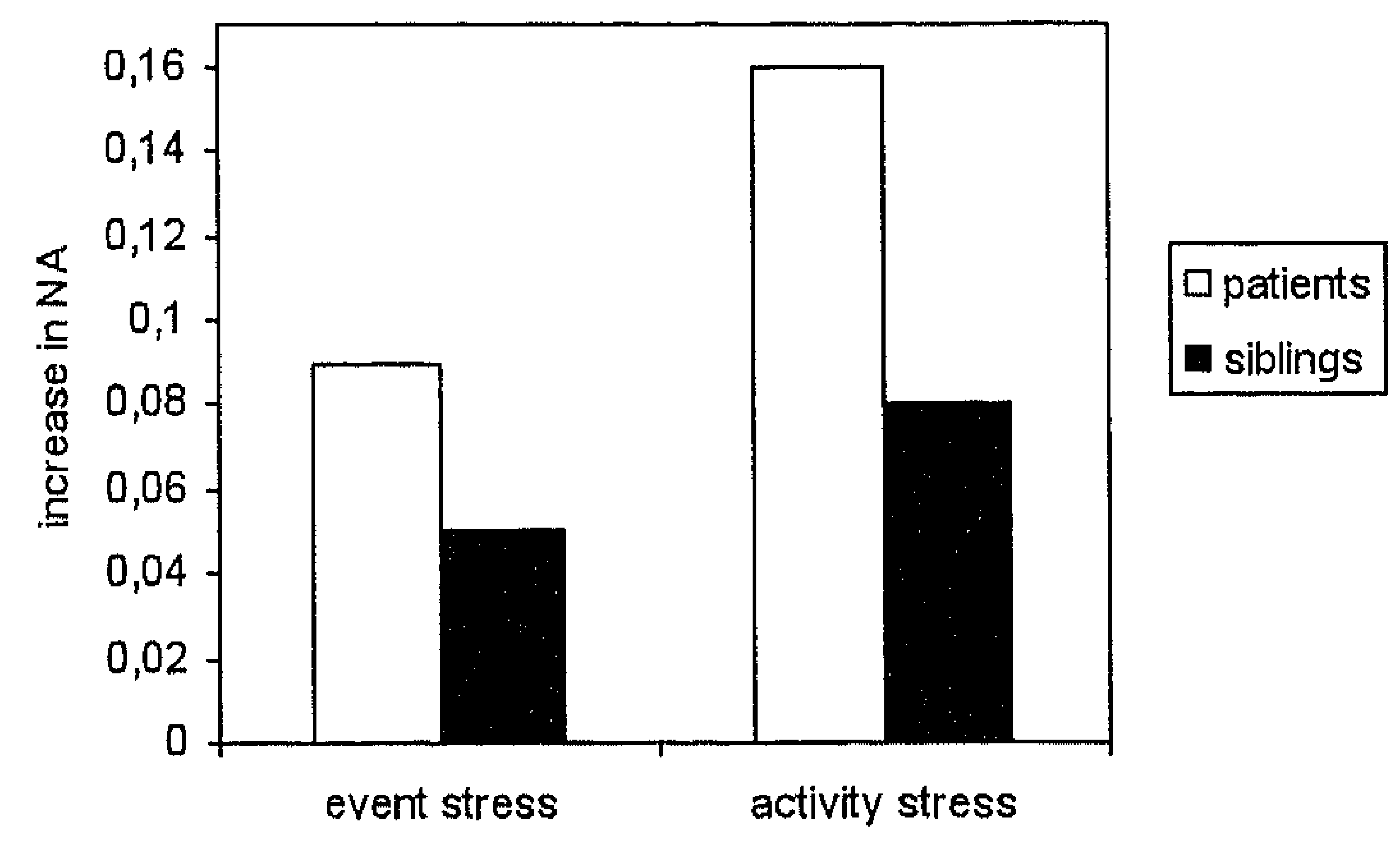

Figure 2. Dotted arrow: Within-trait, cross-sib association. Solid arrow: Cross-trait, cross-sib association; examination of the association between stress reactivity (trait 1 ) in the sibs and psychosis (trait 2) in the patients.

SIBLING PATIENT

TRAIT 1

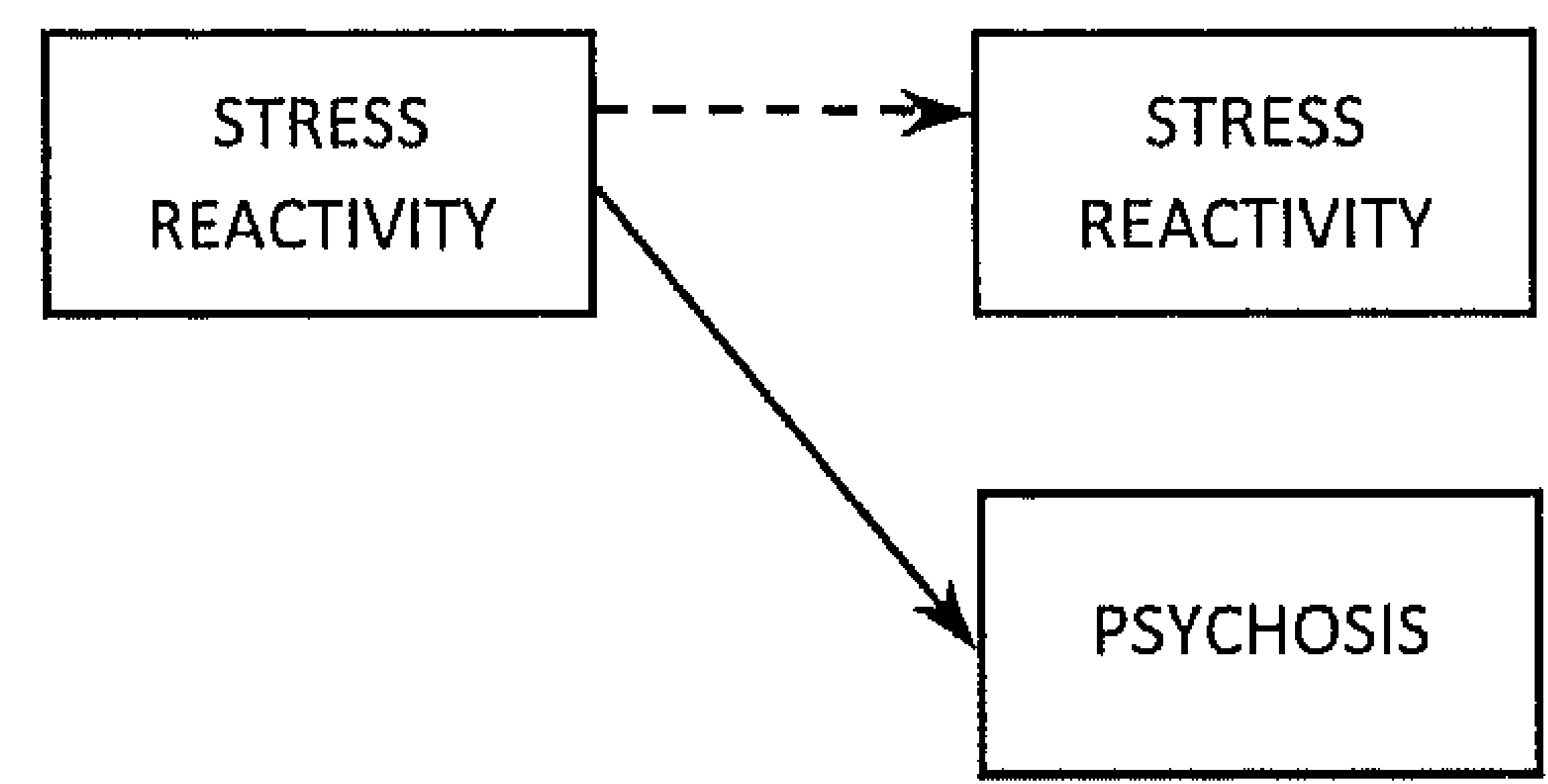




\section{CWAPER 5}

Figure 3. Sibling stress-reactivity and positive symptoms in patients. Association between event- and activity-related stress in the sibling in relation to scores on the positive syndrome scale in the patients. Effect sizes of stressful events and activities on negative affect in siblings ( $N=47)$, stratified by level of positive symptom scores on the PANSS in 47 patients with a diagnosis of non-affective psychosis.

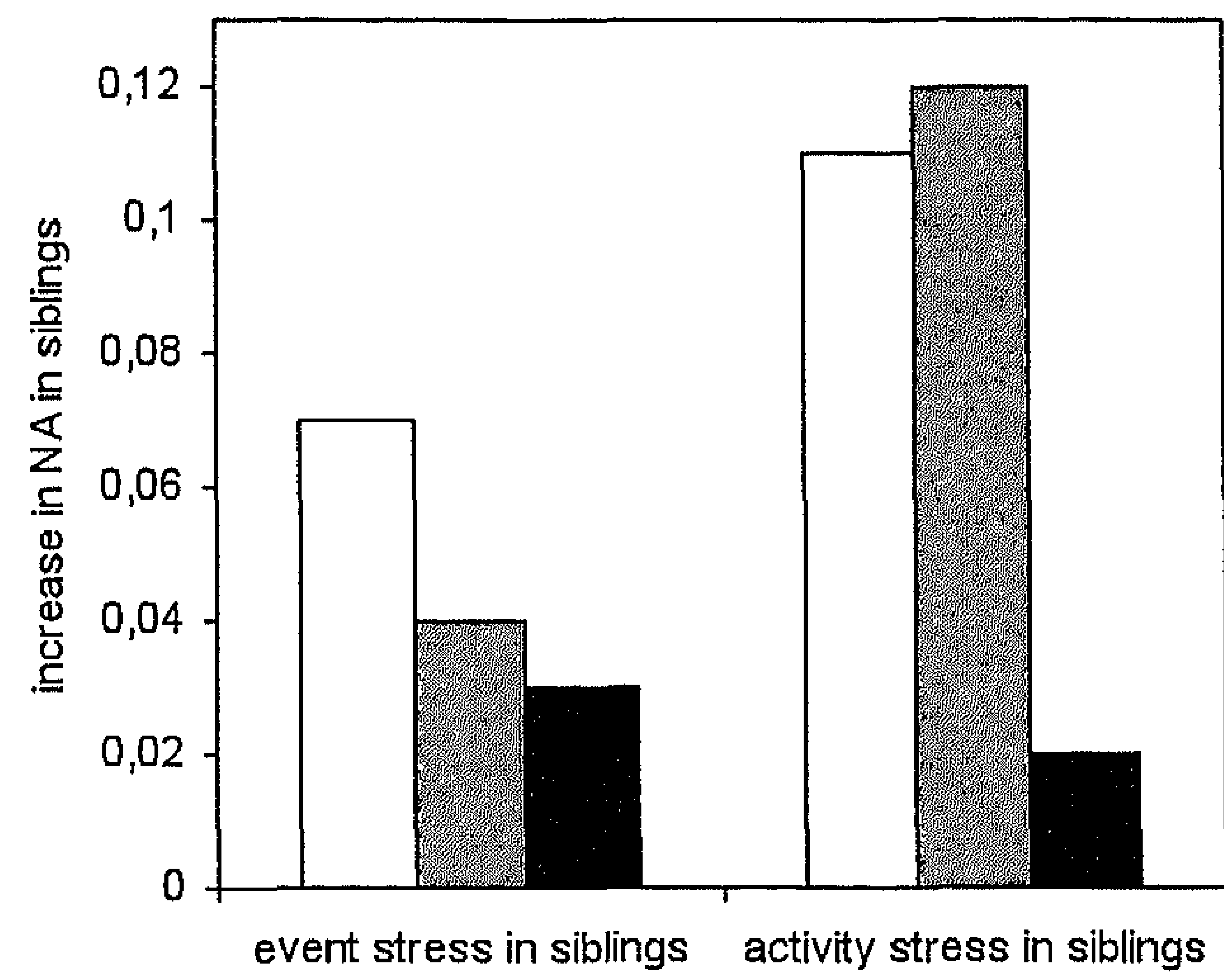

Qhigh levels of positive symptoms in patients

圆 intermediate levels of positive symptoms in patients

low levels of positive symptoms in patients 


\section{ON THE PATHWRY FROM STRESSTO PSYCHOSD}

\section{References}

Andreasen N, Flaum M, Arndt S. 1992. The Comprehensive Assessment of Symptoms and History (CASH). An instrument for assessing diagnosis and psychopathology. Archives of General Psychiatry 49(8):615-623.

Andreasen NC. 1985. Positive vs. negative schizophrenia: a critical evaluation. Schizophr Bull 11(3):380-9.

APA. 1994. Diagnostic and Statistical Manual of Mental Disorders, Fourth Edition: Washington, DC: American Psychiatric Association.

Broderick JE, Schwartz JE, Shiffman S, Hufford MR, Stone AA. 2003. Signaling does not adequately improve diary compliance. Ann Behav Med 26(2):139-48.

Cardno AG, Rijsdijk FV, Sham PC, Murray RM, McGuffin P. 2002. A twin study of genetic relationships between psychotic symptoms. Am J Psychiatry 159(4):539-45.

Chen ZY, Patel PD, Sant G, Meng CX, Teng KK, Hempstead BL, Lee FS. 2004. Variant brain-derived neurotrophic factor (BDNF) (Met66) alters the intracellular trafficking and activity-dependent secretion of wild-type BDNF in neurosecretory cells and cortical neurons. I Neurosci 24(18):4401-11.

Claridge G. 1994. Single indicator of risk for schizophrenia: probable fact or likely myth? Schizophr Bull 20(1):151-68.

Cuesta MJ, Peralta V, Zarzuela A, Zandio M. 2006. Insight dimensions and cognitive function in psychosis: a longitudinal study. BMC Psychiatry 6:26.

Delespaul PAEG. 1995. Assessing schizophrenia in daily life. Maastricht: Universitaire Pers.

Gottesman, II, Gould TD. 2003. The endophenotype concept in psychiatry: etymology and strategic intentions. Am J Psychiatry 160(4):636-45.

Green AS, Rafaeli E, Bolger N, Shrout PE, Reis HT. 2006. Paper or plastic? Data equivalence in paper and electronic diaries. Psychol Methods 11(1):87-105.

Jacobs N, Nicolson NA, Derom C, Delespaul P, van Os J, Myin-Germeys I. 2005. Electronic monitoring of salivary cortisol sampling compliance in daily life. Life Sci 76(21):2431-43.

Jacobs N, Rijsdijk F, Derom C, Vlietinck R, Delespaul P, van Os J, Myin-Germeys 1. 2006. Genes making one feel blue in the flow of daily life: a momentary assessment study of gene-stress interaction. Psychosom Med 68(2):201-6.

Kay SR, Fiszbein A, Opler LA. 1987. The Positive and Negative Syndrome Scale (PANSS) for schizophrenia. . Schizophrenia Bulletin 13:261-276.

Kendler KS, Hewitt J. 1992. The structure of self-report schizotypy in twins. Journal of Personality disorders 6:1-17.

Lardinois M, Lataster T, Mengelers R, van Os J, Myin-Germeys I. submitted. Childhood trauma and Stressinduced Alterations in Salience Attribution in Psychosis: An Experience Sampling Study.

Lataster T, Collip D, Lardinois M, Van Os J, Myin-Germeys I. submitted. Stress-reactivity and cognitive impairments: separate mechanisms underlying different symptoms in psychosis.

Lataster T, Wichers M, Jacobs N, Mengelers R, Derom C, Thiery E, Van Os J, Myin-Germeys I. 2008. Does reactivity to stress cosegregate with subclinical psychosis? A general population twin study. Acta Psychiatr Scand.

Linney YM, Murray RM, Peters ER, MacDonald AM, Rijsdijk F, Sham PC. 2003. A quantitative genetic analysis of schizotypal personality traits. Psychol Med 33(5):803-16.

MacDonald AW, 3rd, Pogue-Geile MF, Debski TT, Manuck S. 2001. Genetic and environmental influences on schizotypy: a community-based twin study. Schizophr Bull 27(1):47-58.

McGorry PD, Bell RC, Dudgeon PL, Jackson HJ. 1998. The dimensional structure of first episode psychosis: an exploratory factor analysis. Psychol Med 28(4):935-47.

Meaney MJ, Szyf M. 2005. Environmental programming of stress responses through DNA methylation: Ilfe at the interface between a dynamic environment and a fixed genome. Dialogues Clin Neurosci $7(2): 103-23$ 


\section{CHA A}

Morrens M, Krabbendam L, Bak M, Delespaul P, Mengelers R, Sabbe B, Hulstijn W, van Os J, MyinGermeys I. 2007. The relationship between cognitive dysfunction and stress sensitivity in schizophrenia: a replication study. Soc Psychiatry Psychiatr Epidemiol 42(4):284-7.

Murray RM, O'Callaghan E, Castle DJ, Lewis SW. 1992. A neurodevelopmental approach to the classification of schizophrenia. Schizophr Bull 18(2):319-32.

Myin-Germeys I, Delespaul P, van Os J. 2005. Behavioural sensitization to daily life stress in psychosis. Psychol Med 35(5):733-41.

Myin-Germeys I, Krabbendam L, Delespaul P, van Os J. 2003a. Can cognitive deficits explain differential sensitivity to life events in psychosis? Soc Psychiatry Psychiatr Epidemiol 38(5):262-8.

Myin-Germeys I, Krabbendam L, Delespaul PA, Van Os J. 2003b. Do life events have their effect on psychosis by influencing the emotional reactivity to daily life stress? Psychol Med 33(2):327-33.

Myin-Germeys I, Krabbendam L, Jolles J, Delespaul PA, van Os J. 2002. Are cognitive impairments associated with sensitivity to stress in schizophrenia? An experience sampling study. Am J Psychiatry 159(3):443-9.

Myin-Germeys I, Oorschot M, Collip D, Lataster J, Delespaul P, van Os J. 2008. Experience sampling research in psychopathology: opening the black box of daily life. Psych Med, epub ahead of print.

Myin-Germeys I, van Os J. 2007. Stress-reactivity in psychosis: evidence for an affective pathway to psychosis. Clin Psychol Rev 27(4):409-24.

Myin-Germeys I, van Os J, Schwartz JE, Stone AA, Delespaul PA. 2001. Emotional reactivity to daily life stress in psychosis. Arch Gen Psychiatry 58(12):1137-44.

Overall JE, Gorham DR. 1962. The Brief Psychiatric Rating Scale (BPRS). Psychological Report 10:799-812.

Simons CJ, Wichers M, Derom C, Thiery E, Myin-Germeys I, Krabbendam L, van Os J. 2009. Subtle geneenvironment interactions driving paranoia in daily life. Genes Brain Behav 8(1):5-12.

Snijders T, Bosker R. 1999. Multilevel analysis: an introduction to basis and advanced multilevel modeling.

Statacorp. 2007. STATA Statistical Software: Release 10.0 Texas, College Station.

Stefanis NC, Henquet C, Avramopoulos D, Smyrnis N, Evdokimidis I, Myin-Germeys I, Stefanis CN, Van Os J. 2007. COMT Val158Met moderation of stress-induced psychosis. Psychol Med 37(11):1651-6.

Stone AA, Shiffman S, Schwartz JE, Broderick JE, Hufford MR. 2002. Patient non-compliance with paper diaries. Bmj 324(7347):1193-4.

Strauss JS. 1994. The person with schizophrenia as a person. Ii: Approaches to the subjective and complex. Br J Psychiatry Suppl(23):103-7.

Tsuang MT. 2001. Defining alternative phenotypes for genetic studies: what can we learn from studies of schizophrenia? Am J Med Genet 105(1):8-10.

van Winkel R, Stefanis NC, Myin-Germeys 1. 2008. Psychosocial stress and psychosis. A review of the neurobiological mechanisms and the evidence for gene-stress interaction. Schizophr Bull 34(6):1095105

Ventura J, Green MF, Shaner A, Liberman RP. 1993. Training and quality assurance with the Brief Psychiatric Rating Scale: "the drift busters". Int J Methods Psychiatr Res 3:221-244.

Weaver IC, Cervoni N, Champagne FA, D'Alessio AC, Sharma S, Seckl JR, Dymov S, Szyf M, Meaney MJ. 2004. Epigenetic programming by maternal behavior. Nat Neurosci $7(8): 847-54$.

Weinberger DR. 1999. Schizophrenia: new phenes and new genes. Biol Psychiatry 46(1):3-7.

Wichers M, Myin-Germeys I, Jacobs N, Peeters F, Kenis G, Derom C, Vlietinck R, Delespaul P, Van Os J. 2007. Genetic risk of depression and stress-induced negative affect in daily life. Br J Psychiatry 191:218-23. 


\section{Chapter 6}

\section{Childhood victimisation and developmental expression of non-clinical delusional ideation and hallucinatory experiences}

Tineke Lataster ${ }^{1}$, Jim van $0 s^{14}$, Marjan Drukker ${ }^{1}$, Cécile Henquet ${ }^{1}$, Frans Feron ${ }^{3}$, Nicole Gunther ${ }^{1}$, Inez Myin-Germeys ${ }^{12}$

\footnotetext{
${ }^{1}$ Department of Psychiatry and Neuropsychology, South Limburg Mental Health Research and Teaching Network, EURON, Maastricht University, The Netherlands.

${ }^{2}$ Mondriaan Zorggroep, Section Social Cognition, Heerlen, The Netherlands.

${ }^{3}$ Youth Health Care Division, Municipal Health Centre, Maastricht, The Netherlands.

${ }^{4}$ Division of Psychological Medicine, Institute of Psychiatry, London, UK.
}

Social Psychiatry and Psychiatric Epidemiology 2006: 41: 423-428 


\begin{abstract}
Background: Victimisation in childhood may be associated with adult psychosis. The current study examined this association in the crucial developmental period of early adolescence and investigated whether 1) unwanted sexual experiences, and 2) being bullied, were associated with non-clinical delusional ideation and hallucinatory experiences in a general population sample of 14 year olds.

Methods: Data were derived from standard health screenings of the Youth Health Care Divisions of the Municipal Health Services in Maastricht, the Netherlands. A self-report questionnaire was filled out by a total of 1290 adolescents to assess nonclinical psychotic experiences, as well as experiences of being bullied and sexual trauma.

Results: Non-clinical psychotic experiences were strongly and independently associated with both bullying $(\mathrm{OR}=2.9,95 \% \mathrm{Cl} 1.8-4.8)$ and sexual trauma $(\mathrm{OR}=4.8,95 \%$ Cl 2.3-10.1).

Discussion: The results suggest that reported associations between childhood victimisation and adult psychosis can be understood in a developmental framework of onset of at-risk mental states in early adolescence. In addition, the data suggest that the traumatic experience of being bullied may also feed the cognitive and biological mechanisms underlying formation of psychotic ideation.
\end{abstract}




\section{Introduction}

Several studies have demonstrated, with one recent exception (Spataro and others 2004), an association between sexual and psychological trauma in childhood and outcomes of psychotic disorder and psychotic symptoms in adulthood (Bebbington and others 2004; Briere and others 1997; Janssen and others 2004; Read 1997; Read 1998; Read and others 2003; Ross and others 1994; Spauwen and others 2006). In addition, it has been suggested that in the general population, childhood trauma is similarly associated with the broader, non-clinical psychosis outcome of psychotic experiences (Janssen and others 2004; Johns and Van Os 2001; Startup 1999).

Less well recognized but arguably equally traumatic, is repeated exposure to bullying in childhood. Several studies have shown that being a victim of bullying is associated with mental (depression, fear, attention deficit disorder, conduct disorder, hyperactivity) and behavioural (aggression in particular) problems (Craig 1998; Kumpulainen and others 2001; Kumpulainen and others 1998). Less is known, however, about the impact on clinical and non-clinical psychosis outcomes.

It has been argued that the link between childhood exposure to victimisation and adult psychosis outcomes is mediated by the formation of cognitive mechanisms facilitating psychotic ideation (Bak and others 2005; Birchwood and others 2004; Garety and others 2001; Morrison and others 2003; Read and others 2001), that in turn may predict the onset of psychotic disorder in adulthood (Hanssen and others 2005; Poulton and others 2000). As the first expression of psychosis rises dramatically after puberty (Galdos and others 1993), one would expect the association between childhood victimisation and expression of psychosis to first become apparent in the form of non-clinical psychotic experiences during the crucial developmental period of early adolescence. The validity of this supposition comes from work demonstrating that a relatively high prevalence of non-clinical psychotic experiences can be measured in early adolescence (Escher and others 2002a; Escher and others 2002b; Fleming and others 1999; McGee and others 2000; Poulton and others 2000), and from work indicating that psychotic experiences in early adolescence increase the risk for adult transition to psychotic disorder (Fleming and others 1999; Poulton and others 2000).

The present study aimed to investigate the association between victimisation and non-clinical delusional ideation and hallucinatory experiences in a general population sample of adolescents aged 14 years. It was hypothesized that being the victim of 1) unwanted sexual experiences, and 2) bullying, would be associated positively and independently with non-clinical delusional ideation and hallucinatory experiences (hereafter called non-clinical psychotic experiences). 


\section{Method}

\section{Subjects}

All children in the Netherlands aged 4 to 18 years are examined regularly by the Youth Health Care Divisions (YHCD) of the Municipal Health Services. Data were derived from these standard health screenings of the YHCD of Maastricht and surrounding areas (total population of 201,000 ), enriched with specific questionnaires in the context of an academic partnership between YHCD and Maastricht University (Drukker and others 2003; Gunther and others 2003). The first wave of these Regional Profiles of Youth health (RPY) data in all adolescents attending second grade of secondary school (age 13/14 years) was used for the current analysis. Health information collected in these secondary school students included a self-report questionnaire, primarily designed to detect physical or mental problems. This questionnaire was administered by a nurse during the health screening.

\section{Assessments}

All variables were derived from the RPY data.

Non-clinical psychotic experiences were assessed with 4 questions rated as yes or no: (1) "Some people believe in mind reading or being psychic. Have other people ever read your mind?", (2) "Have you ever had messages sent just to you through television or radio?", (3) "Have you ever thought that people are following you or spying on you?", and (4) "Have you ever heard voices other people cannot hear?". These questions were derived from the Diagnostic Interview Schedule for Children (DISC-C) (Costello and others 1982) for DSM-III (APA 1980), and were used previously by Poulton et al.(Poulton and others 2000), showing their high predictive validity in relation to adult psychotic disorder. The answers to the questions about delusional ideation and hallucinatory experiences were combined into one psychosis measure with a value of 1 indicating that at least one symptom was present (e.g. a positive answer to one of the questions) and a value of 0 indicating the absence of non-clinical psychotic experiences (e.g. a negative answer to all of the questions). The question about reading thoughts was not included in the psychosis-measure in the current paper. Thirty-six percent of all subjects answered yes to this question which is much higher than would be expected on the basis of other studies (Henquet and others 2005; Van Os and others 2000). This question therefore lacks discriminative power in this age group and was excluded from the analysis.

Bullying was assessed with the question: "How many times have you been the victim of bullying in the past year?". The question was rated on a 5-point scale $11=$ never, 2 = one or two times, $3=$ one or two times per month on average, $4=$ ones per week on average, $5=$ several times per week). Guided by previous research, 
bullying was rated as present when a subject reported incidents of bullying occurring once a week or more (scores 4 or 5) (Janssen and others 2004).

Sexual trauma was assessed with the question "Have you ever had an unpleasant sexual experience?". Sexual trauma was rated as yes or no $(1=$ yes, $0=$ no $)$.

A priori confounders included in the statistical models were age, sex and socioeconomic status (SES). The latter variable was included as previous research has found an association between socio-economic status on the one hand and psychosis (Byrne and others 2004; Mallett and others 2002) and childhood trauma (Coulton and others 1999; Coulton and others 1995) on the other. Socio-economic status was estimated based on house price in the street where each subject was living at the moment of the assessment. The estimated SES was a continuous variable (range $\$ 77,000-\$ 766,582)$ (Drukker and others 2004). As no SES data were available for streets with rented houses only, analyses for SES applied to a sub sample only.

\section{Statistical analyses}

Data were analysed with the LOGISTIC module in STATA (Statacorp 2003). In order to test the hypothesis that victimisation was associated with non-clinical psychotic experiences in young adolescents, two logistic regression analyses adjusted as described above were carried out with the psychosis outcome as dependent variable and 'being bullied' and 'sexual trauma' as independent variables in two separate models. In addition, the two victimisation variables were entered jointly into one model in order to assess the relative independence of their associations.

Dose-response relationships were assessed by dividing the psychosis outcome into three groups (no psychotic experience, 1 psychotic experience, 2 or more psychotic experiences). In addition, in order to test for dose-response between 'being bullied' and psychotic experiences, the severity of being bullied was coded ' 0 ' (never), ' 1 ' (one or two times in the past year), and ' 2 ' (two times per month or more).

\section{Results}

\section{Subjects and descriptive statistics}

The total sample consisted of 1290 subjects ( 634 male and 656 female subjects). The mean age was 14 years ( $S D=1$, range $12.4-16.8$ ). A total of 74 subjects $(5.8 \%)$ reported 'being bullied' and 30 subjects $(2.4 \%)$ reported 'sexual trauma'. The association between the two independent variables was not strong ( $O R=2.6, p=0.08$ ). In the total sample, 244 subjects (19.1\%) met the criteria for the psychosis outcome as described above. A total of 60 subjects (4.7\%) endorsed the question about receiving messages, $165(12.7 \%)$ subjects reported being spied upon, and $90(7.0 \%)$ subjects answered 'yes' to the question about hearing voices. 


\section{ON THE PATHWAY FROM STRESTO TYCHOSIS}

Is victimisation associated with non-clinical psychotic experiences?

The risk of non-clinical psychotic experiences in adolescents exposed to bullying was $40.5 \%(n=30)$ compared to $17.9 \%(n=214)$ in the non-exposed (unadjusted $O R=3.1$, $95 \% \mathrm{Cl} 1.9-5.1)$. For 'sexual trauma', the risk of non-clinical psychotic experiences was $53.3 \%(n=16)$ in the exposed compared with $17.4 \%(n=226)$ in the non-exposed (unadjusted $O R=5.1,95 \% \mathrm{Cl} 2.5-10.6$ ). After controlling for age and gender, the effect of the two independent variables on the psychosis outcome did not change substantially ('being bullied': $O R=2.9,95 \% \mathrm{Cl} 1.8-4.9$; 'sexual trauma': $O R=3.8$, $95 \% \mathrm{Cl} 1.8-8.0$ ). Including SES in the list of confounders revealed similar results ('being bullied': OR=3.4, 95\% Cl 1.7-6.8; 'sexual trauma': OR=4.5, 95\% Cl 1.5-13.3).

The logistic regression analysis with the two independent variables entered together suggested independence of the exposures in their association with the psychosis outcome (bullying: unadjusted $O R=2.9,95 \% \mathrm{Cl} 1.8-4.8$; sexual trauma: unadjusted $O R=4.8,95 \% \mathrm{Cl} 2.3-10.1)$. Controlling for confounders did not change these results.

There was a significant dose-response relationship between frequency of being a victim of bullying and the psychosis outcome, regardless of confounders. Thus, the risk of developing non-clinical psychotic experiences increased with increased frequency of being a victim of bullying (table 1, page 104).

The analysis of severity of non-clinical psychotic experiences revealed a significant dose-response relationship between severity of non-clinical psychotic experiences and both exposures, regardless of confounders, indicating stronger associations with the more severe psychotic experiences (table 2, page 105 and 3, page 106).

\section{Discussion}

\section{Findings}

A strong dose-response association was found between victimising experiences and non-clinical psychotic experiences in young adolescents.

The current results are in line with several studies reporting an association between sexual trauma during childhood and psychotic experiences in adults (Bebbington and others 2004; Janssen and others 2004; Read 1997; Read 1998; Read and others 2003; Ross and others 1994). The current study suggests that the ontogenesis of this association can be traced back to the crucial developmental period of early adolescence, when the expression of psychosis becomes widespread. The results of the present study conflict with the findings of Spataro et al. (Spataro and others 2004) who found no association between childhood sexual trauma and schizophrenia. Spataro et al.(Spataro and others 2004), however, conducted a prospective study, meaning that all exposed children in the study were in contact with child welfare and protection services. This might be an essential element diminishing the risk for the development of psychotic disorders in adulthood (Read and Hammersley 2005). 
Additionally, the current study found that other traumatic experiences, such as being the victim of bullying, have a substantial influence on the development of non-clinical psychotic experiences in young adolescents. This fits with existing evidence on multiple other forms of victimisation (for example emotional, physical and psychological trauma) that have been found to be associated with psychosis later in life (Janssen and others 2004; Read 1997; Read 1998; Read and others 2003; Read and others 2001). Based on these results, it is attractive to speculate that victimisation in childhood is associated with the development of non-clinical psychotic experiences in early adolescence which in turn may shape risk for psychotic disorder later in life.

\section{Dose response association}

In the present study, the report of being a victim of bullying was associated with non-clinical psychotic experiences in early adolescence in a dose-response fashion. Similarly, a dose-response relation was found between non-clinical psychotic experiences on the one hand and being a victim of bullying and sexual trauma on the other. Dose-response is suggestive of causality (Hill 1965) and the findings concur with previous reports indicating that trauma and psychosis are associated particularly at the more severe end of the psychosis spectrum (Janssen and others 2004; Spauwen and others 2006).

\section{Reverse causality}

Since the current results are based on a cross-sectional study, the possibility of reverse causality cannot be excluded. This seems particularly relevant for the bullying exposure. Being different from peers increases the risk of bullying; children with subtle expression of social deviance or unusual ideas due to psychosis liability (Jones and others 1994) may thus become the victim of bullying rather than the other way round. While such a mechanism of person-environment correlation (Van Os and Sham 2003) cannot be excluded, it is unlikely to be the sole explanation, in particular since other forms of childhood trauma (such as sexual trauma), which less likely result from person-environment correlations, also increase the risk for non-clinical psychosis.

\section{Biological and psychological mechanisms}

There are plausible cognitive and biological models to account for the association between childhood trauma and the development of psychosis. According to a recent cognitive model of psychosis, adverse experiences in childhood can induce a cognitive liability for psychosis (Garety and others 2001). It is suggested that childhood trauma can lead to the development of negative schemas of the self and the world (e.g., beliefs about the self as vulnerable to threat, or about others as dangerous) that facilitate external attributions, which may lead to the development of 
paranoid delusions (Bentall and others 2001). Similarly, Birchwood et al. (Birchwood and others 2004) have emphasized that childhood experience of social adversity leads to the development of negative schemas involving social humiliation and subordination, which in turn may fuel voices and paranoia (Morrison and others 2003). Recent biological models have suggested that childhood trauma might lead to enduring and long-lasting changes in the brain. Read et al. (Read and others 2001) suggested that adverse life events, if they occur early enough or are sufficiently severe, actually mould the neurodevelopmental abnormalities that underlie the heightened sensitivity to stressors, which is typically seen in adults diagnosed with schizophrenia. Walker \& DiForio (Walker and Diforio 1997) suggested that exposure to persistent stressors resulting in a chronic heightened glucocorticoid release, may cause permanent changes to the HPA-axis. Stress-induced dysregulation of the HPAaxis may subsequently give rise to increased dopamine (DA) receptor densities and DA release (Walker and Diforio 1997), suggesting that abnormality in the functioning of the HPA axis may underlie the dopaminergic abnormalities that are generally thought to be involved in psychosis (Walker and Diforio 1997; Walker and others 1999). Several recent studies have suggested that the sensitisation of the dopamine system might mediate the expression of psychosis (Kapur 2003; Laruelle and AbiDargham 1999; Laruelle and others 1999). Kapur (Kapur 2003) suggested that a dysregulated, hyperdopaminergic state may lead to stimulus-independent release of dopamine which may take over the normal process of contextually driven salience attribution and leads to aberrant assignment of salience to external objects and internal representations. A recent study extended these findings to subjects at risk for psychosis and demonstrated that a hyperreactive dopamine system might directly influence the intensity of psychotic experiences in response to stress in daily life (Myin-Germeys and others 2005a; Myin-Germeys and others 2005b).

\section{Limitations}

The results of the present study should be viewed in light of several methodological issues. First, data were derived from standard health screenings including numerous questions over a wide range of physical and mental health problems. Consequently, the assessment of certain items was limited. E.g. the assessment of sexual trauma was lacking detail with regard to frequency and qualitative aspects of the trauma. Furthermore, non-clinical psychotic experiences were assessed with only four questions, without further detail with regard to frequency of the experience or degree of conviction. Endorsement of one of these items could, therefore, occasionally result from this being a true event or it could have happened only once. On the other hand, Poulton et al. (Poulton and others 2000) used the same items and showed in a longitudinal study that they had a high predictive value for the later development of psychosis. In addition, $19.1 \%$ of all subjects met criteria for non-clinical psychotic experiences, which is in accordance with findings from other studies using more 
extensive psychosis assessments (Henquet and others 2005; Van Os and others 2000).

Second, at the time they were filling out the questionnaire, subjects were aware of the fact that possible problems would be discussed with a nurse during the health screening. It can be argued that subjects therefore might have underreported sexual trauma, bullying and psychotic experiences. As stated before, this seems unlikely for the psychotic experiences since percentages found in the current study are in accordance with earlier findings (Henquet and others 2005; Van Os and others 2000). However, only $5.8 \%$ of all subjects reported bullying and $2.4 \%$ reported sexual trauma which is much lower than percentages found in other studies (Briere and others 1997; Kumpulainen and others 2001; Kumpulainen and others 1998). This could have led to a reduction of statistical power, suggesting that the association between victimisation and psychosis might even be stronger than reported in the present study.

Third, victimisation was assessed on the basis of self-report. It could be argued that psychosis is associated with proneness to disclose trauma. However, it has been found that incorrect reporting of sexual trauma is no different for schizophrenia than for the general population (Darves-Bornoz and others 1995). Additionally, it has been found that psychosis most likely results in under-reporting rather than over-reporting of victimisation (Dill and others 1991; Read 1997).

Finally, the electronic registration of youth health in the RPY data set has started only recently. Therefore, the present results are based on cross-sectional data. Future research can be performed using longitudinal data, so that a time axis can facilitate causal interference. 


\section{ON THE PATHWAY FROM STRESSTO PSVGHSTS}

\begin{tabular}{|c|c|c|c|c|c|c|}
\hline \multirow[t]{3}{*}{ 'being bullied' } & \multicolumn{6}{|c|}{ psychosis outcome measure } \\
\hline & no & & yes & & OR $(95 \% \mathrm{Cl})^{1}$ & \\
\hline & $n$ & $\%$ & $\mathrm{n}$ & $\%$ & & \\
\hline 0 & 765 & 74.7 & 137 & 56.1 & 1 & \\
\hline 1 & 193 & 18.8 & 66 & 27.0 & $1.91(1.4-2.7)$ & $P=0.00$ \\
\hline 2 & 66 & 6.4 & 41 & 16.8 & $3.47(2.2-5.4)$ & $P=0.00$ \\
\hline Test for trend & \multicolumn{2}{|c|}{$\chi^{2}=40.9$} & \multicolumn{2}{|c|}{$d f=1$} & \multicolumn{2}{|l|}{$P=0.000$} \\
\hline
\end{tabular}

\footnotetext{
${ }^{1}$ Unadjusted OR.
} 


\section{CHAPTE}

Table 2. Odds ratios for 'psychotic experiences' showing a dose-response relationship with 'being bullied' in young adolescents.

\begin{tabular}{lllllll}
\hline $\begin{array}{l}\text { Psychotic expe- } \\
\text { riences }\end{array}$ & \multicolumn{1}{l}{ 'being bullied' } & & & \\
\hline & no & & yes & & OR $(95 \% \mathrm{Cl})^{1}$ & \\
& $\mathrm{n}$ & $\%$ & $\mathrm{n}$ & $\%$ & & \\
0 & 980 & 82.1 & 44 & 60.3 & 1 & \\
1 & 162 & 13.6 & 18 & 24.7 & $2.47(1.4-4.4)$ & $\mathrm{P}=0.00$ \\
2 & 52 & 4.4 & 11 & 15.1 & $4.71(2.3-9.7)$ & $\mathrm{P}=0.00$ \\
Test for trend & $\chi^{2}=25.7$ & $\mathrm{df}=1$ & & $\mathrm{P}=0.000$ & \\
\hline
\end{tabular}

${ }^{1}$ Unadjusted $O R$. 


\section{ONTHE PTHWAY FOM STRESTO PSYCHOSIS}

Table 3. Odds ratios for 'psychotic experiences' showing a dose-response relationship with 'sexual trauma' in young adolescents.

\begin{tabular}{|c|c|c|c|c|c|c|}
\hline \multirow{3}{*}{$\begin{array}{l}\text { psychotic } \\
\text { experiences }\end{array}$} & \multicolumn{6}{|c|}{ sexual trauma } \\
\hline & \multicolumn{2}{|l|}{ no } & \multicolumn{2}{|c|}{ yes } & \multirow[t]{2}{*}{ OR $(95 \% \mathrm{Cl})^{1}$} & \\
\hline & $\mathrm{n}$ & $\%$ & $n$ & $\%$ & & \\
\hline 0 & 1012 & 81.8 & 14 & 46.7 & 1 & \\
\hline 1 & 169 & 13.7 & 11 & 36.7 & $4.70(2.1-10.6)$ & $P=0.00$ \\
\hline 2 & 56 & 4.5 & 5 & 16.7 & $6.45(2.2-18.7)$ & $P=0.00$ \\
\hline Test for trend & \multicolumn{2}{|c|}{$x^{2}=23.6$} & \multicolumn{2}{|c|}{$d f=1$} & \multicolumn{2}{|l|}{$P=0.000$} \\
\hline
\end{tabular}

${ }^{1}$ Unadjusted OR. 


\section{CHAPTER 6}

\section{References}

APA. 1980. Diagnostic and Statistical Manual of Mental Disorders, Third Edition: Washington, DC: American Psychiatric Association.

Bak M, Krabbendam L, Janssen I, Vollebergh W, De Graaf R, Van Os J. 2005. Early trauma may increase the risk for psychotic experiences by impacting on emotional response and perception of control. Acta Psychiatrica Scandinavica 112(5): 372-5.

Bebbington PE, Bhugra D, Brugha T, Singleton N, Farrell M, Jenkins R, Lewis G, Meltzer H. 2004. Psychosis, victimisation and childhood disadvantage: evidence from the second British National Survey of Psychiatric Morbidity. British Journal of Psychiatry 185:220-226.

Bentall RP, Corcoran R, Howard R, Blackwood N, Kinderman P. 2001. Persecutory delusions: a review and theoretical integration. Clinical Psychological Review 21(8):1143-1192.

Birchwood M, Gilbert P, Gilbert J, Trower P, Meaden A, Hay J, Murray E, Miles JN. 2004. Interpersonal and role-related schema influence the relationship with the dominant 'voice' in schizophrenia: a comparison of three models. Psychological Medicine 34(8):1571-1580.

Briere J, Woo R, MCRae B, Foltz J, Sitzman R. 1997. Lifetime victimization history, demographics, and clinical status in female psychiatric emergency room patients. Journal of Nervous and Mental Disease 185(2):95-101.

Byrne M, Agerbo E, Eaton WW, Mortensen PB. 2004. Parental socio-economic status and risk of first admission with schizophrenia- a Danish national register based study. Soc Psychiatry Psychiatr Epidemiol 39(2):87-96.

Costello A, Edelbrock C, Kalas R, Kessler M, Klaric S. 1982. NIMH Diagnostic Interview for Children Child Version. Rockville: Md: National institute of Mental Health.

Coulton CJ, Korbin JE, Su M. 1999. Neighborhoods and child maltreatment: a multi-level study. Child Abuse and Neglect 23(11):1019-1040.

Coulton CJ, Korbin JE, Su M, Chow J. 1995. Community level factors and child maltreatment rates. Childhood Development 66(5):1262-1276.

Craig WM. 1998. The relationship among bullying, victimization, depression, anxiety, and aggression in elementary school children. Personality and Individual Differences 24(1):123-130.

Darves-Bornoz JM, Lemperiere T, Degiovanni A, Gaillard P. 1995. Sexual victimization in women with schizophrenia and bipolar disorder. Social Psychiatry and Psychiatric Epidemiology 30(2):78-84.

Dill DL, Chu JA, Grob MC, Eisen SV. 1991. The reliability of abuse history reports: a comparison of two inquiry formats. Comprehensive Psychiatry 32(2):166-169.

Drukker M, Driessen G, Krabbendam L, Van Os J. 2004. The wider social environment and mental health service use. Acta Psychiatrica Scandinavica 110(2):119-129.

Drukker M, Kaplan CD, Feron FJM, Van Os J. 2003. Children's health-related quality of life, neighbourhood socio-economic deprivation and social capital. A contextual analysis. Social Science and Medicine 57(5):825-841.

Escher 5, Romme M, Buiks A, Delespaul P, Van Os 1. 2002a. Formation of delusional ideation in adolescents hearing voices: a prospective study. American Journal of Medical Genetics 114(8):913-920.

Escher S, Romme M, Buiks A, Delespaul P, Van Os J. 2002b. Independent course of childhood auditory hallucinations: a sequential 3-year follow-up study. British Journal of Psychiatry 43 (supplement):s10-18.

Fleming J, Mullen PE, Sibthorpe B, Bammer G. 1999. The long-term impact of childhood sexual abuse in Australian women. Child Abuse \& Neglect 23(2):145-159.

Galdos PM, van Os JJ, Murray RM. 1993. Puberty and the onset of psychosis. Schizophrenia Research 10(1):7-14.

Garety PA, Kuipers E, Fowler D, Freeman D, Bebbington PE. 2001. A cognitive model of the positive symptoms of psychosis. Psychological Medicine 31(2):189-195. 
Gunther N, Slavenburg B, Feron FJM, Van Os J. 2003. Childhood social and early developmental factors associated with mental health service use. Social Psychiatry and Psychiatric Epidemiology 38(3):101108.

Hanssen M, Bak M, Bijl R, Vollebergh W, Van Os J. 2005. The incidence and outcome of subclinical psychotic experiences in the general population. british Journal of Clinical Psychology in press.

Henquet C, Krabbendam L, Spauwen J, Kaplan C, Lieb R, Wittchen HU, Van Os J. 2005. Prospective cohort study of cannabis use, predisposition for psychosis, and psychotic symptoms in young people. British Medical Journal 330(7481):11-15.

Hill A. 1965. Journal of the Royal Society of Medicine 58:295-300.

Janssen I, Krabbendam L, Bak M, Hanssen M, Vollebergh W, De Graaf R, Van Os J. 2004. Childhood abuse as a risk factor for psychotic experiences. Acta Psychiatrica Scandinavica 109(1):38-45.

Johns LC, Van Os J. 2001. The continuity of psychotic experiences in the general population. Clinical Psychology Review 21(8):1125-1141.

Jones $P$, Rodgers B, Murray R, Marmot M. 1994. Child development risk factors for adult schizophrenia in the British 1946 birth cohort. Lancet 344(8934):1398-1402.

Kapur S. 2003. Psychosis as a state of aberrant salience: a framework linking biology, phenomenology, and pharmacology in schizophrenia. American Journal of Psychiatry 160(1):13-23.

Kumpulainen K, Raesaenen E, Puura K. 2001. Psychiatric disorders and the use of mental health services among children involved in bullying. Aggressive Behavior 27(2):102-110.

Kumpulainen K, Rasanen E, Henttonen I, Almqvist F, Kresanov K, Linna SL, Moilanen I, Piha J, Puura K, Tamminen T. 1998. Bullying and psychiatric symptoms among elementary school-age children. Child Abuse \& Neglect 22(7):705-717.

Laruelle M, Abi-Dargham A. 1999. Dopamine as the wind of the psychotic fire: new evidence from brain imaging studies. Journal of Psychopharmacology 13(4):358-371.

Laruelle M, Abi-Dargham A, Gil R, Kegeles L, Innis R. 1999. Increased dopamine transmission in schizophrenia: relationship to illness phases. Biological Psychiatry 46(1):56-72.

Mallett R, Leff J, Bhugra D, Pang D, Zhao JH. 2002. Social environment, ethnicity and schizophrenia. A case-control study. Social Psychiatry and Psychiatric Epidemiology 37(7):329-335.

McGee R, Williams S, Poulton R. 2000. Hallucinations in nonpsychotic children. Journal of the American Academy of Child and Adolescent Psychiatry 39(1):12-13.

Morrison AP, Frame L, Larkin W. 2003. Relationships between trauma and psychosis: a review and integration. British Journal of Clinical Psychology 42(4):331-353.

Myin-Germeys I, Delespaul P, Van Os J. 2005a. Behavioural sensitization to daily life stress in psychosis. Psychological Medicine 35(5):733-741.

Myin-Germeys I, Marcelis M, Krabbendam L, Delespaul $P$, Van Os J. 2005b. Subtle fluctuations in psychotic phenomena as functional states of abnormal dopamine reactivity in subjects at risk. Biological Psychiatry in press.

Poulton R, Caspi A, Moffitt TE, Cannon M, Murray R, Harrington H. 2000. Children's self-reported psychotic symptoms and adult schizophreniform disorder: a 15-year longitudinal study. Archives of General Psychiatry 57(11):1053-1058.

Read 1. 1997. Child abuse and psychosis: A literature review and implications for professional practice. Professional Psychology: Research-and-Practice 28(5):448-456.

Read J. 1998. Child abuse and severity of disturbance among adult psychiatric inpatients. Child Abuse \& Neglect 22(5):359-368.

Read J, Agar K, Argyle N, Aderhold V. 2003. Sexual and physical abuse during childhood and adulthood as predictors of hallucinations, delusions and thought disorder. Psychological Psychotherapy 76(Pt 1):122.

Read J, Hammersley P. 2005. Child sexual abuse and schizophrenia. Br J Psychiatry 186:76; author reply 76.

Read J, Perry BD, Moskowitz A, Connolly J. 2001. The contribution of early traumatic events to schizophrenia in some patients: a traumagenic neurodevelopmental model. Psychiatry 64(4):319-345. 


\section{CHAPT}

Ross CA, Anderson G, Clark P. 1994. Childhood abuse and the positive symptoms of schizophrenia. Hospital and Community Psychiatry 45(5):489-491.

Spataro J, Mullen PE, Burgess PM, Wells DL, Moss SA. 2004. Impact of child sexual abuse on mental heaith: prospective study in males and females. British Journal of Psychiatry 184:416-421.

Spauwen J, Krabbendam L, Lieb R, Wittchen H, Van Os J. 2006. Impact of Psychological trauma on the development of psychotic symptoms: relationship with psychosis proneness. British Journal of Psychiatry 188: 527-33.

Startup M. 1999. Schizotypy, dissociative experiences and childhood abuse: relationships among selfreport measures. British Journal of Clinical Psychology 38 (4):333-344.

Statacorp. 2003. STATA Statistical Software: Release 8.0. Texas, College Station.

Van Os J, Hanssen M, Bijl RV, Ravelli A. 2000. Strauss (1969) revisited: a psychosis continuum in the general population? Schizophrenia Research 45(1-2):11-20.

Van Os J, Sham P. 2003. Gene-environment interactions. In: Murray RM JP, Susser E, Van Os J, Cannon M, editor. The Epidemiology of Schizophrenia, Cambridge: Cambridge University Press. p 235-254.

Walker EF, Diforio D. 1997. Schizophrenia: a neural diathesis-stress model. Psychological Review 104(4):667-685.

Walker EF, Diforio D, Baum K. 1999. Developmental neuropathology and the precursors of schizophrenia. Acta Psychiatrica Scandinavica 395 (supplement):12-19. 
Chapter 7

Discussion 


\section{A dimensional approach}

The genetic continuity between self-reported subclinical psychotic experiences and clinical psychotic symptoms was examined in a general population twin sample (CHAPTER 2) using a cross-trait, cross-twin design (Figure 1, page 121). The crosstrait, cross-twin analyses allowed for the examination of the relationship in an unconfounded fashion, since it was possible to investigate the association between one trait in twin 1 and a second trait in twin 2, while controlling for the second trait in twin 1 . The analyses revealed a significant association between subclinical psychotic experiences and clinical psychotic symptoms both within and across genetically identical monozygotic twins. Moreover, the association between subclinical psychotic experiences and clinical psychotic symptoms was found to be much stronger in monozygotic than in dizygotic twins. These findings suggest that, in addition to the familial and aetiological continuity found in previous studies (Johns and van Os 2001; Kendler and others 1995), there is also a genetic continuity between common self-reported psychotic experiences and rarer clinical psychotic symptoms. This is in line with recent studies suggesting that subclinical psychotic experiences represent a broadly distributed phenotype that is the developmental expression of genetic liability to psychosis (Cougnard and others 2007), Even though these subclinical psychotic phenomena are transitory in most individuals (Cougnard and others 2007; Hanssen and others 2005), some individuals will eventually develop a clinical psychotic disorder. Dominguez and co-workers (Dominguez and others 2007) have argued that the persistence of subclinical psychotic experiences over time is specifically predictive of eventual transition to clinical psychosis. It has been suggested that the interplay between genetic vulnerability and environmental risk factors plays an important role in this transition to persistent subclinical symptoms and clinical psychotic disorder. Cougnard and colleagues (2007) found that environmental risk factors act additively on the risk for psychosis (e.g. the more risk factors, the higher the risk) (Cougnard and others 2007). Additionally, it was found that the level of environmental risk combines synergistically with the subclinical developmental expression of psychosis to cause abnormal persistence (Cougnard and others 2007), meaning that the interplay between genetic risk, expressed as subclinical psychosis, and environmental risk factors results in persistence of these symptoms.

The age-dependency of the expression of subclinical psychosis was examined in the same sample (CHAPTER 2). The association between subclinical psychotic experiences and clinical psychotic symptoms was found to be much stronger in the younger half of the sample (age was divided at the median age of 25 years: younger age group $<26$ years, older age group $>25$ years). This is in line with findings from previous studies that show a clear association between adolescent age and delu- 


\section{CHAPTER ?}

sional ideation (Galdos and van Os 1995; Galdos and others 1993). Moreover, it seems that the increase in delusional ideation is specific to this age group, since very low rates are found at a younger age (Werry 1992), and a gradual decline in delusional ideation is found in older age groups (Tsuang and others 1979). This agedependent expression of subclinical psychosis is in accordance with a neurodevelopmental approach, where a physiological neurodevelopmental stage in late adolescence/ early adulthood gives rise to subclinical psychotic experiences in normal subjects (Verdoux and others 1998).

Taken together, these findings suggest that the psychosis phenotype exists in nature, that it peaks at the age of young adulthood, and that there is genetic, aetiological, temporal, and familial continuity between the naturalistic phenotype and diagnostic constructs such as psychotic disorder and schizophrenia. These findings are in favour of a dimensional approach to psychosis and it seems particularly useful to investigate underlying risk factors that are related to specific symptom dimensions of the disorder.

\section{An affective pathway}

The studies presented in this dissertation aimed at finding evidence for an affective pathway leading to the development of positive symptoms of psychosis. To this end, increased sensitivity to stress in daily life was studied as possible underlying mechanism of risk within this pathway. A schematic representation of the two pathway model is shown in Figure 4 (page 123). The Experience Sampling Method (ESM) was used to measure emotional reactivity to daily events and activities.

\section{Stress-reactivity in psychosis}

To furher investigate stress-reactivity as possible vulnerability marker for psychosis, the study described in CHAPTER 3 assessed stress-reactivity and subclinical psychotic experiences in 289 female, general population twin-pairs. Again, a twindesign was used to investigate the association between stress-reactivity and psychotic experiences in an unconfounded and uncontaminated way (Figure 2, page 121). Subjects from the general population with an increased psychometric risk for psychosis were found to show higher emotional reactivity to stress in daily life. These results are in line with the finding that subjects with increased familial/genetic risk of psychosis (i.e. relatives of patients with psychotic disorder) also show increased stress-reactivity (Myin-Germeys and others 2001), suggesting that increased psychosis-liability cosegregates with increased reactivity to stress.

In addition, a familial association between stress-reactivity and the subclinical psychosis phenotype at the level of the general population was found. Taken together, these results suggest that stress-reactivity is a behavioural expression of the fa- 
milial/ genetic or psychometric vulnerability for psychosis and, thus, a possible endophenotype of the disorder.

\section{Stress-reactivity and cognition independent markers?}

Another extensively investigated psychosis phenotype is the impairment in cognitive functioning. If increased emotional reactivity to daily life stress truly is an endophenotype for psychosis, one could question how altered stress-sensitivity is related to the cognitive endophenotype. One possible, often implicitly assumed, explanation would be that cognitive deficits decrease the capability to successfully adapt to the stresses of daily life. Another explanation would be that neuropsychological impairments and altered stress-sensitivity constitute independent mechanisms associated with psychosis. The study described in CHAPTER 4 investigated whether cognition and stress-sensitivity are independent mechanisms underlying psychosis. This hypothesis was tested in a clinical sample of 72 patients with non-affective psychosis. The association between stress-reactivity on the one hand and three measures of cognitive functioning (i.e. general cognition, information processing speed, and social cognition) on the other was investigated. In line with findings from two previous studies (Morrens and others 2007; Myin-Germeys and van Os 2007), it was shown that cognitive functioning and stress-sensitivity are not significantly associated. The results of the present study extended these findings to the domain of social cognition. While some suggest that social cognition is an independent domain (Pinkham and others 2003), others suggest that it is part of general neurocognition (Vauth and others 2004). In our study, an inverse association was found for social cognition, with better performance on tests of social cognition being associated with greater stress-reactivity. Traditionally, measures of social cognition are thought to be associated with the positive symptoms of psychosis. This would imply that social cognition is associated with the stress-reactive, good-outcome form of psychosis. The fact that this was not found in the study described in this chapter can possibly be explained by the nature of the social cognition tasks used. A study from our group showed that social cognition is a multidimensional construct with different non-related cognitive domains (van Hooren and others 2008). In our study, the hinting task loaded on both the social and general cognition factor. This is in accordance with recent findings from studies showing that the hinting task is mainly associated with neurocognition (van Hooren and others 2008) and intelligence (Corcoran and others 1995). However, the two other social cognition tasks used in our study (Benton Face Recognition Task and Facial Affect Recognition Task) loaded solely on the social cognition factor. Thus, the social cognition factor partly reflected neurocognitive functioning. In future research, different domains of social cognition that are more closely linked to the development of positive psychotic symptoms (for example source monitoring, reasoning biases, and attribution style) should be investigated. 


\section{CHAPTEP 7}

\section{Independent pathways to psychosis}

As suggested earlier, there is evidence that cognitive impairments are associated with the negative symptoms (Green 1998; van Os and others 2001), but not the positive symptoms of psychosis (Green 1998). In CHAPTER 4 the hypothesis was tested that stress-reactivity (also called "the affective pathway to psychosis") (MyinGermeys and van Os 2007) represents the underlying mechanism of the positive symptoms of psychosis. To do so, the association between stress-reactivity and the positive and negative symptoms of psychosis was investigated in a clinical sample of 72 patients with non-affective psychosis. It was found that greater levels of reactivity to stress are associated with higher levels of positive symptoms and lower levels of negative symptoms. Thus, for the first time, a direct association between increased levels of stress-reactivity and the positive symptoms of psychosis was demonstrated. This suggests that increased stress-reactivity represents a mechanism specifically associated with the positive symptom domain in psychotic syndromes. These findings were not replicated at the sub-clinical level in the general population twin study, where an association was found between stress-reactivity and both the positive and negative subclinical symptom dimension. These data seem contradictory to the hypothesis that increased stress-reactivity is specifically associated with the positive symptom dimension. However, Stefanis and colleagues (2002) found that the correlation between the positive and negative symptom dimension were much higher in a subclinical sample (correlations of around 0.70 ) when compared to correlations usually found in clinical samples (0.20-0.60) (Peralta and Cuesta 1998; Peralta and others 1994). A possible explanation for this difference in correlations is that the expression of the symptom dimensions in the general population is much more attenuated than in clinical samples. This makes them much more difficult to measure and, more importantly, to discriminate. Stefanis and colleagues (2002) suggested that the sensitivity of the CAPE to differentiate symptom dimensions in the general population is insufficient.

Another ESM study from our group reported that both patients and subjects at increased risk for psychosis showed continuous variation in the intensity of subtle psychotic experiences associated with minor stresses in the flow of daily life (MyinGermeys and others 2005), which does support the hypothesis of an affective pathway underlying the positive symptoms. Additional evidence for this assumption comes from a laboratory study (Cohen and others 2003). They found lower levels of stress in patients with a diagnosis of "deficit syndrome" (e.g. patients with high levels of negative symptoms) during a laboratory speech task. In another study it was shown that higher scores on the Behavioural Inhibition System (BIS), a neural motivational system sensitive to cues of threat, were associated with lower scores on the PANSS negative syndrome scale (Scholten and others 2006). However, no association was found with scores on the positive syndrome scale. Thus, the results so far seem to support the idea that the different psychosis-subtypes reflect partly 
independent syndromes at the basis of which are partly independent aetiologies reflected in distinct endophenotypic pathways (Murray and others 1992; Robins and Guze 1970).

\section{Possible genetic contribution to increased stress-reactivity}

Previous studies investigating stress-reactivity in patients and first degree relatives used a sample with patients and relatives that were not genetically related (MyinGermeys and others 2003; Myin-Germeys and others 2002; Myin-Germeys and others 2001). Therefore, the study described in CHAPTER 5 was designed to (i) further investigate a possible genetic contribution to increased reactivity to stress (i.e. does stress-reactivity cluster within families?), and (ii) to investigate whether stressreactivity in relatives cosegregates with positive psychotic symptoms in patients. These research questions were addressed using a semi-genetically sensitive sample of 47 sib-pairs (47 patients with non-affective psychosis and 47 of their brothers/sisters). Again, a cross-sib, within-trait (Figure 3a, page 122) and cross-trait, cross-sib (Figure 3b, page 122) design was applied. The results show that stressreactivity clusters within families of patients with psychotic disorder. Moreover, higher levels of positive symptoms in the patients were found to be associated with higher levels of stress-reactivity in their siblings. Taken together, these results suggest a genetic contribution to increased stress-reactivity, which is specifically underlying the positive dimension of psychosis.

The across and within sib associations suggest common aetiological influences underlying stress-reactivity and the positive dimension of psychosis, and clustering of these within families. This does not necessarily imply that the observed risk indicators are genetically transmitted. The results of this study can be explained by several mechanisms. Stress reactivity may be due to the impact of environmental factors in interaction with genetic factors (Jacobs and others 2006; Wichers and others 2007), or result from the influence of epigenetic factors (Meaney and Szyf 2005; Weaver and others 2004). Additionally, the clustering of stress reactivity within siblings may be the result of genetic effects correlating with the environment, or purely by shared environmental effects between siblings.

Childhood trauma as additional risk factor within the affective pathway

One of the environmental factors possibly contributing to the affective pathway is childhood trauma and experiences of victimization. The study described in CHAPTER 6 investigated whether victimizing experiences were associated with non-clinical delusional ideation and hallucinatory experiences in a general population sample of 14 year olds. A strong dose-response association was found between sexual trauma and non-clinical psychotic experiences. This is in accordance with findings from other studies showing an association between trauma in childhood and subclinical and clinical psychosis in adulthood (Kelleher and others 2008; Read and others 


\section{CHAPTER}

2005; Spauwen and others 2006). In one study no association was found between childhood trauma and psychosis (Spataro and others 2004). The study used a prospective design, however, meaning that all exposed children received protection form child welfare and protection services, thereby possibly diminishing the risk for development of psychotic disorders later in life (Read and Hammersley 2005). The results of the study presented in this chapter add credence to the notion that other forms of victimization, in this case "being the victim of bully activities", may also contribute to the risk for the development of a psychotic disorder. These findings resemble those found for multiple other forms of victimization experiences, such as emotional, physical, and psychological trauma (Janssen and others 2004; Read 1997; Read 1998; Read and others 2003).

Childhood trauma may increase the risk for psychosis by sensitizing subjects to the smaller stresses of daily life, thus increasing the risk to develop positive psychotic symptoms. If this were true, childhood trauma would definitely be an important factor in the affective pathway to psychosis. One study found significantly increased stress-reactivity in subjects from the general population with a history of childhood trauma $(n=90)$. More specifically, this effect was found to be stronger in those subjects who had experienced childhood trauma before the age of 10 (Glaser and others 2006). In a recent study by our group, it was investigated whether early trauma increases the risk for psychosis through sensitizing people for the small stresses of daily life (Lardinois and others submitted). It was found that (i) patiens report higher levels of trauma compared to the other two groups, and (ii) subjects with higher levels of trauma show higher emotional and psychotic reactivity to stress in daily life. Childhood trauma seems to change the underlying sensitivity to stress and this increased stress-reactivity increases the risk to develop psychotic symptoms later in life. This hypothesis is also supported by biological findings. Increased cortisol levels, caused by the traumatic experiences, may play a role, since they have the potential to create changes in the hypothalamic-pituitary-adrenal (HPA) axis, the main stresscircuit of the brain (Read and others 2005). It has been suggested that activation of the HPA axis is associated with activation of those dopamine circuits in the brain that are thought to be implicated in psychosis (Walker and Diforio 1997). In a recent study by Walker and colleagues (2008), for example, an association was found between glucocorticoid secretion and increased dopamine activity in mesolimbic brain areas. Taken together, the results of these studies add credence to the hypothesis that a history of childhood trauma is associated with psychosis and the underlying mechanism of this association is the process of sensitization. Childhood trauma makes people more sensitive to the stresses of daily life, resulting in a more emotional and psychotic reaction to stress. 


\section{Clinical implications and directions for future research}

Even though the results as laid out in the current thesis are still a long way form offering direct therapeutic insight, they do provide a theoretical framework from which important clinical implications can be inferred. The results suggest that stress-reactivity can truly be considered a specific area of vulnerability. Therefore, future research should focus on designing diagnostic instruments specifically aimed at detecting sensitivity to stress in daily life. In addition to the Experience Sampling Method (Delespaul 1995), the Bonn Scale for the Assessment of Basic Symptoms (BSABS) contains a number of questions on "increased emotional reactivity" (Gross and others 1987). Additionally, based on these results it seems useful to tailor treatment aimed at reducing sensitivity to stress in daily life. There are two possible ways of doing this. First, one could aim treatment at reducing stress in the social environment of the patient. For this purpose, research has focused on expressed emotion (EE) (i.e. yelling, shouting, fighting, critical or hostile comments) in families of patients with schizophrenia. High EE was found to be associated with an increased risk of relapse among recently discharged individuals with schizophrenia (Kuipers and others 2006). Based on these findings, family-intervention programmes were developed to improve disorder-and stress-related coping strategies of patients and their relatives. Typically, a family-intervention programme starts with individual or group psychoeducation for patients and their relatives (Pfammatter and others 2006). At the beginning of the programme, the disorder is explained based on the vulnerability-stress model (Zubin and Spring 1977). Thereafter, the intervention is focused on improving coping abilities for dealing with stress arising from symptoms or from the social environment. Cognitive behavioural strategies are used together with training of problem solving and communication skills in both patients and their family members. Several studies showed that these family intervention techniques have positive effects on relapse prevention (Leff 1994; Pharoah and others 2006; Pilling and others 2002), hospitalization rates, compliance with medication (Pharoah and others 2006; Pilling and others 2002), general psychopathology, social functioning, and expressed emotion (Pharoah and others 2006).

As opposed to reducing stress-sensitivity in the environment or family of the patient, several intervention programmes are specifically aimed at reducing stress in the patient. Self-relaxation and distraction techniques have shown to improve emotional well-being in schizophrenia patients, but not in early psychosis (Hodel and others 1998). These self-relaxation and distraction techniques are often incorporated within the Cognitive Behavioural Therapy (CBT) for psychosis protocol

(van der Gaag and others 2003). CBT is nowadays one of the most popular psychological treatments for psychotic disorder. A central idea of this therapy is that "suffering is a consequence of our thoughts about an event rather than the event itself" (Beck 1952; Beck and Rector 2002; Beck and Rector 2003; van der Gaag and others 2003). The treatment of auditory hallucinations is aimed at changing beliefs 
about origin, power and dangerousness of voices (Chadwick and Birchwood 1994). The focus in the treatment of delusions is on challenging dysfunctional beliefs and learning to make more balanced conclusions. According to van der Gaag and his colleagues (2003) paranoid delusions should be viewed as anxiety disorders. Therefore, exposure therapy plays an important role on CBT for psychosis. Several studies have shown that CBT reduces psychotic symptoms (Pfammatter and others 2006; Pilling and others 2002), reduces distress caused by psychotic symptoms (Fowler and others 1995; Garety and others 1997; Kuipers and others 1997; Tarrier and others 2004; Tarrier and Wykes 2004; Valmaggia and others 2005), and there are some studies suggesting that it might reduce relapse rates (Gumley and others 2006; Gumley and others 2003). In a recent study, the effects of CBT and family intervention were compared (Garety and others 2008). No effects were found for family-intervention. For CBT, beneficial effects on depression at 24 months follow up, distress caused by delusions, and social functioning were found. From these findings it can be inferred that CBT helps for depression and emotional distress that accompanies psychotic symptoms, but not for relapse prevention. These findings are in accordance with what was proposed by Birchwood and Trower (2006), namely that $C B T$ should focus primarily on the emotional dysfunction (i.e. affective symptoms) in psychosis rather than focus on improving psychotic symptoms. Extending this therapy in such a way that treatment is additionally focused on emotional sensitivity to stress in daily life may thus have positive effects on depression and distress that are experienced with psychotic symptoms, thereby improving functional outcome.

For the development of a new module, specifically designed to reduce sensitivity to stress in daily life, it seems useful to incorporate elements from the treatment protocols for disorders with similar characteristics such as Post Traumatic Stress Disor$\operatorname{der}$ (PTSD) and Burnout. The protocol for treatment of Burnout could be especially useful for the treatment of the sensitivity to small daily stressors. In Burnout, it is the accumulation of small work-related daily events that produces the more serious emotional complaints. The first phase of treatment is focused on what complaints are present and on the patient's own theories about what caused these complaints. In the second phase, the patient has a choice between several sub-modules: (i) relaxation techniques and registration of relaxing activities/ situations; (ii) improving of day structure and lifestyle, and (iii) a self control program to teach the patient to recognize signs of tension and exhaustion to prevent increase of complaints (Keijsers and others 2004). Treatment as described for PTSD could play an important role in relapse prevention. For many patients, the experience of a psychotic episode is so traumatic that their anxiety of having another one increases dramatically. This fear of having another episode can also lead to an increase in sensitivity to stress in the daily life of these patients. Additionally focusing treatment on the past psychotic episode itself and the traumatic content of it may have a positive effect on relapse 
prevention. Imaginary exposure to the traumatic event is a core feature of treatment for PTSD (Keijsers and others 2004). The most recent technique for the treatment of traumatic experiences, Eye Movement Desensitization and Reprocessing (EMDR), combines imaginary exposure to the traumatic event with distraction techniques (Shapiro 1989; Shapiro 2001). However, the exact mechanisms of action and the effects of this treatment are currently unknown.

\section{Concluding word}

The results of this thesis show that combining data from a psychometric high risk group and (semi-) genetically sensitive group is an elegant way to elucidate intermediate phenotypes of psychotic disorder, since (i) there is no influence of the disease itself, and (ii) a cross-trait cross-subjects design allows us to investigate associations in an unconfounded and uncontaminated way.

In addition, evidence for an affective pathway to psychosis has been presented. Experience Sampling was used to show that increased emotional reactivity to stress contributes to the psychosis risk, independent of cognition. The results presented in this thesis underline the importance of investigating independent mechanisms of risk underlying the different clinical expressions of psychosis to reveal the causal mechanisms. Increased stress-reactivity, as an intermediary phenotype, could play an important role in elucidating the biological and psychological mechanisms that are underlying the positive symptoms of psychosis. 
Figure 1. Solid arrows: Cross-twin, cross-trait associations; examination of the association between selfreported subclinical psychotic experiences $(\mathrm{PE})$ (trait 1) and interview-based clinical psychotic symptoms (PS) (trait 2) across genetically related individuals (twins). If the cross-trait, cross-twin association is greater in monozygotic than in dizygotic twins, a genetic contribution to the observed association may be inferred (Wichers et al., 2007). Dotted arrows: Within-twin, cross-trait associations.

TRAIT 1

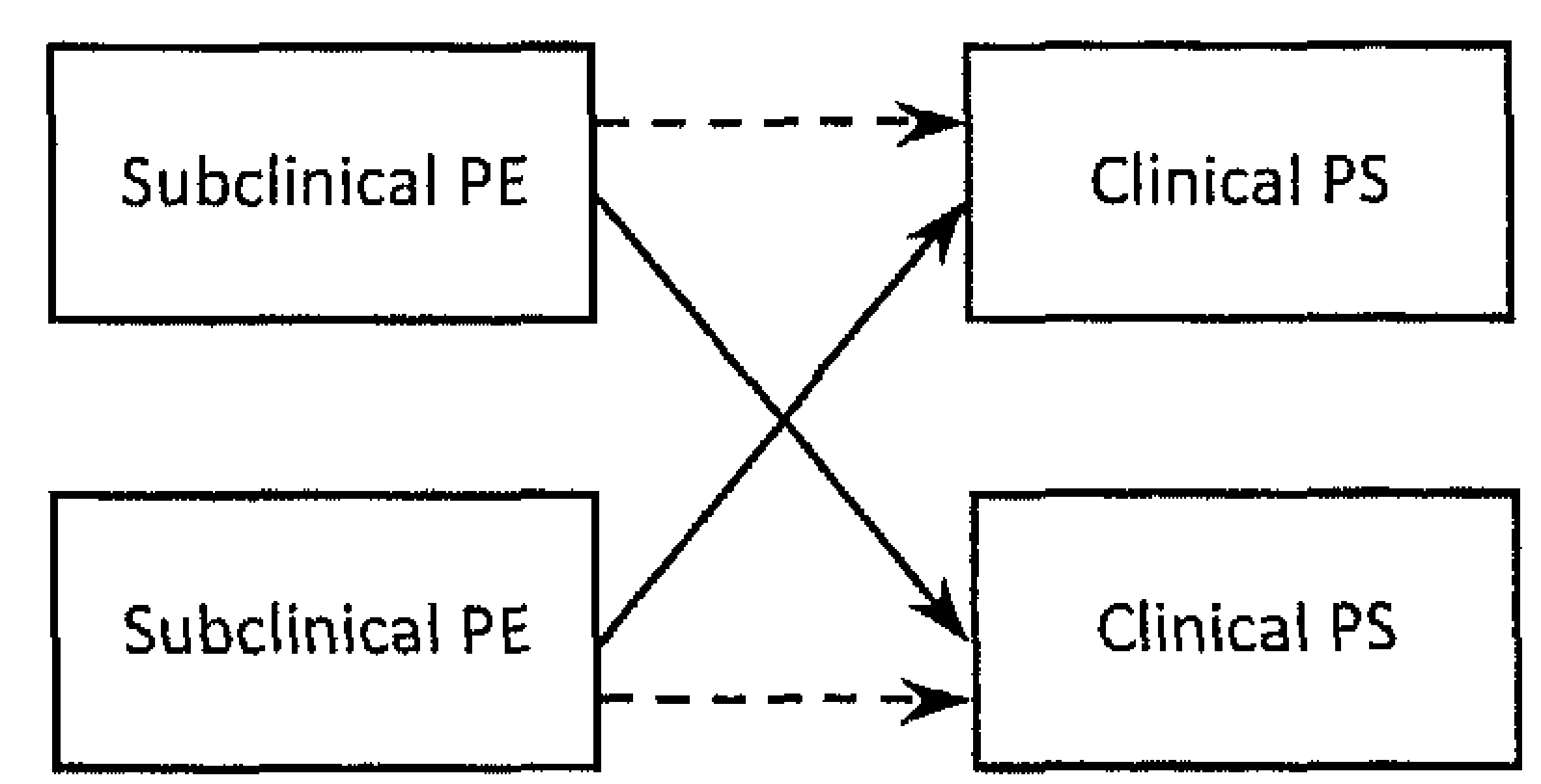

Figure 2. Solid arrows: Cross-twin, cross-trait associations; examination of the association between stress-reactivity (trait 1) and subclinical psychotic experiences (trait 2) across genetically related individuals (twins). If the cross-trait, cross-twin association is greater in monozygotic than in dizygotic twins, a genetic contribution to the observed association may be inferred (Wichers et al., 2007). Dotted arrows: Within-twin, cross-trait associations.

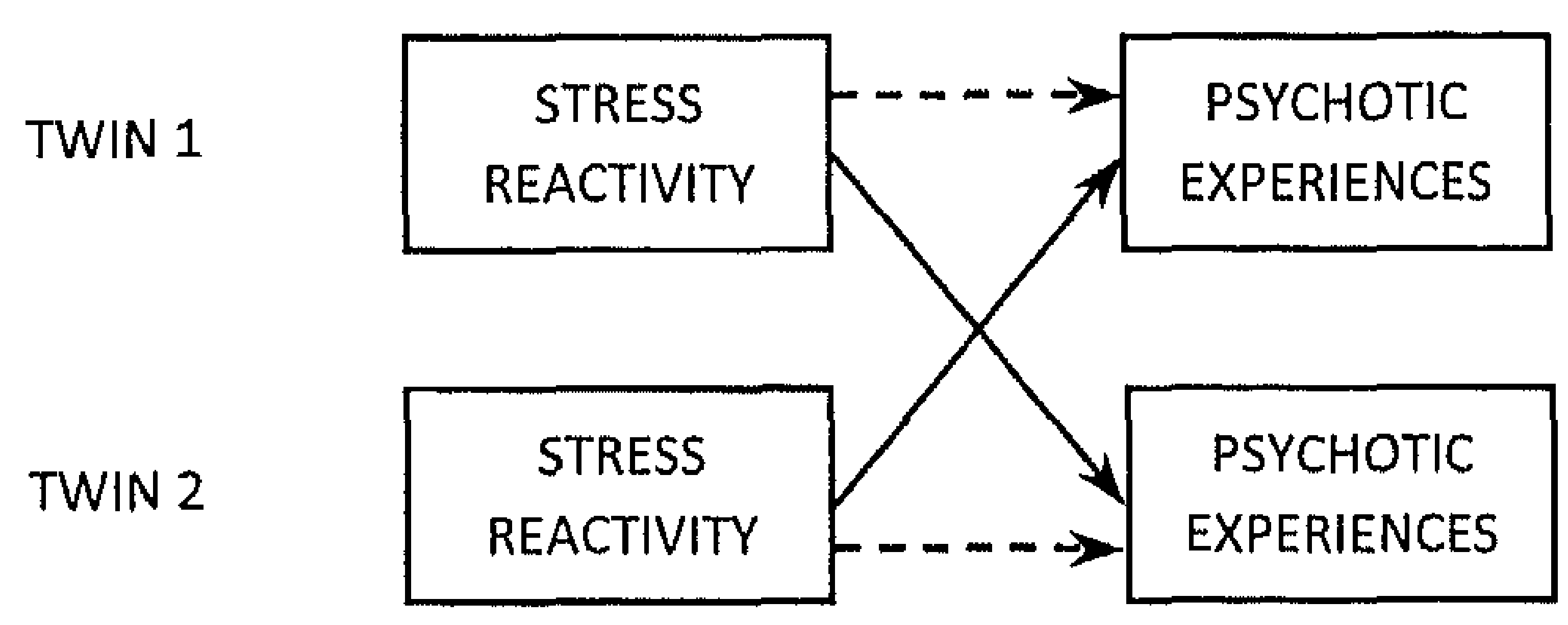


ON THE PATHWAYFROM STRESSTO PSYCHOSIS

Figure 3a. Cross-sib, within-trait associations.

\section{TRAIT 1}

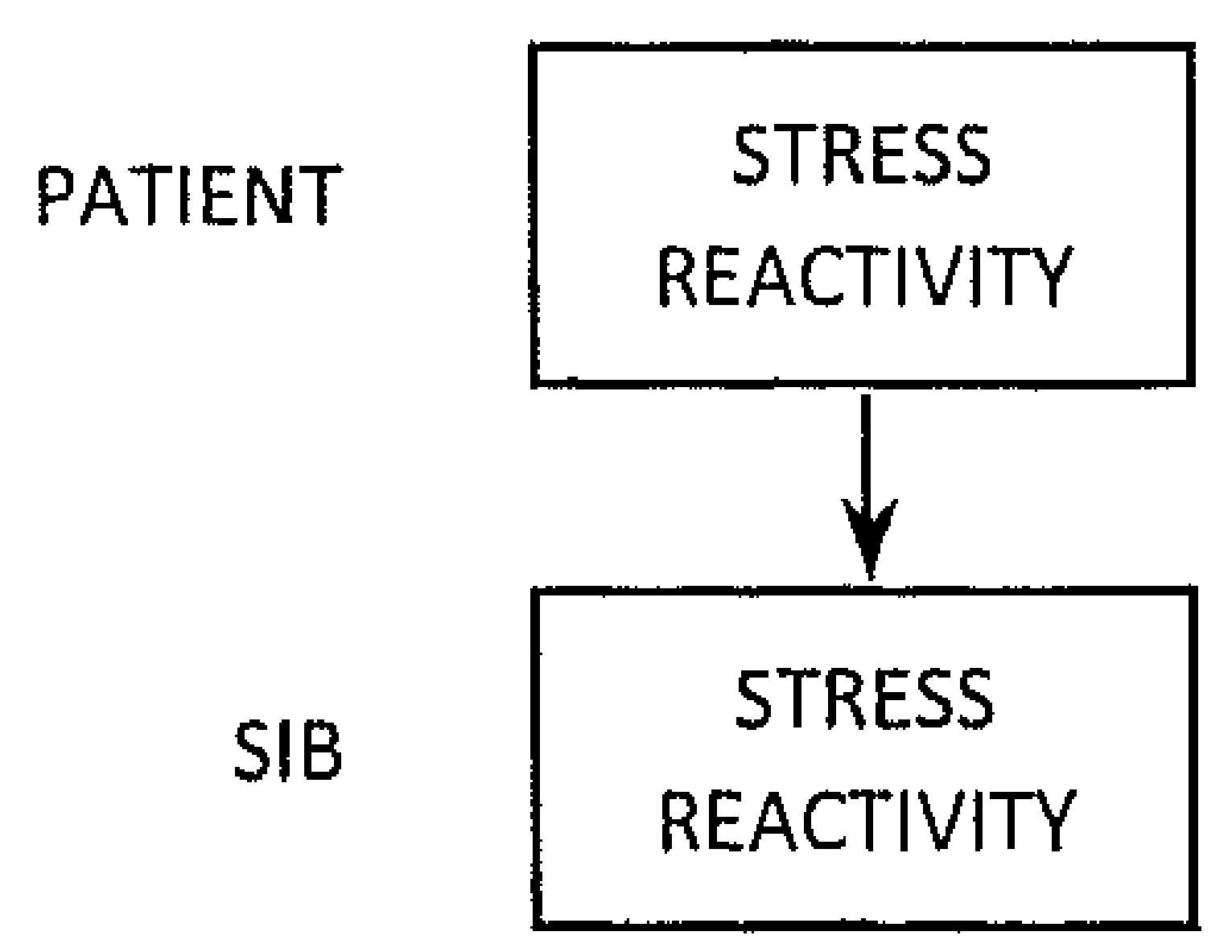

Figure 3b. Cross-sib, cross-trait associations: examination of the association between stress-reactivity (trait 1) and positive psychotic symptoms (trait 2) across genetically related individuals (siblings).

PATIENT

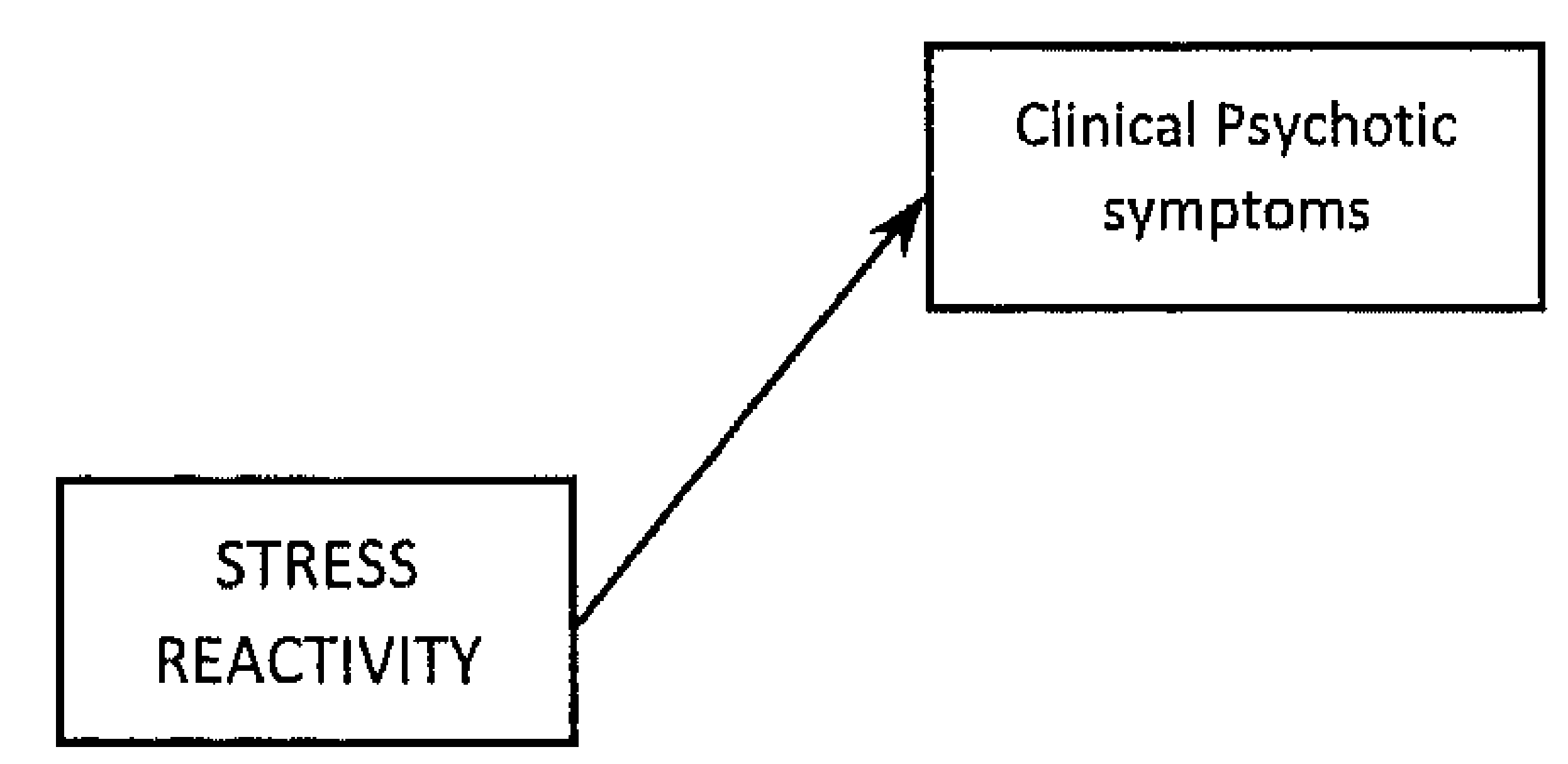




\section{CMABTER T}

Figure 4. The two pathways to psychosis. The studies presented in the current thesis provide evidence for (i) separate pathways to psychosis, and in particular (ii) an affective pathway to psychosis (Myin-Germeys \& van Os, 2007).

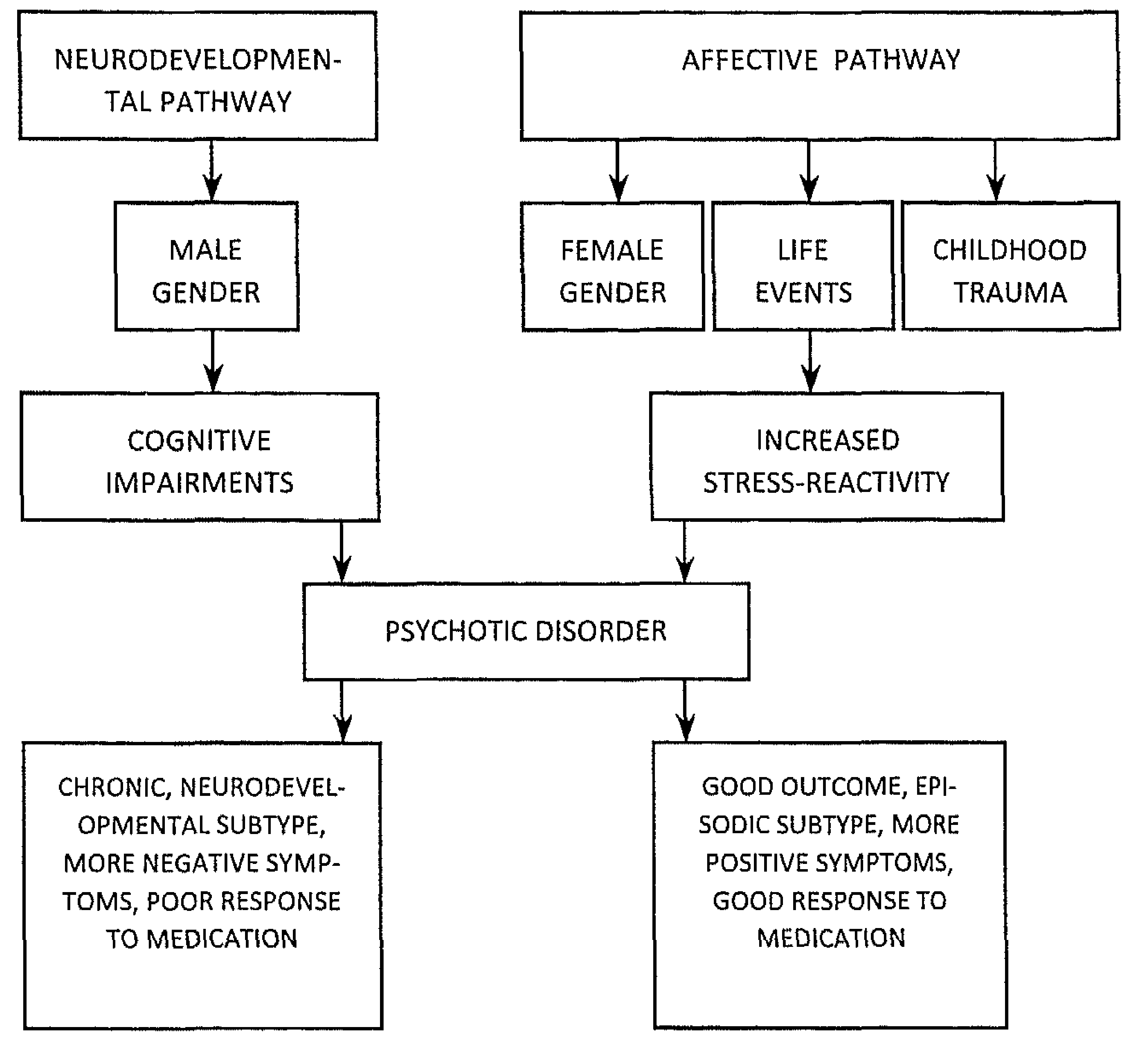


ON THE PATHWAY FROM STRESSTOPSYCHOSIS

\section{References}

Beck AT. 1952. Successful outpatient psychotherapy of a chronic schizophrenic with a delusion based on borrowed guilt. Psychiatry 15(3):305-12.

Beck AT, Rector NA. 2002. Delusions: A cognitive perspective. Journal of Cognitive Psychotherapy 16(4):455-468.

Beck AT, Rector NA. 2003. A cognitive model of hallucinations. Cognitive Therapy \& Research 27(1):1952.

Birchwood M, Trower P. 2006. The future of cognitive-behavioural therapy for psychosis: not a quasineuroleptic. Br J Psychiatry 188:107-8.

Chadwick P, Birchwood M. 1994. The omnipotence of voices. A cognitive approach to auditory hallucinations. Br J Psychiatry 164(2):190-201.

Cohen AS, Docherty NM, Nienow T, Dinzeo T. 2003. Self-reported stress and the deficit syndrome of schizophrenia. Psychiatry 66(4):308-16.

Corcoran R, Mercer G, Frith CD. 1995. Schizophrenia, symptomatology and social inference: investigating "theory of mind" in people with schizophrenia. Schizophr Res 17(1):5-13.

Cougnard A, Marcelis M, Myin-Germeys I, De Graaf R, Vollebergh W, Krabbendam L, Lieb R, Wittchen HU, Henquet $C$, Spauwen $J$ and others. 2007. Does normal developmental expression of psychosis combine with environmental risk to cause persistence of psychosis? A psychosis proneness-persistence model. Psychol Med 37(4):513-27.

Delespaul PAEG. 1995. Assessing schizophrenia in daily life. Maastricht: Universitaire Pers.

Dominguez $M$, Wichers $M$, Lieb R, Wittchen HU, Van Os J. 2007. Evidence that onset of clinical psychosis is the outcome of progressively more persistent subclinical psychotic experiences: an 8-year cohort study. American Journal of Psychiatry submitted.

Fowler D, Garety PA, Kuipers E. 1995. Cognitive Behaviour Therapy for Psychosis. Chichester: John Wiley and Sons.

Galdos P, van Os J. 1995. Gender, psychopathology, and development: from puberty to early adulthood. Schizophr Res 14(2):105-12.

Galdos PM, van Os Jل, Murray RM. 1993. Puberty and the onset of psychosis. Schizophr Res 10(1):7-14.

Garety P, Fowler D, Kuipers E, Freeman D, Dunn G, Bebbington P, Hadley C, Jones S. 1997. London-East Anglia randomised controlled trial of cognitive-behavioural therapy for psychosis. If: Predictors of outcome. Br I Psychiatry 171:420-6.

Garety PA, Fowler DG, Freeman D, Bebbington P, Dunn G, Kuipers E. 2008, Cognitive--behavioural therapy and family intervention for relapse prevention and symptom reduction in psychosis: randomised controlled trial. Br J Psychiatry 192(6):412-23.

Glaser JP, van Os J, Portegijs PJ, Myin-Germeys I. 2006. Childhood trauma and emotional reactivity to daily life stress in adult frequent attenders of general practitioners. J Psychosom Res 61(2):229-36.

Green MF. 1998. Schizophrenia from a neurocognitive perspective: Probing the impenetrable darkness. Boston: Allyn and Bacon.

Gross G, Huber G, Klosterkötter J, Linz M. 1987. Bonner Skala für die Beurteilung von Basissymtomen. Springer-Verlag, editor. Berlin, Heidelberg, New York.

Gumley A, Karatzias A, Power K, Reilly J, McNay L, O'Grady M. 2006. Early intervention for relapse in schizophrenia: impact of cognitive behavioural therapy on negative beliefs about psychosis and selfesteem. Br J Clin Psychol 45(Pt 2):247-60.

Gumley A, O'Grady M, McNay L, Reilly J, Power K, Norrie J. 2003. Early intervention for relapse in schizophrenia: results of a 12-month randomized controlied trial of cognitive behavioural therapy. Psychol Med 33(3):419-31.

Hanssen $M$, Bak $M, B i j l ~ R$, Vollebergh $W$, van Os J. 2005. The incidence and outcome of subclinical psychatic experiences in the general population. Br J Clin Psychol 44(Pt 2):181-91. 


\section{CAPTER T}

Hodel B, Brenner HD, Merlo MC, Teuber JF. 1998. Emotional management therapy in early psychosis. Br J Psychiatry Suppl 172(33):128-33.

Jacobs N, Rijsdijk F, Derom C, Vlietinck R, Delespaul P, van Os J, Myin-Germeys 1. 2006. Genes making one feel blue in the flow of daily life: a momentary assessment study of gene-stress interaction. Psychosom Med 68(2):201-6.

Janssen I, Krabbendam L, Bak M, Hanssen M, Vollebergh W, de Graaf R, van Os J. 2004. Childhood abuse as a risk factor for psychotic experiences. Acta Psychiatr Scand 109(1):38-45.

Johns LC, van Os J. 2001. The continuity of psychotic experiences in the general population. Clinical Psychology Review 21(8):1125-41.

Keijsers GPJ, van Minnen A, Hoogduin CAL. 2004. Protocollaire behandeling in de ambulante geestelijke gezondheidszorg. Houten: Bohn Stafleu van Loghum.

Kelleher I, Harley M, Lynch F, Arseneault L, Fitzpatrick C, Cannon M. 2008. Associations between childhood trauma, bullying and psychotic symptoms among a school-based adolescent sample. $\mathrm{Br} J \mathrm{Psy}$ chiatry 193(5):378-82.

Kendler KS, McGuire M, Gruenberg AM, Walsh D. 1995. Schizotypal symptoms and signs in the Roscommon Family Study. Their factor structure and familial relationship with psychotic and affective disorders. Arch Gen Psychiatry 52(4):296-303.

Kuipers E, Bebbington P, Dunn G, Fowler D, Freeman D, Watson P, Hardy A, Garety P. 2006. Influence of carer expressed emotion and affect on relapse in non-affective psychosis. Br J Psychiatry 188:173-9.

Kuipers E, Garety P, Fowler D, Dunn G, Bebbington P, Freeman D, Hadley C. 1997. London-East Anglia randomised controlled trial of cognitive-behavioural therapy for psychosis. I: effects of the treatment phase. Br \& Psychiatry 171:319-27.

Lardinois M, Lataster T, Mengelers R, van Os J, Myin-Germeys I. submitted. Childhood trauma and Stressinduced Alterations in Salience Attribution in Psychosis: An Experience Sampling Study.

Leff J. 1994. Stress reduction in the social environment of schizophrenic patients. Acta Psychiatr Scand Suppl 384:133-9.

Meaney MJ, Szyf M. 2005. Environmental programming of stress responses through DNA methylation: life at the interface between a dynamic environment and a fixed genome. Dialogues Clin Neurosci $7(2): 103-23$.

Morrens M, Krabbendam L, Bak M, Delespaul P, Mengelers R, Sabbe B, Hulstijn W, van Os J, MyinGermeys I. 2007. The relationship between cognitive dysfunction and stress sensitivity in schizophrenia: a replication study. Soc Psychiatry Psychiatr Epidemiol 42(4):284-7.

Murray RM, O'Callaghan E, Castle DJ, Lewis SW. 1992. A neurodevelopmental approach to the classification of schizophrenia. Schizophr Bull 18(2):319-32.

Myin-Germeys I, Delespaul P, van Os J. 2005. Behavioural sensitization to daily life stress in psychosis. Psychol Med 35(5):733-41.

Myin-Germeys 1, Krabbendam L, Delespaul P, van Os J. 2003. Can cognitive deficits explain differential sensitivity to life events in psychosis? Soc Psychiatry Psychiatr Epidemiol 38(5):262-8.

Myin-Germeys 1, Krabbendam L, Jolles J, Delespaul PA, van Os J. 2002. Are cognitive impairments associated with sensitivity to stress in schizophrenia? An experience sampling study. Am J Psychiatry 159(3):443-9.

Myin-Germeys I, van Os J. 2007. Stress-reactivity in psychosis: evidence for an affective pathway to psychosis. Clin Psychol Rev 27(4):409-24.

Myin-Germeys I, van Os J, Schwartz JE, Stone AA, Delespaul PA. 2001. Emotional reactivity to daily life stress in psychosis. Arch Gen Psychiatry 58(12):1137-44.

Peralta V, Cuesta MJ. 1998. Factor structure and clinical validity of competing models of positive symptoms in schizophrenia. Biol Psychiatry 44(2):107-14.

Peralta V, Cuesta MJ, de Leon J. 1994. An empirical analysis of latent structures underlying schizophrenic symptoms: a four-syndrome model. Biol Psychiatry 36(11):726-36.

Pfammatter M, Junghan UM, Brenner HD. 2006. Efficacy of psychological therapy in schizophrenia: conclusions from meta-analyses. Schizophr Bull 32 Suppl 1:S64-80. 


\section{ON THE PATHWAY FROM STEESS TO PSYCHOSIS}

Pharoah F, Mari J, Rathbone J, Wong W. 2006. Family intervention for schizophrenia. Cochrane Database Syst Rev(4):CD000088.

Pilling S, Bebbington P, Kuipers E, Garety P, Geddes J, Orbach G, Morgan C. 2002. Psychological treatments in schizophrenia: 1. Meta-analysis of family intervention and cognitive behaviour therapy. Psychol Med 32(5):763-82.

Pinkham AE, Penn DL, Perkins DO, Lieberman J. 2003. Implications for the neural basis of social cognition for the study of schizophrenia. Am J Psychiatry 160(5):815-24.

Read J. 1997. Child abuse and psychosis: a literature review and implications for professional practice. Professional Psychology: Res Practice 28(5):448-456.

Read J. 1998. Child abuse and severity of disturbance among adult psychiatric inpatients. Child Abuse Negl 22(5):359-68.

Read J, Agar K, Argyle N, Aderhold V. 2003. Sexual and physical abuse during childhood and adulthood as predictors of hallucinations, delusions and thought disorder. Psychol Psychother 76(Pt 1):1-22.

Read J, Hammersley P. 2005. Child sexual abuse and schizophrenia. Br I Psychiatry 186:76; author reply 76.

Read J, van Os J, Morrison AP, Ross CA. 2005. Childhood trauma, psychosis and schizophrenla: a literature review with theoretical and clinical implications. Acta Psychiatr Scand 112(5):330-50.

Robins E, Guze SB. 1970. Establishment of diagnostic validity in psychiatric illness: its application to schizophrenia. American Journal of Psychiatry 126(7):983-987.

Scholten MR, van Honk J, Aleman A, Kahn RS. 2006. Behavioral inhibition system (BIS), behavioral activation system (BAS) and schizophrenia: relationship with psychopathology and physiology. J Psychiatr Res 40(7):638-45.

Shapiro F. 1989. Eye movement desensitization: a new treatment for post-traumatic stress disorder. I Behav Ther Exp Psychiatry 20(3):211-7.

Shapiro F. 2001. Eye Movement Desensitisation and Reprocessing: Basic principles, protocols, and procedures. New York: The Guilford Press.

Spataro J, Mullen PE, Burgess PM, Wells DL, Moss SA. 2004. Impact of child sexual abuse on mental health: prospective study in males and females. Br J Psychiatry 184:416-21.

Spauwen J, Krabbendam L, Lieb R, Wittchen HU, van Os J. 2006. Impact of psychological trauma on the development of psychotic symptoms: relationship with psychosis proneness. Br J Psychiatry 188:52733.

Stefanis NC, Hanssen M, Smirnis NK, Avramopoulos DA, Evdokimidis IK, Stefanis CN, Verdoux H, Van Os I. 2002. Evidence that three dimensions of psychosis have a distribution in the general population. Psychol Med 32(2):347-58.

Tarrier N, Lewis S, Haddock G, Bentall R, Drake R, Kinderman P, Kingdon D, Siddle R, Everitt J, Leadley K and others. 2004. Cognitive-behavioural therapy in first-episode and early schizophrenia. 18-month follow-up of a randomised controlled trial. Br J Psychiatry 184:231-9.

Tarrier N, Wykes T. 2004. Is there evidence that cognitive behaviour therapy is an effective treatment for schizophrenia? A cautious or cautionary tale? Behav Res Ther 42(12):1377-401.

Tsuang MT, Woolson RF, Fleming JA. 1979. Long-term outcome of major psychoses. I. Schizophrenia and affective disorders compared with psychiatrically symptom-free surgical conditions. Arch Gen Psychiatry 36(12):1295-301.

Valmaggia LR, van der Gaag $M$, Tarrier $N$, Pijnenborg $M$, Slooff CJ. 2005. Cognitive-behavioural therapy for refractory psychotic symptoms of schizophrenia resistant to atypical antipsychotic medication. Randomised controlled trial. Br J Psychiatry 186:324-30.

van der Gaag M, Hageman MC, Birchwood M. 2003. Evidence for a cognitive model of auditory hallucinations. J Nerv Ment Dis 191(8):542-5.

van Hooren S, Versmissen D, Janssen I, Myin-Germeys I, J AC, Mengelers R, van Os J, Krabbendam L. 2008. Social cognition and neurocognition as independent domains in psychosis. Schizophr Res.

van $\mathrm{O}_{5} \mathrm{~J}$, Hanssen M, Bijl RV, Vollebergh W. 2001. Prevalence of psychotic disorder and community level of psychotic symptoms: an urban-rural comparison. Arch Gen Psychiatry 58(7):663-8. 


\section{CHA}

Vauth R, Rusch N, Wirtz M, Corrigan PW. 2004. Does social cognition influence the relation between neurocognitive deficits and vocational functioning in schizophrenia? Psychiatry Res 128(2):155-65.

Verdoux H, van Os J, Maurice-Tison S, Gay B, Salamon R, Bourgeois M. 1998. Is early adulthood a critical developmental stage for psychosis proneness? A survey of delusional ideation in normal subjects. Schizophr Res 29(3):247-54.

Walker E, Mittal V, Tessner K. 2008. Stress and the hypothalamic pituitary adrenal axis in the developmental course of schizophrenia. Annu Rev Clin Psychol 4:189-216.

Walker EF, Diforio D. 1997. Schizophrenia: a neural diathesis-stress model. Psychol Rev 104(4):667-85.

Weaver IC, Cervoni N, Champagne FA, D'Alessio AC, Sharma S, Seckl JR, Dymov S, Szyf M, Meaney MJ. 2004. Epigenetic programming by maternal behavior. Nat Neurosci 7(8):847-54.

Werry JS. 1992. Child and adolescent (early onset) schizophrenia: a review in light of DSM-III-R. J Autism Dev Disord 22(4):601-24.

Wichers M, Myin-Germeys I, Jacobs N, Peeters F, Kenis G, Derom C, Vlietinck R, Delespaul P, Van Os J. 2007. Genetic risk of depression and stress-induced negative affect in daily life, $\mathrm{Br} J$ Psychiatry 191:218-23.

Zubin J, Spring B. 1977. Vulnerability - A new view of schizophrenia. Journal of Abnormal Psychology $86: 103-126$. 


\section{Summary}

Schizophrenia is a clinically heterogeneous disorder and the development of the fifth edition of the DSM has fuelled the discussion whether schizophrenia is a valid and useful entity. More traditional views suggest that the extensive clinical heterogeneity in schizophrenia can be reduced to two main forms, a good outcome positive psychotic syndrome and a poor outcome negative syndrome. In more recent psychiatric literature, on the other hand, several authors have favoured a dimensional approach in which patients have more or less psychopathology rated on several symptom dimensions. This thesis, on the pathway from stress to psychosis, considers such a dimensional approach to psychosis and uses a twin- and siblingdesign to investigate the interplay between genes and exposure to daily life stress in the development of positive psychotic symptoms.

CHAPTER 1 describes the phenomenology of schizophrenia. An overview of evidence from previous studies investigating a dimensional approach to psychosis is given, showing that psychotic disorder exists as a continuum of severity rather than as an all-or-none phenomenon. It is argued that a broad distribution of the psychosis phenotype exists in nature, and that this broad phenotype, even though transitory in most cases, shows aetiological and familial continuity with the clinical phenotype of psychotic disorder. An elegant way of testing the possible genetic continuity between the subclinical and clinical psychosis phenotype in an unconfounded and uncontaminated way (i.e. cross-trait, cross-twin design) is described in this chapter. In addition, it is argued that, in line with a dimensional approach to psychosis, it is particularly useful to investigate underlying risk factors that are related to specific symptom dimensions of the disorder. It is hypothesized that several underlying indicators of genetic risk play a role in the development of psychosis, possibly independent of each other. Emotional reactivity to daily life stress and impairments in cognitive functioning are possible risk factors. An affective pathway to psychosis is put forward. It is hypothesized that emotional reactivity to stress in daily life, independent of cognition, is at the core of a reactive, good outcome, type I schizophrenia with high levels of positive symptoms. Experience Sampling is described as a method to investigate emotional reactivity to stress in the realm of daily life.

The first part of this thesis is aimed at finding evidence for a continuum model of psychosis with genetic risk factors impacting on a broadly distributed and transitory population expression of psychosis during development. 
CHAPTER 2 investigates in a general population twin sample whether self-reported psychotic experiences are genetically continuous with interview-based psychotic symptoms and whether this genetic relationship is age-dependent using a crosstrait, cross-twin design. Cross-trait, cross-twin analyses allow for the examination of the association in an unconfounded fashion, since it is possible to investigate the association between one trait in twin 1 and a second trait in twin 2, while controlling for the second trait in twin 1. A significant association between subclinical psychotic experiences and clinical psychotic symptoms both within and across genetically identical monozygotic twins was revealed. Moreover, the association between subclinical psychotic experiences and clinical psychotic symptoms was found to be much stronger in monozygotic than in dizygotic twins. In addition, the association between subclinical psychotic experiences and clinical psychotic symptoms was shown to be much stronger in the younger half of the sample (age $<26$ years). It is concluded that the psychosis phenotype exists in nature, that it peaks at the age of young adulthood, and that there is genetic, aetiological, temporal, and familial continuity between the naturalistic phenotype and diagnostic constructs such as psychotic disorder and schizophrenia.

The second part of the thesis aims at collecting evidence for a so called "affective pathway to psychosis". Stress-reactivity is hypothesized to be the core vulnerability marker within this pathway to a good outcome type with high levels of positive symptoms.

CHAPTER 3 describes data from a general population twin study using a cross-trait, within- and across-twin design to investigate whether emotional reactivity to stress in daily life is an unconfounded and uncontaminated indicator of risk for developing psychosis. Cross-trait, within-twin analyses showed significant associations between stress-reactivity and subclinical psychotic experiences in each person. In addition, the cross-trait, cross-twin analyses showed that stress-reactivity in one twin is significantly moderated by subclinical psychotic experiences in the co-twin. These results suggest that the psychosis phenotype cosegregates with increased emotional reactivity to stress in daily life, and that stress-reactivity is indeed an unconfounded and uncontaminated intermediary phenotype of psychosis.

The same hypothesis is tested in a semi genetically sensitive sample of patients with non-affective psychosis and their siblings (CHAPTER 5). Within-trait, cross-sib associations in this sample revealed a significant association between stress-reactivity in the patient and stress-reactivity in their first-degree relative. These findings provide evidence for familial transmission of increased stress-reactivity.

CHAPTER 4 describes an observational study investigating whether cognitive impairments and altered stress-reactivity are independent risk mechanisms that are 
possibly underlying different symptom dimensions. Aims of the study are to replicate the previous finding that stress-reactivity is not or inversely associated with cognitive performance in patients with psychotic disorder and to examine whether stress-reactivity is specifically associated with the positive psychotic symptom dimension. Patients with psychotic disorder were assessed with the Positive and Negative Syndrome Scale and a neuropsychological test battery. The experience sampling method was used to measure stress-reactivity. In some instances, cognitive functioning did not alter the emotional reaction to stress. In other instances, an inverse relationship was found, with better performance on cognitive tests being associated with greater stress-reactivity. Additionally, higher levels of stressreactivity were associated with higher levels of positive symptoms and lower levels of negative symptoms. The findings of this study suggest that increased stressreactivity is a mechanism specifically related to positive psychotic symptoms, independent of cognition.

CHAPTER 5 investigates further whether stress-reactivity is an intermediary phenotype for a positive syndrome of psychosis. The first aim of the study is to investigate whether stress-reactivity clusters within families of patients with a diagnosis of psychotic disorder. The second aim is to test whether stress-reactivity in relatives cosegregates with positive symptoms in patients. In a group of patients with psychotic disorder and their siblings, the Experience Sampling Method was used to measure the increase in negative affect in reaction to stress in daily life (i.e. stressreactivity). Positive symptoms in the patients were measured with the PANSS. Within-trait, cross-sib associations showed a significant association between stressreactivity in the patient and stress-reactivity in their first degree relative. Additionally, significant cross-trait, cross-sib associations were established showing a significant association between the patient's positive symptoms and stress-reactivity in the first-degree relative. Furthermore, increased stress-reactivity levels in the sibling were associated with increased positive symptom intensity in the patients. This study provides evidence for familial transmission of increased stress-reactivity and suggests a possible genetic contribution to increased stress-reactivity, which is specifically underlying the positive symptom dimension of psychosis.

CHAPTER 6 describes a study in which the association between victimization in childhood and psychosis in adulthood is investigated. This association was examined in the crucial developmental period of early adolescence. It was tested whether (i) unwanted sexual experiences, and (ii) being bullied, were associated with nonclinical delusional ideation and hallucinatory experiences in a general population sample of 14 year olds. A strong dose-response association was found between sexual trauma and non-clinical psychotic experiences. The results of this study suggest that reported associations between childhood victimization and adult psychosis 


\section{ON THE PATHWAY FROM STRESS TO PSYCHOSIS}

can be understood in a developmental framework of onset of at-risk mental states in early adolescence. In addition, the data suggest that the traumatic experience of being bullied may also feed the cognitive and biological mechanisms underlying formation of psychotic ideation.

In CHAPTER 7, the results of this thesis including the data from two general population twin studies, two clinical observational studies, and one young adolescent general population study are discussed and integrated into a dimensional model in which an affective pathway to the positive symptoms of psychosis is set out. Clinical implications of the findings in this thesis are provided as well as directions for future research. 


\section{Samenvatting}

Schizofrenie is een van de meest ernstige psychiatrische aandoeningen met een prevalentie van ongeveer 1 procent. De ziekte manifesteert zich in de adolescentie of vroege volwassenheid en wordt gekenmerkt door een aantal symptomen zoals positieve symptomen (wanen en hallucinaties), cognitieve stoornissen (bijvoorbeeld verminderde aandacht en concentratie tijdens mentale inspanning), negatieve symptomen (vervlakt affect, anhedonie) en een sombere stemming. De ziekte kent een sterk heterogeen klinisch beeld en in recente literatuur wordt daarom steeds vaker geopteerd voor een dimensionele benadering waarbij patiënten meer of minder psychopathologie hebben die gescoord wordt op verschillende symptoomdimensies. In dit proefschrift, On the pathway from stress to psychosis, wordt een dergelijke dimensionele benadering van psychose onderzocht en wordt gebruik gemaakt van een twin (tweeling)- en een sibling (broer en/of zus) design om het samenspel tussen genetische kwetsbaarheid en blootstelling aan stress in het dagelijks leven in de ontwikkeling van positieve psychotische symptomen te onderzoeken.

HOOFDSTUK 1 biedt een literatuuroverzicht van de etiologie en fenomenologie van schizofrenie, als ook uitleg over een dimensie benadering van psychose, het continuümmodel. Dit model gaat er, in tegenstelling tot een dichotoom verklaringsmodel (je hebt een ziekte wel of niet), van uit dat er een continuüm van psychotische ervaringen bestaat. Dit continuüm loopt van subklinische psychoseachtige ervaringen die voorkomen in de algemene bevolking tot gedragsveranderingen met klinische psychotische symptomen en uiteindelijk een klinisch psychotische stoornis. In dit hoofdstuk wordt een elegante methode beschreven waarmee de genetische continuïteit tussen de brede algemene populatie expressie van subklinische psychoseachtige ervaringen en klinische psychotische stoornis op niet gecontamineerde wijze kan worden onderzocht. In overeenstemming met een dimensie benadering van psychose wordt in dit hoofdstuk tevens gesteld dat het bijzonder zinvol is om risicofactoren te onderzoeken die met specifieke symptoomdimensies samenhangen. Emotionele gevoeligheid voor stress in het dagelijks leven en cognitieve stoornissen worden voorgedragen als mogelijke onafhankelijke intermediaire fenotypen die het risico op het ontwikkelen van een psychotische stoornis vergroten. [Een intermediair fenotype is een afspiegeling van genetisch risico die niet direct met het blote oog kan worden waargenomen.] Een affectief pad naar een psychotisch syndroom gekenmerkt door m.n. positieve symptomen (wanen en hallucinaties) met een gunstig ziektebeloop wordt beschreven met als hypothese dat stress- 


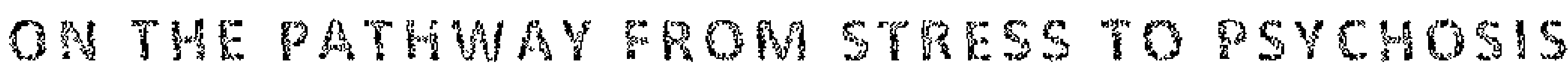

gevoeligheid aan de basis ligt van dit syndroom. Tot slot wordt Experience Sampling beschreven. Dit is een gestructureerde dagboekmethode die gebruikt wordt om emotionele gevoeligheid voor stress in het dagelijks leven te meten.

In het eerste deel van dit proefschrift wordt bewijs gezocht voor een continuüm model van kwetsbaarheid voor psychose.

HOOFDSTUK 2 beschrijft een onderzoek waarbij gebruik werd gemaakt van een twin sample uit de algemene populatie. Een cross-trait, cross-twin design werd toegepast om te onderzoeken of subklinische psychotische ervaringen genetische continuitteit vertonen met klinische psychotische symptomen en of deze genetische associatie leeftijdsafhankelijk is. Een cross-trait, cross-twin design maakt het mogelijk om associaties op niet gecontamineerde wijze te onderzoeken. Het is immers mogelijk om de associatie tussen kenmerk 1 , gemeten bij tweeling 1 en kenmerk 2 , gemeten bij tweeling 2 te onderzoeken terwijl je op hetzelfde moment controleert voor kenmerk 2 in tweeling 1. De resultaten van deze studie laten zien dat er een significante associatie bestaat tussen subklinische psychotische ervaringen in tweeling 1 en klinische psychotische symptomen in tweeling 2 . Bovendien blijkt deze associatie veel sterker te zijn voor eeneiige dan twee-eiige tweelingen en sterker in de jongere helft van het sample (jonger dan 26 jaar). We concludeerden dat het psychose fenotype bestaat in de algemene populatie, dat dit fenotype piekt in de adolescentie of vroege volwassenheid en dat er een genetische, etiologische, (leef)tijdsgebonden, en familiale continuïteit bestaat tussen dit fenotype uit de algemene populatie en diagnoses als psychotische stoornis en schizofrenie die overeenstemt met het continuümmodel.

In het tweede deel van dit proefschrift wordt bewijs gezocht voor een "affectief pad naar psychose" met als hypothese dat stress-gevoeligheid een belangrijk intermediair fenotype is binnen dit pad naar een positief psychotisch syndroom met een gunstig ziektebeloop en met name positieve psychotische symptomen.

HOOFDSTUK 3 beschrijft een studie waarbij opnieuw gebruik werd gemaakt van hetzelfde tweeling sample uit de algemene populatie. Een cross-trait, within-twin en een cross-trait, cross-twin design werden gebruikt om te onderzoeken of stressgevoeligheid een niet gecontamineerd intermediair fenotype voor psychose is. Cross-trait, within-twin analyses toonden aan dat er een significante associatie bestaat tussen stress-gevoeligheid en subklinische psychotische ervaringen in elk individu. Cross-trait, cross-twin analyses toonden aan dat stress-gevoeligheid in de ene tweeling beïnvloed wordt door subklinische psychotische ervaringen in de andere tweeling. Deze resultaten laten zien dat er cosegregatie bestaat tussen het psychose fenotype en gevoeligheid voor stress in het dagelijks leven. Bovendien kunnen we 
hieruit concluderen dat stress-gevoeligheid inderdaad een niet gecontamineerd intermediair fenotype voor psychose is.

Dezelfde hypothese werd getest in een sample bestaande uit patiënten met een psychotische stoornis en hun broer(s) en/of zus(sen) (siblings) (HOOFDSTUK 5). In deze studie werd een associatie gevonden tussen stress-gevoeligheid in patiënten en stress-gevoeligheid in hun broer(s) en/of zus(sen). Patiënten die meer gevoelig zijn voor stress in het dagelijks leven hebben broers en/of zussen die ook meer gevoelig zijn voor kleine dagelijkse stress. Dit duidt op familiale transmissie van deze risicofactor.

In HOOFDSTUK 4 wordt onderzocht of cognitieve stoornissen en stress-gevoeligheid onafhankelijke mechanismen zijn die ten grondslag liggen aan verschillende symptoomdimensies. Met deze studie wilden we aantonen dat stress-gevoeligheid niet of omgekeerd geassocieerd is met cognitieve stoornissen bij patiënten met een psychotische stoornis. Tevens wilden we aantonen dat stress-gevoeligheid met name samenhangt met positieve psychotische symptomen (i.e. wanen en hallucinaties). Bij patiënten met een psychotische stoornis werden positieve en negatieve symptomen gemeten met de PANSS (Positive and Negative Syndrome Scale). Tevens werd iedereen neuropsychologisch onderzocht. De Experience Sampling Methode (ESM) werd gebruikt om stress-gevoeligheid te meten. De resultaten van deze studie toonden aan dat (i) in sommige gevallen cognitie en stress-gevoeligheid niet samenhangen, (ii) in andere gevallen een slechte prestatie op cognitieve taken juist samenhangt met een lage gevoeligheid voor stress en (iii) een toegenomen gevoeligheid voor stress geassocieerd is met hoge scores op positieve symptomen en lage scores op negatieve symptomen. Hieruit concludeerden we dat stress-gevoeligheid een intermediair fenotype is dat specifiek samenhangt met de positieve psychotische symptoomdimensie, onafhankelijk van cognitie.

In HOOFDSTUK 5 wordt verder bewijs gezocht voor stress-gevoeligheid als intermediair fenotype voor een positief psychotisch syndroom. Hier werd gebruik gemaakt van een within-trait, cross-sibling en cross-trait, cross-sibling design. In deze studie werden de volgende vragen onderzocht: (i) clustert stress-gevoeligheid binnen families van patiënten met een psychotische stoornis?, en (ii) is er cosegregatie van stress-gevoeligheid in broers en/of zussen (siblings) en positieve psychotische symptomen in broers en/of zussen die patiënt zijn? In een groep patiënten en hun siblings werd stress-gevoeligheid gemeten met de ESM, symptomen werden gemeten met de PANSS. De resultaten van deze studie toonden aan dat patiënten die meer gevoelig zijn voor stress in het dagelijks leven broers en zussen hebben die ook meer gevoelig zijn voor kleine dagelijkse stress. Een significante associatie werd gevonden tussen stress-gevoeligheid in de broers/zussen en positieve psychotische symptomen in broers/zussen die patiënt zijn. Hoe hoger de stress-gevoeligheid bij 


\section{ON THE PATHWAY FROM STRESS TO PYCHOSIS}

de sibling bovendien, hoe groter de intensiteit van positieve psychotische symptomen in de patiënt. Dit duidt op familiale transmissie en een mogelijke invloed van genen bij stress-gevoeligheid als risicofactor voor de positieve symptoom dimensie van psychose.

HOOFDSTUK 6 beschrijft een studie naar de associatie tussen traumatische ervaringen in de kindertijd en psychose op volwassen leeftijd. Deze associatie werd onderzocht in de vroege adolescentie, een belangrijke fase in de ontwikkeling. In een steekproef van 14-jarigen uit de algemene populatie werd onderzocht of (i) onprettige seksuele ervaringen en (ii) gepest worden geassocieerd zijn met subklinische psychotische ervaringen. Beide hypothesen werden bevestigd in deze studie. We concludeerden dat traumatische ervaringen in de kindertijd mogelijk bijdragen aan de ontwikkeling van subklinische psychotische ervaringen in de vroege adolescentie. Deze subklinische psychotische ervaringen vergroten op hun beurt weer het risico op het ontwikkelen van een klinische psychotische stoornis op volwassen leeftijd. In dit hoofdstuk wordt een aantal cognitieve en biologische mechanismen beschreven die hierbij mogelijk een rol spelen.

In HOOFDSTUK 7 worden de resultaten van dit proefschrift samengevat en wordt een dimensioneel model gepresenteerd met een affectief pad naar de positieve symptoom dimensie van psychose. Tot slot worden klinische implicaties en suggesties voor verder onderzoek gegeven. 


\section{Dankwoord}

Dit proefschrift is het eindstuk van werk waarvoor onnoemelijk veel mensen zich hebben ingezet. ledereen die een bijdrage heeft geleverd wil ik hiervoor heel hartelijk bedanken.

Allereerst gaat mijn dank uit naar mijn promotor, Prof. dr. Jim van Os en copromotor, Dr. Inez Myin-Germeys. Jim, bedankt voor alle kennis die je met zoveel enthousiasme weet over te brengen. Jij zorgt voor inspiratie bij zo velen. Inez, jij bedacht dit project en was de afgelopen jaren verantwoordelijk voor mijn dagelijkse begeleiding. Zonder jou zou dit proefschrift niet tot stand zijn gekomen. Dankjewel voor alles dat je me leerde en voor de mogelijkheden die ik heb gekregen. Jouw optimisme, gedrevenheid, geloof en vertrouwen dat je steeds in mij hebt gehad, maken dat ik met veel plezier (en wellicht over een tijdje weemoed, nu ben ik vooral blij dat het gedaan is) terugblik op mijn Aio-periode.

Ook wil ik alle proefpersonen bedanken die hebben meegewerkt aan GROUP, en in het bijzonder de proefpersonen die zo goed waren om 6 dagen lang met een piepend horloge rond te lopen.

Dr. Lucia Valmaggia, dankjewel dat je speciaal uit Londen wilt komen om plaats te nemen in mijn corona. Met je no-nonsense mentaliteit verruimde je mijn onderzoeksblik en deed me inzien hoe noodzakelijk (en mogelijk!) het is om goed onderzoek in te bedden in de klinische praktijk. Ik heb veel van je geleerd en ben blij met het mooie paper dat het resultaat is van onze samenwerking. Ook wil ik graag de andere leden van de beoordelingscommissie en corona bedanken.

Tevens wil ik alle co-auteurs bedanken. In de afgelopen jaren had ik het geluk te mogen werken met twee mooie datasets. Prof. dr. Frans Feron, bedankt voor de GGD dataset. Prof. dr. Catherine Derom en Prof. dr. Evert Thiery, bedankt voor de data uit het Vlaams Tweeling Register.

Nienke en Cécile, mijn paranimfen, zonder jullie zou ik hier vandaag met veel minder plezier (misschien ook iets minder ontremd) staan. $\mathrm{k}$ had me geen betere collega's kunnen wensen! "Niekje", zonder jou is werken bij SP niet meer hetzelfde. Cécile, jij was mijn eerste coach in het onderzoek. Doordat je zo betrokken bent en eindeloos veel geduld kunt opbrengen, heb ik veel plezier gekregen in het doen van 


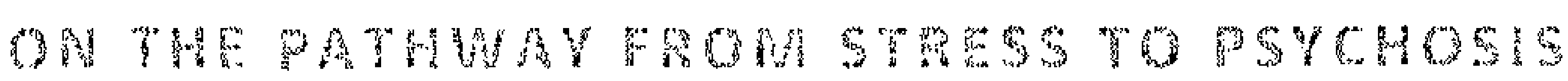

onderzoek. Ik ben blij dat we collega's blijven en hoop dat we nog veel zullen samenwerken.

Ook wil ik de andere collega's van SP en KP bedanken die allemaal, op een meer directe of indirecte manier, hun bijdrage hebben geleverd aan dit werk. Mijn dank gaat uit naar alle onderzoeksassistenten en stagiaires die hebben geholpen met de werving en dataverzameling. In het bijzonder wil ik Debora, Silvie, Kathleen en Marlou bedanken. Mariëlle, jij was de collega AiO op dit project, bedankt voor de prettige samenwerking. Ook alle andere collega's van GROUP bedankt. Ron, bedankt dat je het moederbord van mijn computer repareerde nadat ik er een flesje water overheen had gegooid. En natuurlijk voor alle andere technische support. Aan Truda, Inge en Frieda heel veel dank voor alle ondersteuning bij het project en de data invoer. Dr. Philippe Delespaul, voor alle hulp bij ESM. Marieke en Marjan, bedankt dat ik met al mijn vragen over methoden en statistiek bij jullie mocht aankloppen. Lydia, door jou ben ik bij SP terecht gekomen. Ik had me geen betere werkplek kunnen wensen, dankjewel daarvoor.

Binnen Mondriaan kreeg ik de kans om ervaring op te doen op het gebied van behandeling van psychotische aandoeningen. Alle collega's van Psycope team 1: bedankt dat jullie me wilden opleiden. Dank jullie wel voor de pretige werksfeer. Ook de collega's van de McCUP wil ik hier bedanken, ik werk graag met jullie samen.

Verder dank ik alle vrienden en familieleden die op hun manier een steentje hebben bijgedragen aan dit boekje. Mama en papa, jullie zijn de basis, het thuishonk, bedankt dat ik altijd bij jullie mag aankloppen om raad te vragen. Johan, bovenste beste broertje, dankjewel voor de humor. And last but not least I thank Gabriel, for making my life a lot more relaxed. 


\section{Curriculum Vitae}

Tineke Lataster werd geboren op 3 oktober 1981 in Kerkrade. Na het afronden van het Atheneum aan het St. Bernardinuscollege in Heerlen, startte zij in 1999 met de opleiding Psychologie aan de Universiteit Maastricht, waaraan zij in 2003 afstudeerde in de studierichting Neuropsychologie. In datzelfde jaar werd zij aangesteld als onderzoeksmedewerker bij de Capaciteitsgroep Psychiatrie en Neuropsychologie, sectie Sociale Psychiatrie en Psychiatrische Epidemiologie van de Faculteit Geneeskunde van dezelfde universiteit en werkte zij mee aan onderzoek naar de relatie tussen cannabisgebruik en psychose. In 2004 begon zij bij dezelfde capaciteitsgroep als assistent in opleiding aan haar promotieonderzoek naar de relatie tussen gevoeligheid voor stress in het dagelijks leven en psychose. Tijdens haar AiO-periode verbleef zij een aantal maanden in Londen, waar ze als onderzoeker verbonden was aan het Institute of Psychiatry, King's College London, middels een beurs van het KNAW Van Walree Fonds. Tevens werkte zij als psycholoog binnen een Assertive Community Treatment team van Psycope, een transmuraal zorgprogramma voor mensen met psychotische aandoeningen. In 2009 ontving zij een Kootstra Fellowship van de Universiteit Maastricht, Faculty of Health, Medicine and Life Sciences. Momenteel is zij aangesteld als universitair docent bij de Universiteit Maastricht en is zij werkzaam als psycholoog bij Mondriaan, divisie Integrale Zorg. 


\section{List of publications}

\section{International journals}

Lataster, T., Drukker, M., Henquet, C., Feron, F., Gunther, N., Van Os, J. MyinGermeys, I. (2006). Childhood victimisation and developmental expression of non-clinical delusional ideation and hallucinatory experiences. - Victimisation and non-clinical psychotic experiences. Social Psychiatry and Psychiatric Epidemiology, 41(6): 423-428.

Lataster, T., Wichers, M., Jacobs, N., Mengelers, R., Derom, C., Thiery, E., Van Os, J., Myin-Germeys, I. (2009). Does reactivity to stress cosegregate with subclinical psychosis? Findings from a general population twin study. Acta Psychiatrica Scandinavica, 119(1): 45-53.

Lataster, T., Myin-Germeys, I., Derom, C., Thiery, E., Van Os, J (2009). Evidence that self-reported psychotic experiences represent the transitory developmental expression of genetic liability to psychosis in the general population. American Journal of Medical Genetics Part B: Neuropsychiatric Genetics, in press.

Krach, S., Blümel, I., Majoram, D., Lataster, T., Krabbendam, L., Weber, J., Van Os, J., Kircher, T. (2008). Are women better minreaders? Sex differences in neural correlates of mentalizing detected with functional MRI. BMC Neuroscience, in press.

Havermans, R., Keuker, J., Lataster, T., Jansen, A. (2005). Contectual control of extinguished conditioned performance in humans. Learning and motivation, $36(1)$ : 1-19.

Havermans, R., Roefs, A., Lataster, T., Jansen, A. (accepted pending revision). Comparing carbohydrates and dietary fat in conditioning flavour preferences in humans. Journal of Sensory Studies.

\section{National journals}

Havermans, R., Lataster, T., Thewissen, R., Jansen, A. (2004). Uitdoven is geen afleren: Implicaties voor exposuretherapie/ Extinction is no unlearning: Implications for exposure therapy. Gedragstherapie, 37(2): 77-86. 
ONTHE PATHWAY FROM STPESSTO PSYCHOSIS

\section{Submitted papers}

Lataster, T., Valmaggia, L., Lardinois, M., Van Os, J., Myin-Germeys, I. (2009). Stressreactivity and cognitive impairments: separate mechanisms underlying different symptoms in psychosis. Submitted.

Lataster, T., Valmaggia, L., Lardinois, M., Van Os, J., Myin-Germeys, I. (2009). Stressreactivity in psychosis: a specific mechanism underlying the positive symptoms.

Lataster, T., Collip, D., Lardinois, M., Van Os, J., Myin-Germeys, I. (2009). Increased reactivity to stress clusters within families of patients with non-affective psychosis. Submitted.

Lardinois, M., Lataster, T., Van Os, J., Myin-Germeys, I. (2009). Childhood trauma and increased stress-sensitivity in psychosis: an experience sampling study. Submitted.

Kircher, T., Lataster, T., Blümel, I., Majoram, D., Krabbendam, L., Weber, J., Van Os, J., Krach, S. (2009). Online mentalising investigated with functional MRI. Submitted.

\section{Conference presentations}

Lataster, T., Van Os, J., Drukker, M., Henquet, C., Feron, F., Gunther, N., MyinGermeys, I. (2006). Childhood victimisation and developmental expression of psychotic experiences. 13th AEP Symposium (Association of European Psychiatrists), Bordeaux, France.

Lataster, T., Van Os, J., Drukker, M., Henquet, C., Feron, F., Gunther, N., MyinGermeys, 1. (2006). Schizophrenia Research Childhood victimisation and developmental expression of psychotic experiences. $13^{\text {th }}$ Biennial Winter Workshop on Schizophrenia Research, Davos, Switserland.

Lataster, T., Wichers, M., Jacobs, N., Derom, C., Vlietinck, R., van Os, J., \& MyinGermeys, I. (2007). Is reactivity to stress an endophenotype for psychosis? Findings from a general population twin study. International Conference on Schizophrenia Research, Colorado, United States.

Lataster, T., De Loore, E., Drukker, M., Gunther, N., Feron, F., Deboute, D., Henquet, C., Van Os, J., Myin-Germeys, I. (2008). Does the environment increase sensitivity to develop psychosis in Young adolescents? 16th AEP Symposium (Association of European Psychiatrists), Nice, France.

Lataster, T., Valmaggia, L., Lardinois, M., McGuire, P., Van os, J., Myin-Germeys, I. (2008). Emotional reactivity to stress in daily life, cognitive functioning and the symptoms of psychosis: evidence for a positive versus negative syndrome. 1st Schizophrenia International Research Society Conference, Venice, Italy. 
Lataster, T., Collip, D., Lardinois, M., Van Os, J., Myin-Germeys, I. (2009). Increased stress-reactivity clusters within families of patients with non-affective psychosis. International Conference on Schizophrenia Research, San Diego, United States. 